Aus der Abteilung Allgemeinmedizin

(Prof. Dr. med. M. M. Kochen, MPH, FRCGP)

im Zentrum Innere Medizin

der Medizinischen Fakultät der Universität Göttingen

\title{
Pharmakogenetische Untersuchungen beim Hausarzt aus Sicht von Patienten
}

\author{
INAUGURAL - DISSERTATION \\ zur Erlangung des Doktorgrades \\ der Medizinischen Fakultät \\ der Georg-August-Universität zu Göttingen
}

vorgelegt von

Daniela Prause

aus

Bad Arolsen

Göttingen 2008 
Dekan: $\quad$ Prof. Dr. med C. Frömmel

I. Berichterstatter: Prof. Dr. disc. pol. W. Himmel

II. Berichterstatter/in:

III. Berichterstatter/in:

Tag der mündlichen Prüfung: 


\section{Inhaltsverzeichnis}

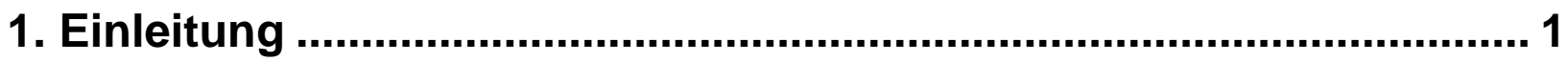

2. Stand der Forschung ................................................................... 2

2.1 Pharmakogenetik - Definition ....................................................................

2.2 Grundlagen pharmakogenetischer Untersuchungen .................................... 3

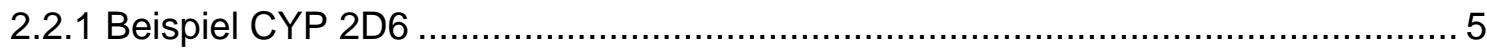

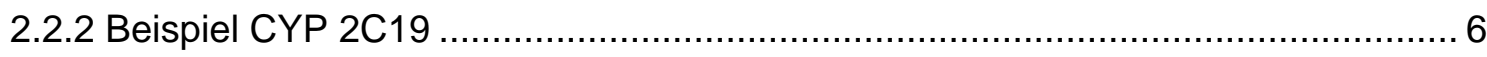

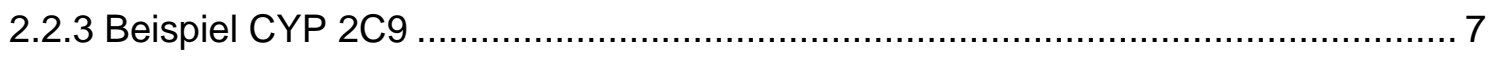

2.2.4 Beispiel Thiopurin-S-Methyltransferase (TPMT) ………………................... 8

2.2.5 Beispiel Polymorphismen des Beta-2-Adrenozeptors....................................... 10

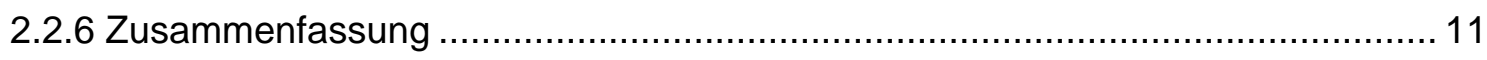

2.3 Ziele und Eigenschaften pharmakogenetischer Untersuchungen ............. 13

2.4 Aktuelle Untersuchungen zur Einstellung der Bevölkerung ...................... 17

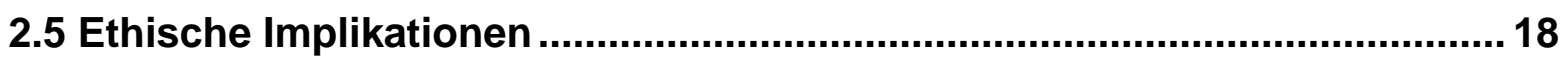

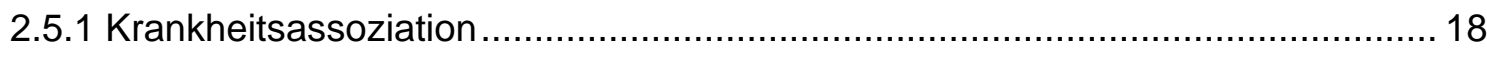

2.5.2 Konsequenzen für Arbeitgeber und Krankenkasse ........................................ 20

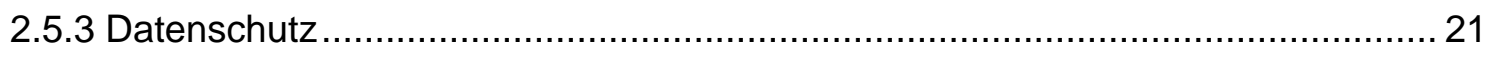

2.5.4 Zugang zu pharmakogenetischen Tests........................................................ 22

2.5.5 Emotionale Auswirkungen auf den Patienten und seine Familie ........................ 23

2.6 Pharmakogenetik: Konsequenzen für die hausärztliche Praxis ................. 25

2.7 Pharmakogenetik: Konsequenzen für die Patienten..................................... 28

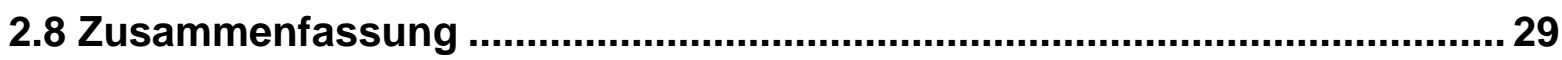

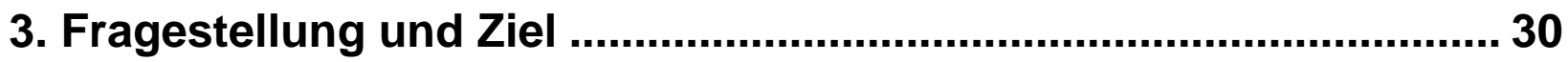

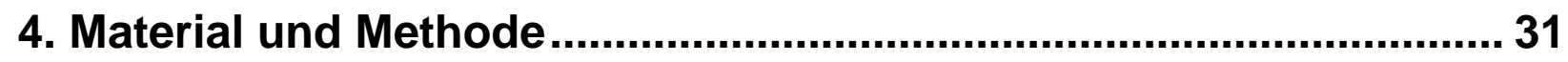

4.1 Methodische Anlage der Untersuchung ….................................................... 31

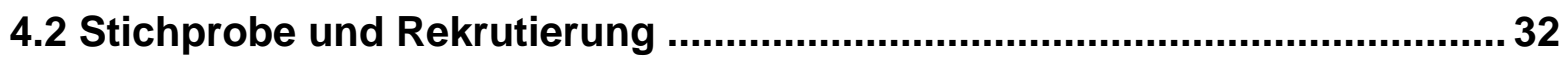

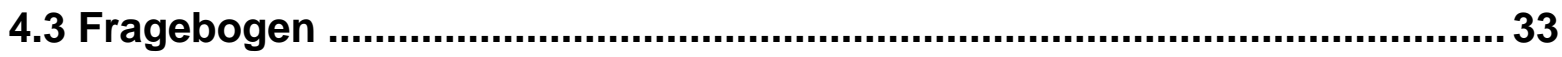




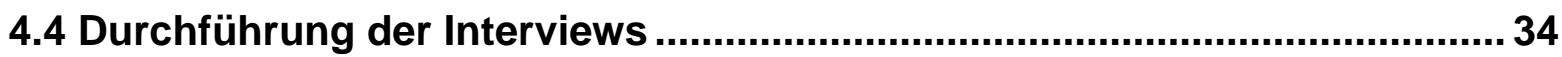

4.5 Auswertung der offenen Fragen .............................................................. 36

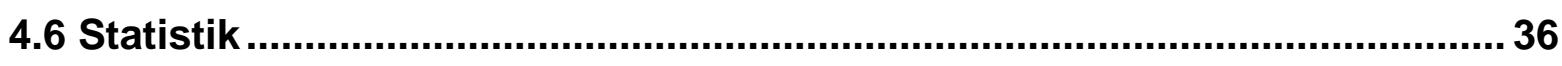

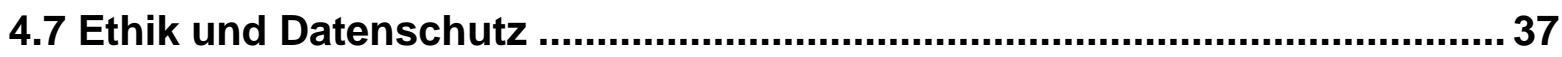

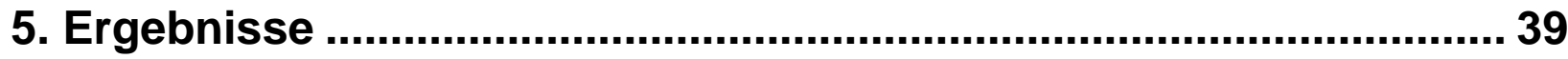

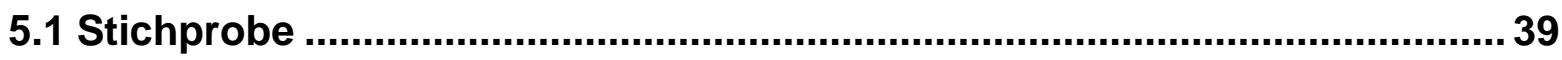

5.2 Bereitschaft und Rahmenbedingungen zur Durchführungvon pharmakogenetischen Untersuchungen.................................................... 40

5.3 Zustimmungsgründe zur Testdurchführung und Hoffnungen in

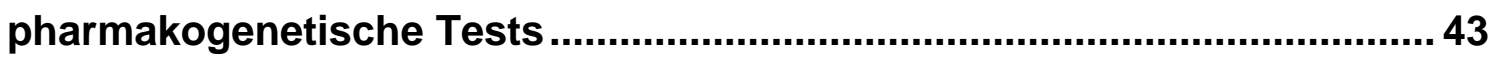

5.4 Gründe für die Ablehnung eines Tests und Sorgen gegenüber pharmakogenetischen Untersuchungen 48

5.5 Informationswünsche für die Entscheidungsfindung zur Durchführung pharmakogenetischer Untersuchungen ...................................................53

5.6 Determinanten und Prädiktoren einer hoffnungsvollen bzw. sorgenvollen Einstellung gegenüber pharmakogenetischen Tests ........... 55

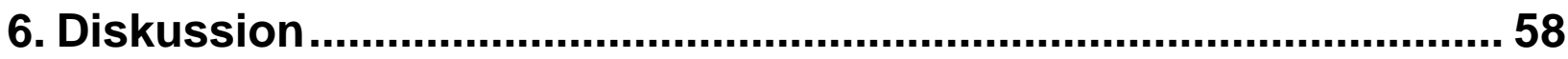

6.1 Rahmenbedingungen für die Durchführung pharmakogenetischer

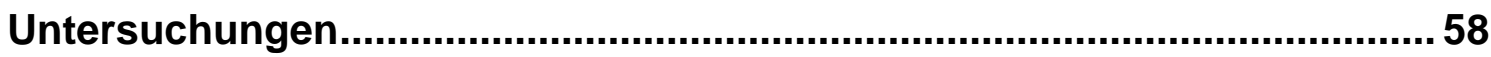

6.2 Einstellung und Hoffnungen von Patienten bezüglich

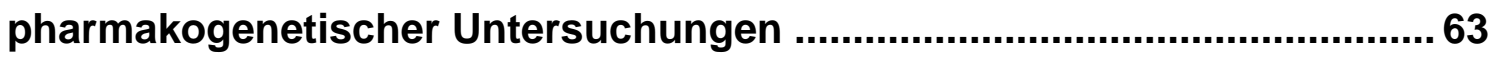

6.3 Sorgen bezüglich pharmakogenetischer Untersuchungen.........................65

6.4 Konsequenzen für die hausärztliche Praxis: Beratungsanliegen und Informationsbedarf .................................................................................. 70

6.5 Diskussion der Methode ............................................................................. 72

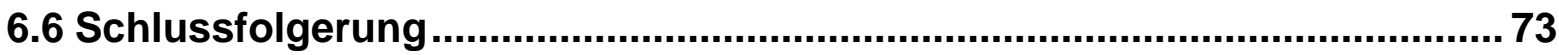

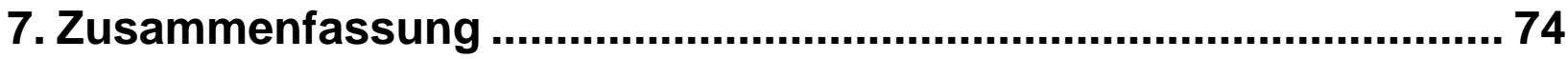

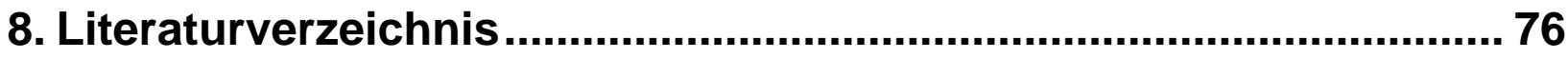




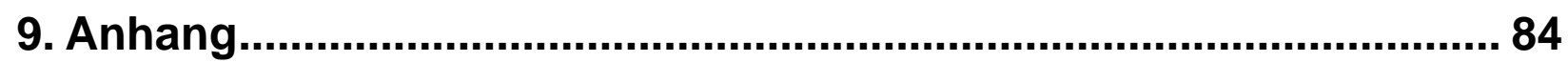

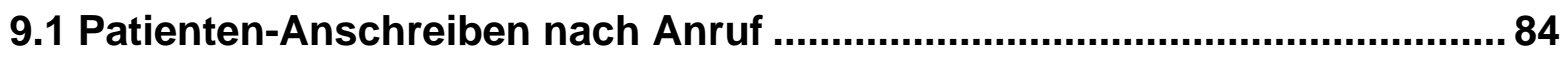

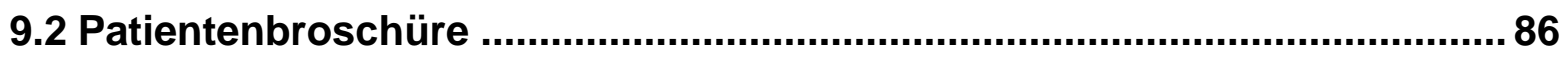

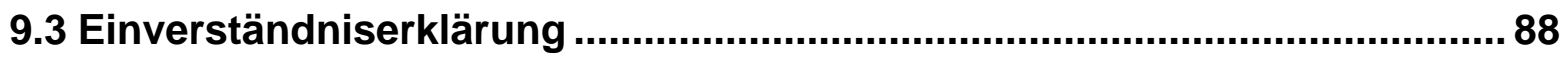

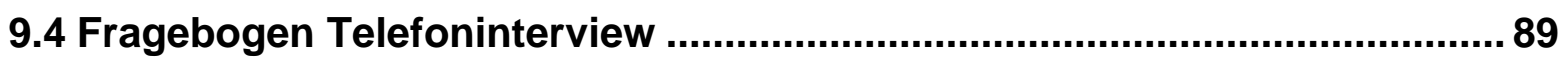

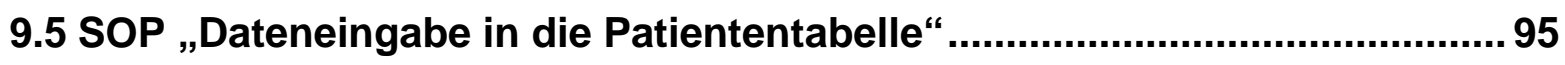

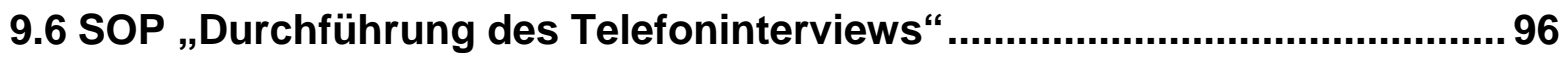




\section{Tabellenverzeichnis}

Tabelle 1: Gründe von Patienten für die Einnahme eines Medikaments entgegen der Empfehlung pharmakogenetischer Tests

Tabelle 2: Gründe von Patienten für die Nichteinnahme eines Medikaments entsprechend der Empfehlung pharmakogenetischer Tests 43

Tabelle 3: Gründe für die Zustimmung zum pharmakogenetischen Test 45

Tabelle 4: Art der Hoffnungen in Bezug auf pharmakogenetische Tests. .47

Tabelle 5: Gründe für die Ablehnung eines pharmakogenetischen Tests (wenn zutreffend) 48

Tabelle 6: Sorgen oder Ängste bezüglich pharmakogenetischer Tests. 51

Tabelle 7: Gewünschte Informationen zur Entscheidung für oder gegen einen pharmakogenetischen Test 54

Tabelle 8: Prädiktoren für eine ängstliche bzw. sorgenvolle Einstellung bezüglich pharmakogenetischer Tests 56

Tabelle 9: Prädiktoren für eine hoffnungsvolle Einstellung bezüglich pharmakogenetischer Tests. .57 


\section{Abbildungsverzeichnis}

Abbildung 1: Veränderungen durch pharmakogenetische Untersuchungen (aus Kirchheiner et al. 2003, S. 843).

Abbildung 2: Studienteilnahme von Patienten mit Asthma bronchiale oder chronisch-obstruktiver Lungenerkrankung (COPD)

Abbildung 3: Schulischer Abschluss der Interviewteilnehmer

Abbildung 4: Hoffnungen von Patienten bezüglich pharmakogenetischer Tests.

Abbildung 5: Sorgen der Patienten bezüglich pharmakogenetischer

Tests. 50

Abbildung 6: Einschätzung über mögliche Nachteile bei einem negativen Ergebnis eines pharmakogenetischen Tests 52

Abbildung 7: Wie würden sich Patienten mit einem negativen Ergebnis pharmakogenetischer Tests erleben 52 


\section{Einleitung}

Wenn Menschen mit nahezu identischer Krankheit auf dasselbe Medikament unterschiedlich ansprechen bzw. unterschiedliche Nebenwirkungen erleiden, kann dies in der individuellen genetischen Ausstattung begründet sein. Mittels pharmakogenetischer Untersuchungen lassen sich Unterschiede in den Genen bestimmen, die metabolisierende Enzyme, Transporter oder Zielorte der Medikamente regulieren (Evans und McLeod 2003). Ziel der Pharmakogenetik ist es, diese individuellen Besonderheiten schon im Vorfeld der Medikamentenverordnung, nämlich bei Therapieplanung und Dosisfestlegung mit zu berücksichtigen (Meyer et al. 2002).

Die Hoffnung, die daher von Forschern, Ärzten und Industrie in pharmakogenetische Untersuchungen gesetzt wird, ist: dem einzelnen Patienten eine optimal effektive medikamentöse Therapie anbieten zu können - mit geringeren Folgekosten, z. B. weniger Arztbesuchen bzw. Krankenhausaufenthalten aufgrund von Schwierigkeiten mit Dosierung oder Nebenwirkungen. Unbekannt aber ist, welche Chancen oder Risiken Patienten selbst in pharmakogenetischen Untersuchungen sehen. Diese Fragen und weitere Aspekte pharmakogenetischer Untersuchungen sind Thema der vorliegenden Arbeit und sollen mit Hilfe einer Patientenbefragung beantwortet werden. 


\section{Stand der Forschung}

\subsection{Pharmakogenetik - Definition}

Pharmakogenetik ist „die Untersuchung der Effekte von genetischen Unterschieden zwischen Individuen in Hinblick auf eine Medikamentenwirksamkeit" (Nuffield Council on Bioethics 2003). Grundlage ist die Tatsache, dass Gene, die die Informationen über Enzyme, Transporter oder die Zielorte von Medikamenten enthalten, die nötige Dosierung und Wirksamkeit eines Arzneimittels beeinflussen (Rogausch et al. 2005). Enzyme sind Proteine, die als Biokatalysatoren chemische Reaktionen beeinflussen, daher sind ihre Aktivität und die vorhandene Enzymmenge mitentscheidend für den Abbau oder die Umwandlung eines Arzneistoffes. Ist z. B. für die Aktivierung eines Arzneistoffes zur aktiven und wirksamen Substanz eine enzymvermittelte Umwandlung nötig und von diesem Enzym nur wenig vorhanden, kann auch nur ein kleiner Teil des Arzneiwirkstoffes in die wirksame Form überführt werden. Durch interindividuelle genetische Abweichungen unterscheiden sich demzufolge die „Verstoffwechselung" (Metabolisierung) eines Wirkstoffes und somit seine Plasmakonzentration und Wirksamkeit von Patient zu Patient (Evans und McLeod 2003). Mögliche Folgen können von einem „Nicht-Ansprechen“ der Medikation bis zu tödlichen Nebenwirkungen reichen (Smart et al. 2004).

Die Beobachtung, dass Unterschiede in der Art, wie ein Arzneimittel verstoffwechselt wird, familiären Erbgängen unterliegen, führte bereits 1959 zur Prägung des Begriffes Pharmakogenetik durch den deutschen Pädiater Friedrich Vogel (Vogel 1959). Genetische Variabilität ist inzwischen auf allen Ebenen sowohl der Pharmakokinetik, z. B. bei der Absorption, der Metabolisierung und der Exkretion, als auch der Pharmakodynamik, z. B. bei Rezeptoren oder in der Signaltransduktion bekannt (Cascorbi 2002). Die unterschiedlichen Effekte eines Medikamentes bei verschiedenen Patienten beruhen dabei unter anderem auf ererbten Genvarianten (Lindpaintner 2003) und erklären, warum ein Medikament bei einem Patienten sehr gut wirkt, bei einem anderen aber kaum oder gar nicht. 
Von dem Begriff „Pharmakogenetik“ ist die „Pharmakogenomik“ zu trennen. Pharmakogenomik bedeutet die Untersuchung des ganzen Genoms oder einer beträchtlichen Zahl von Genen in der Absicht, potentielle Ziele für Medikamente zu identifizieren (Nuffield Council on Bioethics 2003).

\subsection{Grundlagen pharmakogenetischer Untersuchungen}

Die Entwicklung der Pharmakogenetik hängt entscheidend mit dem Abschluss des „Humanen Genomprojektes“ und dem „HapMap-Project“ zusammen. Ziel des humanen Genomprojekts war die vollständige Entschlüsselung des menschlichen Genoms, d. h. die Abfolge der Basenpaare in der menschlichen DNS zu identifizieren. Ergänzend wurde vom Internationalen HapMap Consortium die Haplotype-Map (HapMap) ${ }^{1}$ entwickelt, die Variationen der DNS-Sequenzen innerhalb des menschlichen Genoms aufdecken soll. Dieses Wissen bietet das Grundwerkzeug, um genetische Variationen und unterschiedliche Medikamentenreaktionen verstehen zu können, und sollte die Entwicklung einer individuellen medikamentösen Therapie, die auf dem Genotyp des einzelnen Patienten beruht, erlauben (Lin et al. 2005).

Eine weitere Grundlage der Pharmakogenetik ist der von dem britischen Arzt Archibald Garrod um 1900 geprägte Begriff der „chemischen Individualität“ (Prasad und Galbraith 2005). Durch das Humane Genomprojekt konnte gezeigt werden, wodurch diese chemische Individualität entsteht; das entscheidende Schlüsselwort ist der genetische Polymorphismus (Vielgestaltigkeit). Der Begriff Polymorphismus beschreibt die Tatsache, dass zwar alle Menschen den gleichen Satz von etwa 30.000 - 35.000 Genen besitzen, es aber von Mensch zu Mensch viele geringe, punktuelle Unter-

\footnotetext{
${ }^{1}$ Haplotyp: Zusammensetzung aus haploid und Genotyp, bezeichnet den genetischen Aufbau eines individuellen Chromosoms.
} 
schiede in den einzelnen Genen gibt. Diese Gene wiederum bestimmen die unterschiedliche Gestalt, Funktion oder Expression der von innen kodierten Proteine, die wiederum die Gestalt und Funktion von Zellen und Organen bestimmen. Die Unterschiede der Gene beruhen oft auf dem Austausch einer der vier Nukleotid-Bausteine, welche die DNS bilden. Diese Variationen von einzelnen Basenpaaren in einem DNS-Strang werden als "Single Nucleotid Polymorphism" (Einzel-NukleotidVielgestaltigkeit) und mit der Kurzform „SNP“ (ausgesprochen „snip“) bezeichnet. Diese Unterschiede im genetischen Baumuster kommen etwa alle 300 bis 500 Bausteine vor (Simm 2008), wobei die weitaus größte Anzahl sicherlich „stumm“ bleibt (Lindpaintner 2003). Laut Pandhi (2006) sind von den schätzungsweise 20 Millionen bekannten SNPs nur ca. 300.000 für die Proteinbiosynthese - und somit klinisch - relevant. Dabei muss unterschieden werden zwischen punktuellen Änderungen und SNPs. Bei punktuellen Änderungen handelt es sich um spontan aufgetretene und nicht vererbbare zufällige Mutationen, die daher in einer gegebenen Gruppe von Menschen mit einer Häufigkeit von nicht mehr als $1 \%$ auftreten (Eichelbaum und Schwab 2005). Ist die Häufigkeit größer als $1 \%$, handelt es sich um die stabilen SNPs, die vererbt werden und über mehrere solcher Vererbungen unverändert bleiben.

Da im menschlichen Genom etwa pro 500 bis 1000 Basenpaare ein SNP gefunden wird, hat jeder Mensch um die drei bis sechs Millionen SNPs in seinem Erbgut. Ob ein SNP jedoch überhaupt Auswirkungen auf den menschlichen Organismus hat, hängt von seiner Lokalisation ab. Die meisten SNPs befinden sich in nichtkodierenden DNA-Abschnitten, so dass sie keine bisher eindeutig nachweisbaren Veränderungen hervorrufen.

Die SNPs, die sich aber in kodierenden oder regulierenden Genregionen befinden, also Informationen über den Aufbau von Enzymen oder deren Anzahl tragen, können sich auf verschiedene Weisen auswirken, sie können den medikamentösen Transport, den Arzneistoffmetabolismus - also die chemische Umwandlung des Arzneistoffes im Körper z. B. durch einen verlangsamten oder beschleunigten Wirkstoffabbau oder die Rezeptoren am Wirkort beeinflussen. Schätzungsweise für ca. $90 \%$ der ge- 
netischen Inhomogenität unter den Menschen sind die SNPs verantwortlich. Das HapMap-Projekt stellt eine Bewertung der genetischen Variationen des menschlichen Genoms mit über einer Million SNPs dar und bietet damit eine große Ressource für genetische Assoziationsstudien (De La Vega et al. 2006).

\subsubsection{Beispiel CYP 2D6}

Beispielhaft für einen pharmakogenetisch bedingten, relevanten Polymorphismus sind Variationen der Enzyme des Cytochrom-P450 (CYP)-Systems ${ }^{2}$, welche die wichtigste Gruppe des Phase-I-Arzneimittelmetabolismus ${ }^{3}$ sind und eine zentrale Rolle in der oxidativen Phase des Medikamentenabbaus spielen. Es sind mindestens 58 verschiedene humane CYP-Enzyme bekannt, die unterschiedliche Oxidationsund Reduktionsreaktionen im Fremdstoffwechsel, aber auch im Lipid- und Steroidhormonmetabolismus katalysieren. Durch genetische Varianten v. a. in den Genen von CYP 2C9, CYP 2C19 und CYP 2D6 tragen sie maßgeblich zur interindividuell unterschiedlichen Pharmakokinetik von ca. 30 \% aller in der Leber verstoffwechselten Arzneimittel bei (Cascorbi 2002).

Das polymorphe CYP 2D6 metabolisiert ca. ein Viertel aller Medikamente (z. B. Psychopharmaka), wobei es aber - aufgrund von Polymorphismen - in 70 verschiedenen bekannten Varianten vorliegt, deren Auswirkungen von fehlender über verminderte bis zur gesteigerten Aktivität reichen (Schmitz und Drobnik 2003). Demgemäß liegt es bei ca. 5 - $10 \%$ aller Europäer in einer sehr wenig aktiven Form vor. Als Folge

2 Cytochrom P 450: Familie mischfunktioneller Monooxygenasen, die im Komplex mit CO eine Absorptionsbande bei $450 \mathrm{~nm}$ aufweisen.

3 Biotransformation von Arzneimitteln und Fremdstoffen zur Förderung der Ausscheidung durch Oxidation, Reduktion oder Hydrolyse. 
dieser verminderten Aktivität kann es schon bei normaler Dosierung eines Psychopharmakons zu einer effektiven Überdosierung mit entsprechenden Nebenwirkungen kommen. Zugleich haben 1 - 2 \% der Europäer durch Genduplikation ${ }^{4}$ des CYP 2D6 eine überaktive Form des Enzyms. Durch den ultra-rapiden Abbau des Medikaments erreichen sie bei normaler Dosierung nicht die für eine Arzneimittelwirkung nötige Konzentration und benötigen daher eine wesentlich höhere Dosis, wenn sie z. B. trizyklische Antidepressiva einnehmen (Lindpaintner 2003). Aufgrund der Ergebnisse pharmakogenetischer Untersuchungen werden die Patienten in Abhängigkeit von ihrer CYP-2D6-Aktivität in folgende Gruppen klassifiziert: Poor-, Intermediate-, Extensive- und Ultrarapid-Metabolisierer. Für die Poor-Metabolisierer wird generell eine Dosis-Reduktion um ca. $50 \%$ bei den trizyklischen Antidepressiva empfohlen. Klinisches Beispiel ist das Antidepressivum Imipramin, das sich in der für eine therapeutische Plasmakonzentration benötigten Dosierung zwischen einem langsamen und einem ultraschnellen Metabolisierer um den Faktor 6 unterscheidet, also „Poor Metabolizer“ verglichen mit den „Ultrarapid Metabolizern“ eine sechsfach geringere Dosis benötigen (Kirchheiner et al. 2004).

\subsubsection{Beispiel CYP 2C19}

Ein weiteres Beispiel sind die genetischen Variationen des CYP-2C19-Enzyms, das über $80 \%$ des Protonenpumpeninhibitors Omeprazol metabolisiert. Liegt bei einem Patienten - im Gegensatz zum CYP-2C19*1-Allel - das defiziente CYP-2C19*2-Allel vor, wird der Wirkstoff Omeprazol wesentlich langsamer über den alternativen CYP3A4-Stoffwechsel metabolisiert, so dass die Bioverfügbarkeit um bis zu zehnfach erhöht ist (Brockmöller et al. 2000). Vorteilhaft hier ist die auch bei solch hohen Plas-

\footnotetext{
${ }^{4}$ Genduplikation: dauerhafte Verdoppelung (bis Vervielfachung) einzelner Gene oder Gengruppen (mit anschließender getrennter Entwicklung).
} 
makonzentrationen geringe Toxizität von Omeprazol, so dass bisher bei Patienten mit 2C19*2-Allel unerwünschte Arzneimittelwirkungen nicht gehäuft beobachtet worden sind. Allerdings zeigten mehrere klinische Studien aus Japan und Korea höhere Heilungsraten von Helicobacter-Pylori-Infektionen bei homozygoten Trägern des defizienten CYP 2C19*2 als bei Patienten mit mindestens einem stoffwechselaktiven CYP-2C19*1-Wildtypallel (Dojo et al. 2001). Vor allem innerhalb der asiatischen Bevölkerung liegt die CYP-2C19-Defizienz in bis zu 25 \% vor, also in etwa 5-mal häufiger als bei Europäern. Wird vor einer Behandlung mit Omeprazol der CYP-2C19Genotyp bestimmt, könnte man die Omeprazol-Dosierung entsprechend anpassen und so die Helicobacter-Pylori-Therapie verbessern.

\subsubsection{Beispiel CYP 2C9}

Ein weiterer häufiger Polymorphismus betrifft das in der Leber häufig vorkommende Cytochrom CYP 2C9, über das ca. $15 \%$ aller Arzneistoffe, die der Phase-IBiotransformation unterliegen, metabolisiert werden. Zu seinen Substraten gehören oft verwendete Medikamente wie z. B. orale Antikoagulanzien, Sulfonylharnstoffe und Phenytoin. Für das CYP-2C9-Gen existieren Polymorphismen, die bei bis zu 40 \% der weißen Bevölkerung zu teilweise funktionell defekten Enzymformen führen (Gerloff und Roots 2005). Klinisch relevant ist dieses Wissen am ehesten in der Therapie mit dem in den USA verwendetem Antikoagulans Warfarin: Studien haben gezeigt, dass Träger des *2(R144C)- und *3(I359L)-Allels eine geringere Dosis als Patienten mit dem CYP-2C9-Wildtyp benötigen (Kirchheiner und Brockmöller 2005). Laut Lee CR et al. (2002) kann dabei der Dosisunterschied zwischen langsamen und schnellen Metabolisierern bis zu 4 mg pro Tag betragen. Patienten mit CYP-2C9*2 oder *3-Allelen fallen daher besonders bei Therapiebeginn durch häufigere Blutungskomplikationen und längere Hospitalisierungszeiten auf.

Für den in Deutschland als Antikoagulans vorwiegend verwendeten Wirkstoff Phenprocoumon zeigten sich allerdings nur geringe mit dem CYP-2C9-Genotyp assoziierte Abweichungen in der Pharmakokinetik. Ein erhöhtes Blutungsrisiko fand sich nur bei der CYP-2C9*3-Variante (Hummers-Pradier et al. 2003). Dieser Aspekt veranschaulicht, dass Voraussagen für Arzneistoffgruppen aus Untersuchungen von 
Einzelsubstanzen nicht generell getroffen werden können. Um auch klinisch angewendet zu werden, müssen pharmakogenetische Untersuchungen erst noch zeigen, dass sie bereits existierenden Methoden - wie z. B. der Bestimmung des INR (International Normalized Ratio) als Kontrollwert - überlegen sind (Campos-Outcalt 2007).

\subsubsection{Beispiel Thiopurin-S-Methyltransferase (TPMT)}

Feststellbar sind die Polymorphismen durch biochemische Assays über den Nachweis der Enzymaktivität ${ }^{5}$ oder Genotypisierung. Der am weitesten verbreitete pharmakogenetische Test ist die Analyse der Thiopurin-S-Methyltransferase (TPMT). Die TPMT spielt eine wichtige Schlüsselrolle bei der Verstoffwechselung der Thiopurine z. B. Azathioprin, 6-Mercaptopurin und Thioguanin, die therapeutisch zur Immunsuppression eingesetzt werden (Kaskas et al. 2003). Das Prodrug Azathioprin wird im Körper zu 6-Mercaptopurin metabolisiert, welches dann wiederum erst durch seine Umwandlung in den aktiven Metaboliten 6-Thioguanin-Nukleotid (6-TGN) seine antiinflammatorischen bzw. zytostatischen Effekte entfaltet. Das Enzym TPMT verhindert durch die Methylierung und Inaktivierung von 6-Mercaptopurin die Bildung der aktiven 6-TGN.

Während die Mehrheit (ca. 90 \%) der kaukasischen Bevölkerung eine normale TPMT-Aktivität zeigt, hat der Rest aufgrund genetisch bedingter Variationen eine herabgesetzte bis extrem niedrige Enzymaktivität (Weinshilboum 2003). Bei Patienten mit einer genetisch bedingten TPMT-Defizienz kann es schon unter Standarddosierungen von Azathioprin zur toxischen Anreicherung von aktiven Thioguaninnukleotiden in Blutzellen kommen, was zu einer schweren bis tödlichen Myelo-

\footnotetext{
${ }^{5}$ Enzymaktivität: Maß, wie schnell das Enzym die Umwandlung des Substrats katalysiert; Bestimmung durch Messung des Substratverbrauches oder der gebildeten Reaktionsprodukte.
} 
suppression führen kann (McLeod et al. 1993). Bisher sind acht verschiedene TPMTGenvarianten bekannt, die mit einer verminderten Enzymaktivität einhergehen, bei ungefähr einem von 300 Patienten findet sich eine Homozygotie ${ }^{6}$ mit geringer oder fehlender TPMT-Aktivität.

Eine geringe bis fehlende TPMT-Aktivität bedeutet, dass nur wenig 6-Mercaptopurin inaktiviert wird und in der Folge eine große Menge des aktiven Metaboliten entsteht. Solche Patienten können daher unter Therapie mit Azathioprin eine schwerwiegende Knochenmarkdepression entwickeln, die aber durch eine Dosisreduktion um 90 bis $95 \%$ - bei gleichbleibendem Therapieerfolg - vermieden werden kann (Evans 2004). Durch pharmakogenetische Assays können die wichtigsten genetischen TPMTDefektvarianten erfasst werden. Da der TPMT-Genotyp gut mit der TPMTEnzymaktivität in Erythrozyten und lymphoblastischen Zellen korreliert (Schaeffeler et al. 2004), kann das Risiko einer Myelosuppression nach Thiopurinbehandlung sehr gut vorausgesagt werden. Um die Auswirkungen einer TPMT-Genotypsierung und einer entsprechend angepassten Therapie festzustellen, verglichen Oh et al. 2004 die Abbruchquoten einer Azathioprin-Therapie aufgrund von ernsten Nebenwirkungen: Bei 0,1 \% der Patienten mit Genotyp-basierter Dosierung und bei 2,94 \% der Patienten mit Standarddosierung war eine Beendigung der Therapie aufgrund von erheblichen unerwünschten Wirkungen notwendig. Van den Akker-van Marle et al (2006) schätzen, dass der Tod eines von 1000 Kindern, die aufgrund einer akuten lymphoblastischen Leukämie mit Azathioprin behandelt werden, durch eine TPMTGenotypsierung verhindert werden könnte.

\footnotetext{
${ }^{6}$ Homozygotie: Reinerbigkeit. Ein diploider Organismus besitzt von jedem Gen zwei Kopien, im Normalfall eine von jedem Elternteil. Wenn die beiden Gene eines Individuums für ein bestimmtes Merkmal genau gleich sind, ist das Erbgut, bezogen auf dieses Merkmal, reinerbig oder homozygot.
} 
Dennoch wird diese Testung auf Aktivität der TPMT europaweit nur bei ca. $12 \%$ der Fälle durchgeführt, als Gründe dafür werden v. a. logistische Probleme, Kosten und Aufwand bezüglich Patientenaufklärung, Befundinterpretation und Laborsuche genannt (Zika et al. 2006). In England bieten z. B. nur zwei klinische Labors diesen Test für ca. $28 £$ an (Payne 2008). Außerdem darf dabei nicht vergessen werden, dass außer genetischen noch weitere Faktoren das Auftreten von unerwünschten Wirkungen beeinflussen, also ein pharmakogenetischer Test regelmäßige Kontrollen nicht ersetzen kann, sondern nur eine Ergänzung darstellt (van Aken et al. 2003).

\subsubsection{Beispiel Polymorphismen des Beta-2-Adrenozeptors}

Welches Potential und welche Komplexität in der genetischen Betrachtungsweise von Arzneimittelwirkungen liegen, wird auch am Beispiel der Asthma-Therapie mittels des weltweit häufig verschriebenen kurzwirksamen Beta-2-Agonisten Salbutamol (United States adopted name „Albuterol“) deutlich (Kelly 2005). Dessen Wirksamkeit erfolgt über die Bindung an den Beta-2-Adrenozeptor, für den eine Vielzahl von Polymorphismen festgestellt wurde, die dann zu Änderungen in den Aminosäurenketten und z. B. zur Bildung des Arg16Gly- oder des Arg19Cys-Polymorphismus ${ }^{7}$ führen (Hall 2006).

Klinische Studien haben gezeigt, dass bei akuter Gabe von Salbutamol Asthmatiker mit dem Genotyp Arg / Arg bei Aminosäure 16 des Beta-2-Adrenozeptors im Vergleich mit Patienten, die an dieser Stelle die Aminosäuren Gly / Gly oder auch Arg / Gly tragen, eine mehr als doppelt so starke Verbesserung der forcierten Ausatemleistung (FEV 1) erfahren (Lima et al. 1999). Ursache dafür ist, dass es beim Geno-

\footnotetext{
${ }^{7}$ Die hier verwendeten Abkürzungen beziehen sich auf die Aminosäuren: Arg = Arginin, Gly = Glycin, Cys $=$ Cystein .
} 
typ Arg / Arg - im Gegensatz zu den beiden anderen Varianten - nicht zu einer „Downregulation“ des Beta-2-Adrenozeptors, dem Wirkort des Salbutamol, durch endogene Katecholamine kommt. Dieser Effekt kann für die Therapie allerdings nur unter Vorbehalt genutzt werden, wie nachfolgende Untersuchungen gezeigt haben. So ist die kaukasische Patientengruppe mit der Anlage Arg / Arg bei länger dauernder und regelmäßiger mehrfach täglicher Gabe einer festgelegten Dosis kurzwirksamer Beta-2-Agonisten (Salbutamol-Inhalation) sogar gefährdet, eine Verschlechterung der Ausatemleistung zu erfahren (Israel et al. 2004), dabei beträgt die Häufigkeit dieses Genotyps Arg / Arg laut Kirchheiner et al. (2003) etwa 16 \%. Gegenteilige Ergebnisse wurden für Afroamerikaner berichtet, so fanden Ferdinands et al. 2007 heraus, dass Asthmatiker mit afroamerikanischer Herkunft und dem Genotyp Arg / Arg bei Aminosäure 16 des Beta-2-Adrenozeptors (Arg 16-homozygot) bei regelmäßiger Einnahme von Salbutamol eine bessere Lungenfunktion als Heterozygote oder Gly16 - Homozygote aufwiesen. Insgesamt ist daher laut Corvol und Burchard (2008) von einer durch regelmäßigen Salbutamol-Gebrauch entstehenden Wirkstofftoleranz auszugehen, für die Arg-16 - homozygote Asthmatiker ein stärkeres Risiko zeigen.

Bevor zukünftig eine Genotypsierung des Beta-2-Adrenorezeptors vor einer Behandlung mit entsprechenden Agonisten für eine pharmakogenetisch basierte Therapie klinisch nutzbar sein wird (Gerloff und Roots 2005), sind daher weitere Untersuchungen über die pharmakogenetischen Wechselwirkungen bei Asthma und die unterschiedlichen Auswirkungen zwischen ethnischen Gruppen notwendig (Corvol und Burchard 2008).

\subsubsection{Zusammenfassung}

Die Bedeutung eines genetischen Polymorphismus ist abhängig von der therapeutischen Breite des Arzneimittels, von der Stellung des Enzyms im Gesamtmetabolismus und von der möglichen Bildung aktiver Metaboliten (Collette und Thürmann 2002). Zudem werden aufgrund der probabilistischen Ergebnisse pharmakogenetischer Untersuchungen Patienten lediglich mit einer gewissen Wahrscheinlichkeit in die einander überlappenden Gruppen der „Ansprecher“ und „NichtAnsprecher" (responder versus non-responder) eingeteilt (Schmedders et al. 2003). 
Es können also auch unter genotypischen „Ansprechern“ klinische „NichtAnsprecher" vorliegen. Statt einer Einteilung in „Responder“ und „Non-Responder“ wäre es korrekter, die Patienten in Gruppen mit einer höheren bzw. niedrigeren Wahrscheinlichkeit, auf das Medikament anzusprechen, einzuteilen (Lindpaintner 2003).

Weitere Faktoren modifizieren die Reaktionen auf ein Medikament, z. B. Geschlecht, Alter, ethnische Zugehörigkeit, Rauchen, Leber- und Nierenfunktion (Schmedders et al. 2003). Diese Größen kann der behandelnde Arzt in der Regel unmittelbar beurteilen und sollte sie - gegebenenfalls neben der Empfehlung eines pharmakogenetischen Tests - auch bei der Therapieentscheidung berücksichtigen (Schmitz und Drobnik 2003). Komplizierend kommt hinzu, dass oft mehr als ein Gen die erwünschten und unerwünschten Wirkungen von Arzneimitteln beeinflusst (Evans und Reiling 1999). Durch den Einfluss mehrerer Gene und die Interaktionen zwischen Genen und Umwelt sind die Ergebnisse pharmakogenetischer Tests selten eindeutig (Buchanan et al. 2002). Zudem wird die Wirkung von Medikamenten durch zusätzliche Faktoren wie z. B. Alter, Geschlecht und Begleiterkrankungen beeinflusst (Johnson und Lima 2003). Der Begriff der „Individualisierung“ von Therapien durch die Anwendung pharmakogenetischer Untersuchungen ist daher übertrieben, da die Untersuchungsergebnisse tatsächlich nur eine Erfassung genetischer Merkmale bedeuten, die zu individuell unterschiedlichen Wirkungen bzw. Nebenwirkungen von Medikamenten führen können. Statt einer „maßgeschneiderten Therapie“ im eigentlichen Sinne wird nur der am besten sitzende Anzug (Medikament) aus der vorhandenen Menge ausgewählt und nicht erst einer nach den Maßen des Patienten angefertigt (Peters 2003). Eine Berücksichtigung des „ganzen Menschen“ in seiner Individualität findet nicht statt (Ach et al. 2004), sondern die Zugehörigkeit zu einer Subgruppe bildet die tatsächliche Grundlage der „individuellen“ Therapie (Lee SS 2003). Der Begriff "Individualisierung“ in Verbindung mit Pharmakogenetik steht daher genau genommen eher für eine Typisierung und nicht für die Individualisierung der Arzneimitteltherapie bis auf die Ebenen der einzelnen Person (Ach et al. 2004). 
Ein positiver Aspekt bleibt, dass die Pharmakogenetik bei der Auswahl angemessener Medikamente und Dosierungen genutzt werden kann, statt diese zu vereinheitlichen („one size fits all“) (Badcott 2006). Letztlich aber bleibt das Untersuchungsergebnis eine probabilistische Aussage, da die individuellen Patienten nicht immer reagieren, wie es auf Genotypisierung basierende Einteilungen erwarten lassen (Schmedders et al. 2003).

Bisher ist der Einfluss der Pharmakogenetik auf die medizinische Routineversorgung noch gering, aber die breite Anwendbarkeit pharmakogenetischer Tests könnte in einigen Jahren möglich sein (Nebert et al. 2003). Gründe, warum pharmakogenetische Erkenntnisse bisher selten in der medizinischen Routineversorgung angewendet werden, sind z. B. der verzögerte Wissenstransfer aus der Forschung in die Praxis und die Alternative des "therapeutischen Drug-Monitoring (TDM)“ (Becquemont 2003). Die zukünftige Herausforderung ist, den genotyp-bedingten Einfluss auf Interaktionen zu verstehen, die ethnische Zugehörigkeit zu berücksichtigen und Studien durch Präzision, hohes Maß an Qualität und neuester Technologie zu optimieren (Stoughton und Friend 2005). Für die weitere Anwendung pharmakogenetischer Untersuchungen werden ausführliche Daten, die eine Verbesserung der therapeutischen Erfolge und die Wirtschaftlichkeit dieser Untersuchungen belegen, benötigt (Swen et al. 2007).

\subsection{Ziele und Eigenschaften pharmakogenetischer Untersuchungen}

Das Verständnis für die Variabilität in der Wirksamkeit und Toxizität derselben Dosis eines Medikamentes bei verschiedenen Patienten könnte zu einer sichereren und wirksameren Arzneimitteltherapie beitragen (Shastry 2006). Das Ziel pharmakogenetischer Untersuchungen ist daher die Vermeidung von unerwünschten Arzneimittelwirkungen, die Reduzierung von „Therapieversagern“ und die Durchführung einer zielgerichteten Therapie (Wolf et al. 2000). Dosis und Art des Arzneimittels sollen unter Berücksichtigung des Genotyps angepasst und so eine „individuelle“, optimale Therapie mit größtem Nutzen und geringsten Nebenwirkungen ermöglicht werden. Ärzte und Patienten sollen schon im Vorfeld den potentiellen Nutzen und Schaden 
verschiedener Wirkstoffe gegeneinander abwägen und eine entsprechende Wahl treffen können (Weihrauch 2002). Zukünftig könnten pharmakogenetische Untersuchungen die Auswahl von Arzneimitteln beeinflussen und die Methode von „Versuch und Irrtum (Trial and Error)“ ersetzen (Ginsburg und McCarthy 2001). Ziel ist die mittels pharmakogenetischer Tests schnellere und angemessene Auswahl von Medikament und Dosis, wie Abbildung 1 veranschaulicht.

Statt sich - wie heutzutage üblich - nach der Diagnosestellung auf eine medikamentöse Therapie festzulegen und diese durch Monitoring überprüfen und optimieren zu müssen, könnte zukünftig durch einen pharmakogenetischen Test entweder bereits vor oder direkt nach der Diagnosestellung das für den Patienten vermutlich optimale Medikament in der richtigen Dosierung gewählt werden. Die Vorteile wären eine eventuell schnellere, effektivere Therapie und eine möglicherweise höhere Lebensqualität für den Patienten, für den dies weniger Arztbesuche aufgrund von Nebenwirkungen und Dosiseinstellung bedeuten könnte (Weihrauch 2002). Auch die Kosten im Gesundheitswesen könnten so durch die Verwendung pharmakogenetischer Untersuchungen möglicherweise gesenkt werden (Roses 2000).

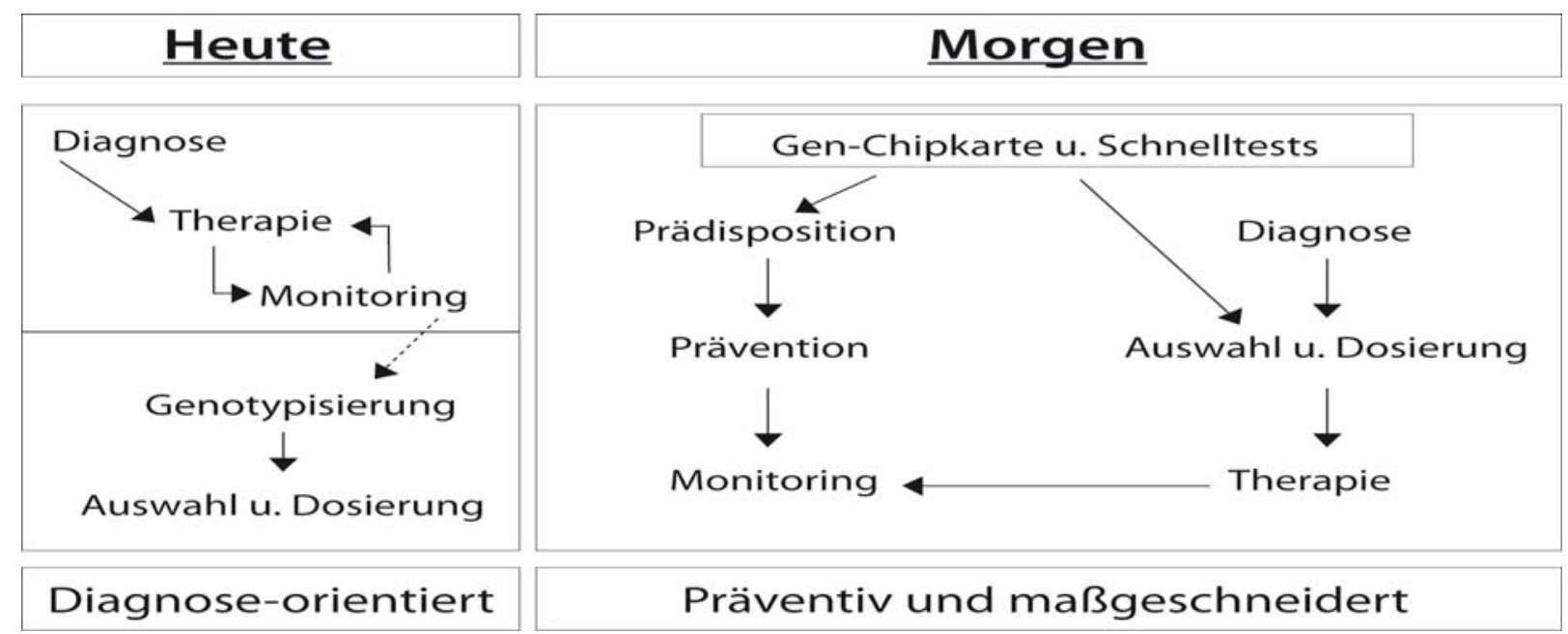

Abbildung 1: Veränderungen durch pharmakogenetische Untersuchungen (aus Kirchheiner et al. 2003, S. 843)

Einen weiteren großen Vorteil böte die höhere Sicherheit in der Arzneimitteltherapie. Unerwünschte Arzneimittelwirkungen sind ein häufiger und oft vermeidbarer Grund für medizinische Zwischenfälle bei ambulanten Patienten. 2006 haben Budnitz et al. 
in einer Studie in den USA untersucht, wie oft Arzneimittelzwischenfälle zu einer Vorstellung in der Notaufnahme bzw. zur stationären Aufnahme führen. Ihr Ergebnis war, dass 0,6 \% der Fälle in der Notaufnahme auf unerwünschte Arzneimittelwirkungen zurückzuführen und besonders Patienten ab dem 65. Lebensjahr gefährdet seien. Laut Redfern lagen in den USA schwere „Arzneimittelzwischenfälle“ an vierter bis sechster Stelle in der Statistik der häufigsten Todesursachen (Redfern et al. 2002).

In Deutschland ist die Rede von ca. 120.000 Fällen schwerer unerwünschter Arzneimittelreaktionen mit schätzungsweise 16.000 tödlichen Zwischenfällen pro Jahr (Gerloff und Roots 2005). Diese Zahlen verdeutlichen, wie wichtig es ist, Nebenwirkungen medikamentöser Therapien zu berücksichtigen und Strategien zu deren Vermeidung zu entwickeln (Schmitz und Drobnik 2003). Zusätzlich könnten sich durch die Reduzierung des Auftretens von Nebenwirkungen und Komplikationen medikamentöser Therapien eventuell Kosten im Gesundheitswesen vermindern lassen (Ginsburg und McCarthy 2001), allerdings müssten von Fall zu Fall die variierenden Kosten für die pharmakogenetischen Untersuchungen mit einkalkuliert werden.

Auch Gerloff und Roots (2005) sind der Meinung, die Berücksichtigung der individuellen genetischen Besonderheiten bei Arzneimittelauswahl und Dosisfestlegung könnte zur Reduktion der Behandlungskosten beitragen. Hierbei muss jedoch bedacht werden, dass die genetisch begründete Anpassung der Dosierung eines Arzneimittels nur bei einem kleinen Teil der Medikamente von Bedeutung wäre, wahrscheinlich in der Größenordnung von ca. 200 - 300 wichtigen Arzneimitteln. Im Sinne einer evidenzbasierten Medizin folgt daraus die Forderung, dass die Überlegenheit einer solchen dosisadjustierten Medikation im Vergleich zur Gabe von Standarddosen durch klinische Studien belegt werden müsste (Kirchheiner et al. 2003). Mögliche strukturelle Auswirkungen auf den pharmazeutischen Markt sind derzeit noch unabsehbar (Horrobin 2001).

Vorteile könnten pharmakogenetische Untersuchungen auch im Rahmen der Forschung bieten, z. B. könnten Medikamente, die bisher in klinischen Studien ausgesondert werden mussten, für bestimmte Subgruppen eines Genotyps verwendet 
werden (Lash et al. 2003). Dies böte die Option, im Rahmen der Arzneimittelzulassung kleinere, kostengünstigere und kürzere klinische Studien mittels der Untersuchung "genetisch homogener" Stichproben durchzuführen (Brazell et al. 2002). Patienten, die aufgrund ihrer genetischen Ausstattung für die Einnahme eines bestimmten Medikaments nicht geeignet sind, könnten so vor der Teilnahme an klinischen Prüfungen geschützt werden (Lipton 2003). In diesem Zusammenhang denkbarer Nachteil ist allerdings die Gefahr fehlender oder verspäteter Aufdeckung eventueller Nebenwirkungen oder Wechselwirkungen mit anderen Medikamenten. Dies könnte dann vor allem Patienten betreffen, für die diese medikamentöse Therapie aufgrund ihres Genotyps nicht eindeutig vorgesehen war (Rothstein und Epps 2001). Ebenso könnten genetisch bedingte kleine Subgruppen entstehen, die aus ökonomischen Aspekten für die Pharmaindustrie unattraktiv sind (Smart et al. 2004).

Pharmakogenetische Tests könnten ebenfalls die Kennzeichnung von Medikamenten beeinflussen, in dem Sinne, dass die Verschreibung nur auf Personen mit passendem genetischem Profil begrenzt wird bzw. vor der Einnahme ein pharmakogenetischer Test empfohlen wird (Wertz 2003). Bisher enthalten Packungsbeilagen von Medikamenten nur selten Hinweise auf mögliche pharmakogenetische Effekte. Selbst wenn diese Information vorhanden ist, reicht sie für den behandelnden Arzt in der Regel nicht aus, um für therapeutische Entscheidungen hilfreich zu sein (Zineh et al. 2004). Eine wichtige Rolle werden in diesem Zusammenhang die zuständigen Arzneimittelbehörden spielen (Hodgson und Marshall 1998). So hat die amerikanische Zulassungsbehörde 2006 bereits für einige Medikamente wie Azathioprin und 6-Mercaptopurin veranlasst, in den Fachinformationen die Testung auf pharmakogenetische Variationen zu empfehlen (Kichheiner et al. 2006).

Bei ca. 10 - $15 \%$ der medikamentösen Therapien liegt wahrscheinlich eine enge Verknüpfung zwischen Genotyp und Wirkung des Arzneimittels vor, bei weiteren 35 $40 \%$ ist der Zusammenhang durch die Beteiligung mehrerer Gene vermutlich vorhanden, aber weniger eng. Dies bedeutet, dass bei ca. $50 \%$ der Arzneimitteltherapien Genvarianten keine relevanten Rollen spielen (Ingelman-Sundberg 2001). Außerdem sollten gerade bei Techniken, die sich noch im Entwicklungsstadium befin- 
den und deren breite Anwendung noch einige Jahre auf sich warten lassen wird, Hoffnungen und Versprechungen sehr sorgfältig auf ihren Realitätsgehalt und das zu erwartende Leistungspotential hin analysiert werden. Dazu gehört v. a. die kritische Auseinandersetzung mit den Leitbildern, Visionen und Nutzversprechen, mit denen technische Innovationen ausgestattet werden (Feuerstein et al. 2003).

\subsection{Aktuelle Untersuchungen zur Einstellung der Bevölkerung}

Berth et al. (2002) haben eine deutschlandrepräsentative Stichprobe von 2.076 Personen zu den möglichen Vor- und Nachteilen genetischer Untersuchungen befragt. Nach der vorangestellten Erklärung, dass zahlreiche Krankheiten erblich bedingt und familiär vererbbar sind und es möglich sei, das Risiko für solche erblichen Erkrankungen sicher zu bestimmen, wurden die Teilnehmer nach der persönlichen Meinung zu solchen genetischen Untersuchungen befragt. Die dreizehn verwendeten Items, die aus einer finnischen Untersuchung übernommen worden sind, enthielten je vier befürwortende und ablehnende Aussagen bezüglich genetischer Untersuchungen. Außerdem umfassten sie weitere Aussagen zu Befürchtungen und zur persönlichen Autonomie hinsichtlich der Durchführung einer genetischen Untersuchung. Zur Beantwortung der Items war eine fünfstufige Skala vorgegeben. Die Untersuchung zeigte, dass ca. zwei Drittel der Bevölkerung genetische Untersuchungen befürworten. Während Geschlecht und Alter keinen bzw. wenig Einfluss hatten (Ältere sahen etwas häufiger negative Aspekte als Jüngere), zeigten sich deutlicher Unterschiede zwischen konfessionsgebundenen und konfessionslosen Personen. Personen mit höherer Bildung sahen mehr positive Aspekte bezüglich genetischer Untersuchungen.

Broadstock et al. (2000) überprüften die psychologischen Konsequenzen von prädiktiven Gentests. Weder die Träger noch die Nicht-Träger eines untersuchten, krankheitsassoziierten Gens wiesen während der zwölf Monate nach der Testdurchführung eine erhöhte psychische Belastung auf. Im Gegenteil, beide Seiten zeigten verminderte Sorgen nach dem Test; diese Entwicklung trat bei den Nicht-Trägern schneller und in größerem Ausmaß ein. Allerdings gehörten die Probanden zu aus- 
gewählten Populationen, die den psychologischen Studien zugestimmt hatten, und wurden nicht länger als höchstens drei Jahre beobachtet. Daher sind für ein besseres Verständnis der Beziehung zwischen Beratung und emotionalen Reaktionen weitere empirische Studien notwendig.

Parallel zu unserer Untersuchung über die Einstellung von Patienten zur Pharmakogenetik wurde eine ähnliche Untersuchung mit dieser Fragestellung auch 2006 vom englischen „Nowgen“ - einem Zentrum für Genetik im Gesundheitswesen - durchgeführt (Fargher et al. 2007 a).

Neben der Einstellung von Patienten zur Pharmakogenetik ist natürlich auch die Meinung der Ärzte zu diesem Thema von Bedeutung. Eine Umfrage unter Hausärzten ergab, dass pharmakogenetische Untersuchungen nur dann als hilfreich angesehen werden, wenn entsprechende therapeutische Optionen zur Verfügung stehen (Robertson et al. 2002). Bei einer weiteren Befragung von 48 Experten (Ärzten, Wissenschaftlern, Patientenvertretern) erwarteten $70 \%$, dass pharmakogenetische Untersuchungen innerhalb der nächsten 15 Jahre für über $15 \%$ der Krankenhauspatienten an Bedeutung zunehmen würden (Melzer et al. 2003).

\subsection{Ethische Implikationen}

Für den Patienten scheint die pharmakogenetische Untersuchung mit dem Ziel der maßgeschneiderten, „individuellen“ Arzneitherapie nur Vorteile durch die Optimierung der Therapie und die Reduzierung von Nebenwirkungen zu bringen, dennoch müssen auch einige mögliche ethische Probleme beachtet werden.

\subsubsection{Krankheitsassoziation}

Ein ethisches Problem könnte eine mögliche Krankheitsassoziation des Befundes mit sich bringen, wenn der pharmakogenetische Marker zugleich mit einem erhöhten Risiko für die Manifestation einer zugrunde liegenden genetisch bedingten Erkrankung einhergeht (Meyer et al. 2002). 
Am Beispiel Morbus Alzheimer lassen sich (1) die probabilistische Natur pharmakogenetischer Aussagen und (2) die mögliche Assoziation von pharmakogenetischem Befund und Erkrankungsrisiko (Post et al. 1997) veranschaulichen. Liegt bei einem Patienten mit Morbus Alzheimer der Genotyp E4 des Apolipoproteins E vor, so hat dieser Patient - unabhängig von der medikamentösen Therapie - eine schlechtere Prognose für den Krankheitsverlauf (Sjögren et al. 2001). Zugleich war das Apo-E4Allel aber auch für die Erfolgsprognose der medikamentösen Therapie mit dem früher verwendeten Cholinesterase-Inhibitior Tacrin von Bedeutung (Poirier et al. 1995, Emilien et al. 2000): So sprachen 80 \% der Patienten ohne Apo-E4 gut auf Tacrin an, während 60 \% der Patienten mit Apo-E4-Genotypisierung nicht auf Tacrin ansprachen (Meyer et al. 2002). Der therapeutische Erfolg ist in diesem Fall also eng mit dem spezifischen Genotyp verknüpft (Cacabelos 2007).

Würde einem Alzheimer-Patienten nach einem pharmakogenetischen Test von der Therapie mit Tacrin abgeraten, könnte er daraus folgern, dass er wahrscheinlich zu den Patienten gehört, bei denen Apo-E4 vorliegt, und er daher eine schlechtere Prognose hat. Als mögliche Folge könnte diese Implikation den weiteren Verlauf der Krankheit entscheidend verändern, indem sie - wie eine sich selbst erfüllende Prophezeiung - das Verhalten und die Erwartung von Arzt und Patient beeinflusst. Unabhängig von der Diskussion über den Nutzen antidementiver Therapien bleibt auch mit pharmakogenetischen Untersuchungen die Entscheidung schwierig, welchem Patienten eine medikamentöse Therapie empfohlen werden sollte und welchem nicht, da ja immerhin noch $40 \%$ der Apo-E4-Patienten von Tacrin profitierten (Evans und Johnson 2001).

Auch die ärztliche Interpretation des genetischen Tests und die Art der Befundmitteilung könnten beim Patienten Ängste wecken. Wird bei einem pharmakogenetischen Test eine eventuelle Krankheitsassoziation festgestellt, könnte dies nicht nur für den Patienten, sondern auch für seine Verwandten von Bedeutung sein. Das heißt, Daten dieser Art könnten nicht nur die getestete Person, sondern auch deren Angehörige betreffen, die auf diese Weise ungewollte Informationen über ihre mögliche zukünftige Gesundheit erhalten (Hapgood 2003). Der behandelnde Arzt muss diese Konse- 
quenzen schon im Vorfeld bedenken und sollte eine derartige Untersuchung nur nach einem ausführlichen Aufklärungsgespräch über verbundene Risiken und erhofften Nutzen nach Einwilligung des Patienten durchführen (Meyer et al. 2002).

Aber ist eine mögliche Krankheitsassoziation nur negativ zu sehen? Immerhin könnte sie auch die Chance auf eine bessere Therapierbarkeit durch Früherkennung bzw. auf eine gesündere Lebensweise aufgrund des Wissens über individuell höhere Krankheitsrisiken bieten. Marteau und Lerman zeigten 2001 am Beispiel eines Testresultats, das auf eine genetisch bedingte Erkrankung hinweist, wie die Einhaltung von Vorsorge- und Früherkennungsprogrammen verbessert werden kann. So könnten Patienten eine Krankheitsassoziation prinzipiell als „genetischen Fluch“ oder als eine Chance empfinden.

\subsubsection{Konsequenzen für Arbeitgeber und Krankenkasse}

Ein eventueller Nachteil pharmakogenetischer Untersuchungen ist die Möglichkeit, dass eine verminderte Ansprechbarkeit von Medikamenten ein höheres Risiko für Versicherer und Arbeitgeber bedeuten könnte. Dies könnte bei Bekanntwerden zu Nachteilen bei Lebens- und Krankenversicherungen bzw. auf dem Arbeitsmarkt führen (Nebert und Bingham 2001, Feuerstein et al. 2002). Zeigt z. B. ein pharmakogenetischer Test, dass für einen Patienten mit einer chronischen Krankheit kein optimales Medikament vorhanden ist - also die möglichen Medikamente nur wenig nutzen und mit Nebenwirkungen behaftet sind - könnte ein Arbeitgeber infolge der schlechteren Therapiemöglichkeiten mit einem vermehrten Krankheitsausfall rechnen und sich gegen die Einstellung des Arbeitnehmers entscheiden.

Krankenkassen könnten die Bezahlung pharmakogenetischer Tests oder spezieller Subgruppen-Medikamente verweigern (Wertz 2003). Auch für sie wäre ein Patient, für den es keine gut wirksame Therapie gibt und der eventuell teurere SubgruppenMedikamente benötigt, ebenfalls ein Kostenfaktor. Aber auch der gegenteilige Effekt wäre möglich, dass durch den gezielten Einsatz von Medikamenten eine effektivere Therapie mit geringeren Folgekosten erreicht werden könnte. Ein aktuelles Beispiel 
ist der Einsatz von BiDil (ein Kombinationspräparat aus Isorbiddinitrat und Hydralazinhydrochlorid), einem in den USA vorhandenen Arzneimittel zur Therapie der Herzinsuffizienz, das nur für Afroamerikaner zugelassen ist. Auch wenn sich genetisch die höhere Wirksamkeit von BiDil bei dieser Gruppe nicht erklären lässt, so könnten doch zukünftig pharmakogenetische Tests die Patienten - unabhängig von ihrer Rasse - identifizieren, die von dieser Medikation profitieren könnten (Brody und Hunt 2006).

Weitere nachteilige soziale Folgen könnten sich für den betroffenen Patienten ergeben, wenn rechtliche Regelungen wie die Offenbarungspflicht und der Grundsatz „gleiche Information von Antragsteller und Versicherer vor Vertragsabschluss" auch bei prädiktiven genetischen Informationen angewendet werden. Nicht auszuschließen wären dann z. B. ein eingeschränkter Zugang zu Hauseigentum, wenn die Hypotheken von Lebensversicherungen gestützt werden, oder die Verweigerung von privatem Versicherungsschutz, was schon jetzt für HIV-Infizierte beobachtet wurde (McGleenan und Wiesing 2001).

\subsubsection{Datenschutz}

Ergebnisse pharmakogenetischer Untersuchungen sind äußerst sensiblen Daten, die dem strengsten Datenschutz unterliegen sollten (Austin 2002), besonders da sie als Erbanlagen nicht nur den Patienten, sondern auch seine Angehörigen betreffen könnten. Doch lässt sich ein absoluter Datenschutz überhaupt gewährleisten? Der Patient teilt im Falle der Verschreibung eines nur für eine bestimmte, pharmakogenetisch definierte Untergruppe zulässigen Medikamentes indirekt dem Apotheker oder dem Sachbearbeiter der Krankenversicherung seinen Genotyp mit (Lindpaintner 2002). Allein die Tatsache, dass ein bestimmter Patient vielleicht in eine pharmakogenetische Subgruppe gehört, bei der es nur ein bestimmtes Medikament bzw. eine spezielle Dosierung gibt, gleicht schon einer Offenlegung seiner Daten. Wenn er nämlich über dieses spezielle Medikament ein Rezept erhält, könnten Apotheker und die Krankenkasse aus diesem Wissen Rückschlüsse ziehen. 
Auch im privaten Umfeld des Patienten hätten Personen, die das Medikament zu Gesicht bekommen - z. B. bei der Einnahme am Arbeitsplatz - die Möglichkeit, daraus Rückschlüsse auf die genetische Veranlagung des Patienten zu ziehen. Besonders problematisch wäre dies natürlich, wenn zeitgleich auch eine Krankheitsassoziation vorliegt, also z. B. ein Alzheimer-Patient kein Tacrin erhielte und Personen aus diesem Wissen auf das Vorliegen von Apo E4 und somit eine schlechtere Prognose schließen könnten. Andererseits gilt dies natürlich ebenso für zahlreiche gebräuchliche Medikamente (z. B. bei Diabetes, Epilepsie), durch deren Erwerb oder Einnahme die betroffene Person ihre gesundheitliche Beeinträchtigung offenbart und möglicherweise Stigmatisierung oder Diskriminierung ausgesetzt ist.

Laut Wertz (2003) sei eine spezielle Einverständniserklärung vor der Durchführung pharmakogenetischer Tests nicht nötig. Durch das Benennen des Tests als „genetisch“ würden die Patienten nur verängstigt und abgeschreckt, so dass sie diese Möglichkeit nicht mehr nutzen würden. Die Abgrenzung zwischen „genetischen“ und „nicht-genetischen“ Tests sei ohnehin schwierig, da so viele Krankheiten zumindest teilweise genetisch bedingt sind. Um die Akzeptanz genetischer Untersuchungen zu verbessern, müsste gesichert sein, dass genetische Daten nicht zur Diskriminierung einzelner Bevölkerungsgruppen verwendet werden (Alcalde und Rothstein 2002), der Patient die vollständige Kontrolle über seine genetischen Daten und Proben behält und der Schutz der Daten gewährleistet wird (Paul und Roses 2003).

\subsubsection{Zugang zu pharmakogenetischen Tests}

Der Zugang zu pharmakogenetischen Tests müsste prinzipiell allen Patienten gleichermaßen offen stehen. Aber wie bei allen neuen Technologien, die immer auch mit Kosten verbunden sind, werden die daraus resultierenden Vorteile zunächst von Wohlstandsgesellschaften (wie z. B. den USA oder in Europa) genutzt werden können und Entwicklungsländern noch nicht zugänglich sein. Auch innerhalb einer Gesellschaft stellt sich die Frage, ob jeder zu pharmakogenetischen Tests Zugang hätte (Nuffield Council on Bioethics 2003), wenn z. B. die Krankenkassen deren Bezahlung nicht oder nur zum Teil übernehmen würden. 
Unklar ist bisher der optimale Durchführungszeitpunkt für pharmakogenetische Untersuchungen. Eine Möglichkeit ist die frühzeitige, routinemäßige Durchführung, um diese Ergebnisse bei der Anpassung der medikamentösen Therapie nutzen zu können (Wertz 2003). Andererseits könnten genetische Untersuchungen zu einer „Medikalisierung" führen, so dass bereits das Vorhandensein eines Markers auch bei fehlender Symptomatik als Behandlungsanlass betrachtet werden könnte (Melzer und Zimmern 2002).

\subsubsection{Emotionale Auswirkungen auf den Patienten und seine Familie}

Angehörige eines Patienten könnten durch das Ergebnis eines pharmakogenetischen Tests mitbetroffen sein. Wenn eine Person ein Medikament nicht einnehmen kann, ist es wahrscheinlich, dass es andere Familienmitglieder ebenfalls nicht nutzen können (Hapgood 2003). Daher ist eine mögliche Gefahr, dass Familienmitglieder oder bestimmte Bevölkerungsgruppen mit dem Hinweis auf eine höhere Rate von „Nicht-Ansprechern“ diskriminiert werden könnten (Weijer und Miller 2004).

Ein Hauptproblem ist die Frage wie ein Patient mit dem möglichen ungünstigen Testergebnis umgeht. Schließlich könnte das bedeuten, dass momentan kein passendes Medikament für inn vorhanden ist, also auf dem Markt befindliche Medikamente für inn keinen großen Nutzen hätten bzw. mit starken Nebenwirkungen verbunden wären. Wird der Patient diese Medikamente dann trotzdem ausprobieren wollen? Wird sich z. B. ein Gefühl von Machtlosigkeit, Pessimismus oder einer Abhängigkeit bzw. Fremdbestimmung durch die Gene einstellen, fragt Robertson (2001). Mögliche Folgen wären z. B. ein verzerrtes Selbstbild mit dem Gefühl, aufgrund einer genetischen Variabilität „anders“ oder „defekt" zu sein (Issa 2002). Auch könnte ein Gefühl der vollkommenen Abhängigkeit, der Macht- bzw. Hilflosigkeit oder des Ausgeliefertseins gegenüber den eigenen Genen entstehen (Robertson 2001). Weitere mögliche negative Aspekte für die Patienten könnten ein verstärkter Druck zur Durchführung pharmakogenetischer Untersuchungen sein (Ach et al. 2004) bzw. eine von ärztlicher Seite aus höhere Bewertung der Testergebnisse gegenüber der subjektiven Sichtweise des Patienten. 
Bisherige Untersuchungen zu den emotionalen Folgen prädiktiver genetischer Untersuchungen haben gezeigt, dass diese - unabhängig vom Testergebnis - kein negatives emotionales Befinden nach sich ziehen müssen, sie können ebenso zu positiven Emotionen wie Erleichterung und Gewissheit führen (Broadstock et al. 2000). Einen stärkeren Einfluss als die Testergebnisse scheinen die individuellen Verarbeitungsmechanismen und Beratung zu haben.

Pharmakogenetik definiert die „Individualität“ über biochemische bzw. physiologische Faktoren. Der Wunsch des Patienten nach einer bestimmten Therapie und andere psychologische und soziale Aspekte sind am pharmakogenetischen Konzept der „Individualisierung" nicht beteiligt. Wie bereits in Kapitel 2.2.6 diskutiert, bleibt die Frage, ob die Möglichkeiten der Pharmakogenetik überhaupt angemessen mit dem Term „Individualisierung" beschrieben sind (Schmedders et al. 2003). Der Patient muss daher über die konkreten Auswirkungen einer pharmakogenetischen Untersuchung informiert sein, er muss verstehen, dass es sich bei den Testergebnissen um probabilistische Vorhersagen handelt, d. h. um eine höhere oder niedrigere Wahrscheinlichkeit, auf ein Medikament anzusprechen. Durch den Begriff „Individualisierte Therapie" dürfen nicht unrealistische oder überzogene Erwartungen auf Seiten der Patienten geweckt werden.

In diesem Zusammenhang ist daher auch die Rolle des Arztes als Berater und Ansprechpartner wichtig, er muss sich durch Aufklärungsbedarf und Dokumentation höheren Anforderungen stellen als bei der „traditionellen“ Arzneitherapie (Ach et al. 2004). Einerseits muss er die Ergebnisse eines pharmakogenetischen Tests korrekt bewerten, gleichzeitig aber auch dem Patienten verständlich machen, dass sie nicht die alleinige Grundlage einer Behandlung sind, sondern noch weitere Aspekte wie z. B. Alter oder andere Erkrankungen mit einbezogen werden, damit Patienten das Gewicht pharmakogenetischer Ergebnisse nicht überbewerten. Zudem bezieht sich die pharmakogenetische Untersuchung nur auf die medikamentöse Therapie, diese stellt jedoch selten eine Einzelmaßnahme dar und ist meistens in einen ganzheitlichen Behandlungsansatz eingebettet, der funktionelle und psychosoziale Komponenten mitberücksichtigt (Borchelt 2005). 


\subsection{Pharmakogenetik: Konsequenzen für die hausärztliche Praxis}

Hausärzte werden möglicherweise zahlreichen Hoffnungen, Sorgen und Befürchtungen seitens ihrer Patienten begegnen, wenn pharmakogenetische Untersuchungen in der Hausarztpraxis angeboten und durchgeführt werden. Ist die Einstellung von Patienten gegenüber pharmakogenetischen Tests bekannt, kann man gezielt überzogenen Ängsten oder übertriebenen Erwartungen begegnen. Grundsätzlich stellt sich jedoch zunächst die Frage, ob Patienten diese Untersuchungen überhaupt wünschen und wenn ja, welchen Arzt sie zur Durchführung konsultieren würden.

Für Hausärzte stellen sich weitere Fragen, z. B. inwieweit sie auf die Beratungen von Patienten in Hinblick auf pharmakogenetische Tests vorbereitet sind und wie stark sie das Ergebnis eines pharmakogenetischen Tests gewichten würden. Von den Einstellungen des Arztes kann es abhängen, ob er überhaupt - und wenn ja, wie - er seine Patienten auf genetische Untersuchungen hinweist (Berth et al. 2003). Auch ist noch unklar, welcher Grad von Verständnis auf Seiten der Patienten nötig ist, um wirklich informiert zustimmen zu können (March et al. 2001). Gerade aufgrund der weit reichenden Konsequenzen und Einflüsse ist das Ziel der „geteilten Entscheidungsfindung" (shared decision) durch eine pharmakogenetische Beratung wahrscheinlich alles andere als einfach (Emery 2001). Handlungsanweisungen zur effektiven Patientenaufklärung und Beratung über pharmakogenetische Untersuchungen müssten entwickelt und evaluiert werden (Gurwitz et al. 2003).

Könnten pharmakogenetische Untersuchungen in die hausärztliche Versorgung integriert werden, böten sich auch dem behandelnden Arzt eine Vielzahl neuer Möglichkeiten. Die Auswahl eines Medikamentes aus der Vielzahl von zur Verfügung stehenden Präparaten wäre erleichtert, auf das Auftreten von bestimmten Nebenwirkungen wäre man besser vorbereitet bzw. könnte sie vermeiden und die Dosierung wäre dem Patienten angepasster. Ein weiterer Vorteil wäre die Möglichkeit der Reduzierung der Medikamentenanzahl, was einerseits, wie in Studien gezeigt wurde, zu einer Verbesserung der Compliance führt und andererseits die Gefahr von Einnahmefehlern durch die Anzahl gleichzeitig verordneter Medikamente vermindert (Borchelt 2005). Bei steigender Zahl der verordneten Medikamente kommt es zudem zu 
einer Zunahme an unerwünschten Arzneimittelwirkungen und von Wechselwirkungen der Medikamente untereinander (Wehling und Peiter 2003), so dass sich auch in diesen Punkten eine mögliche Reduzierung der Medikamentenanzahl positiv auswirken könnte.

Allerdings erfordert die Einbeziehung pharmakogenetischer Untersuchungen in den hausärztlichen Alltag die Fähigkeit des Arztes zur pharmakogenetischen Beratung: Dies bedeutet, dass der Arzt in Aufklärungsgesprächen die nötigen Informationen dem Patienten verständlich vermitteln und die Testergebnisse richtig interpretieren und angemessen erläutern können muss (Emery und Hayflick 2001). Untersuchungen zur evidenzbasierten Medizin lassen vermuten, dass Risiken und Prognosen in Abhängigkeit von der Darstellungsweise häufig fehlinterpretiert werden (Hoffrage et al. 2000). Diese Gefahr der Über- oder Fehlinterpretation besteht natürlich auch bei Ergebnissen einer pharmakogenetischen Untersuchung (Emery et al. 1998). Bei fehlenden oder falschen Anordnungen, Interpretationen oder Erläuterungen pharmakogenetischer Tests müssten sich Ärzte möglicherweise neuen rechtlichen Fragen stellen.

Sowohl für den Arzt als auch für den Patienten sollte die pharmakogenetische Untersuchung nur eine diagnostische Maßnahme innerhalb eines umfassenden Behandlungskonzeptes sein, welches auch präventive und nicht-medikamentöse Therapiemaßnahmen sowie psychosoziale Aspekte der Krankheitsentstehung mit einbezieht. Gerade aufgrund der Komplexität bei chronischen Erkrankungen benötigen die Betroffenen multiprofessionelle, kooperativ angelegte Behandlungs- und Versorgungskonzepte (Schaeffer 2006). Von der Anwendung genetischer Tests sollte abgesehen werden, wenn der Patient seine Zustimmung verweigert bzw. von seinem Recht auf „Nicht-Wissen“ Gebrauch macht (Meyer et al. 2002). Zumindest müssen das „Recht auf Nicht-Wissen" einerseits und die mögliche Vorteile dieser Informationen anderseits gegeneinander abgewogen werden (Anderson et al. 2002).

In der Folge dieser Veränderungen wird sich wahrscheinlich die Rolle des Arztes mehr in Richtung des Mentors bzw. Beraters verschieben, der den Patienten unter 
Berücksichtigung seiner einzigartigen genetischen Anlagen behandelt, berät und anleitet (Schmedders et al. 2003). Die „individuelle Therapie“ wird dadurch verwirklicht, dass der Arzt physiologische, biochemische, psychologische, soziologische und kulturelle Faktoren in die Behandlung einbezieht. Eine gute Kommunikation zwischen Arzt und Patient ist dabei eine unerlässliche Anforderung für eine patientenorientierte und individuelle Medizin im psychosozialen Sinn. Wird stattdessen durch die Pharmakogenetik die Aufmerksamkeit des Arztes vermehrt auf die Bewertung sogenannter „objektiver Faktoren“ wie z. B. genetischer Variationen von metabolisierenden Enzymen gelenkt, werden vermutlich weder die Arzt-Patient-Beziehung verbessert, noch der Wunsch des Patienten nach einer auf seine persönlichen Bedürfnisse angepassten Therapie erfüllt (Schmedders et al. 2003).

Eine Umfrage unter Hausärzten ergab, dass sie pharmakogenetische Untersuchungen nur dann als hilfreich ansehen, wenn entsprechende therapeutische Optionen, wie z. B. die Wahl zwischen verschiedenen Präparaten oder Dosisveränderungen, zur Verfügung stehen (Robertson et al. 2002). Daher begründen einige Hausärzte ihre bisherige Zurückhaltung gegenüber prädiktiven genetischen Untersuchungen mit dem ethischen Dilemma, dass genetische Informationen vorliegen, aber keine Therapie zur Verfügung steht (Kumar und Gantley 1999, Robins und Metcalfe 2004). Auch sind bisher nur wenige Leitlinien für die Interpretation und Verwendung pharmakogenetischer Ergebnisse vorhanden (Swen et al. 2008). Für die Integration von pharmakogenetischen Tests in den ärztlichen Alltag wären klare und konkrete therapeutische Maßnahmen, die sich aus dem Test ergeben, notwendig. Zurzeit können diese Daten aber nur mit Vorbehalt abgeleitet werden (Kirchheiner et al. 2004). Die zukünftig möglicherweise routinemäßige Anwendung pharmakogenetischer Untersuchungen wird sowohl die Patienten als auch die Ärzte, die über ihre Durchführung zu entscheiden haben, vor neue Herausforderungen stellen (Delden et al. 2004), doch scheinen wir heute von einer breiten medizinischen Anwendung pharmakogenetischer Untersuchungen noch entfernt (Kirchheiner et al. 2006). 


\subsection{Pharmakogenetik: Konsequenzen für die Patienten}

Würde die Pharmakogenetik zu einer verbesserten Auswahl wirksamer Medikamente und zur Abnahme von Nebenwirkungen führen, könnte die Compliance der Patienten steigen, da sie möglicherweise durch den pharmakogenetischen Test von der Wirksamkeit ihrer Medikamente überzeugter wären (Placebo- bzw. Kontexteffekt) (Di Blasi et al. 2001). Würde ein pharmakogenetischer Test eine hohe Ansprechwahrscheinlichkeit ergeben, könnte auf Seiten der Patienten das Vertrauen in das Medikament gestärkt und die Bereitschaft zur regelmäßigen Einnahme gesteigert werden (Hapgood 2003). Umgekehrt könnte auch der gegenteilige Effekt eintreten und durch das Testergebnis der Placeboeffekt eines Medikaments reduziert werden, wenn dem Patienten die Prognose einer verminderten Ansprechwahrscheinlichkeit mitgeteilt wird.

Des Weiteren böte die den genetischen Besonderheiten individuell angepasste Beratung zu Lebensstil und Krankheitsprävention dem Patienten die Chance, sich für einen gesünderen Lebensstil zu entscheiden (Kirchheiner et al. 2003). Wird bei einem Patienten also z. B. gleich zu Beginn einer Asthma-Erkrankung durch einen pharmakogenetischen Test festgestellt, dass bestimmte Medikamente nur bedingt helfen werden, würde sich der Patient vielleicht von Anfang an weniger auf eine medikamentöse Therapie stützen und sich mehr auf z. B. physikalische Maßnahmen oder eine gesündere Lebensführung konzentrieren.

Mögliche negative Aspekte für die Patienten könnten sein, dass es durch die Einführung pharmakogenetischer Untersuchungen zu einer unangemessenen generellen Zurückhaltung bei lebenswichtigen Arzneimitteln (z. B. Azathioprin) und zu Unterdosierung kommen könnte, vor allem wenn nur bei wenigen Patienten eine genetisch bedingte Überempfindlichkeit zu erwarten wäre und alternativ Dosisanpassungen durch Blutkontrollen und TDM (Therapeutisches Drug Monitoring) möglich wären (Marshall 2003). 


\subsection{Zusammenfassung}

Gene spielen eine wichtige Rolle im Arzneistoffmetabolismus und beeinflussen dadurch die Wirksamkeit eines Medikamentes. Durch pharmakogenetische Untersuchungen lassen sich diese durch genetische Variationen bedingten Unterschiede im Arzneimittelstoffwechsel vorhersagen. Patienten könnten nach solchen Untersuchungen gemäß ihrer Wahrscheinlichkeit, auf ein Medikament anzusprechen, in Gruppen eingeteilt werden.

Vorteile pharmakogenetischer Untersuchungen sind z. B. eine gezieltere Auswahl bzw. Dosierung von Arzneimitteln und dadurch eventuell eine Reduzierung der Kosten im Gesundheitswesen. Nachteile pharmakogenetischer Untersuchungen sind die Gefahr der Verletzung des Datenschutzes mit Verlautbarung sensibler genetischer Daten an Arbeitgeber oder Krankenkasse sowie die emotionalen Auswirkungen auf den Patienten.

Die Anwendung von pharmakogenetischen Untersuchungen wird daher vor allem abhängen von der Qualität des Informationsmaterials für Ärzte und Patienten, dem Beratungsgespräch sowie von der Einverständniserklärung und der Sicherstellung des Datenschutzes.

Weitgehend offen blieb die Frage, wie die Patienten selbst diese Aspekte beurteilen und ob sie pharmakogenetische Untersuchungen durchführen lassen würden. 


\section{Fragestellung und Ziel}

In der Literatur finden sich zahlreiche Beispiele für ethische, soziale und emotionale Konsequenzen von pharmakogenetischen Untersuchungen. Die Literaturrecherche zeigte aber auch, dass sich die zum Thema „Pharmakogenetik“ veröffentlichten Artikel fast ausschließlich theoretisch mit den Implikationen und möglichen Konsequenzen für die Patienten beschäftigen. Die Frage, wie aber Patienten darüber denken und welche Sorgen und Befürchtungen sie wirklich beschäftigen, bleibt weitgehend unbeantwortet. Die von Berth et al. (2002) durchgeführte und bereits erwähnte Studie zur Akzeptanz von genetischen Untersuchungen in der Bevölkerung zeigte, dass genetische Tests im Allgemeinen befürwortet werden. Es fehlen aber konkrete Untersuchungen zur Akzeptanz von pharmakogenetischen Untersuchungen bei Patienten, also den möglichen späteren Nutzern.

Daher sollte die vorliegende Studie folgende Fragen beantworten:

1. Würden Patienten eine pharmakogenetische Untersuchung durchführen lassen? Welche Rahmenbedingungen sind für sie entscheidend?

2. Welche Gründe für Zustimmung und welche Hoffnungen haben Patienten gegenüber pharmakogenetischen Tests?

3. Welche Gründe für Ablehnung bzw. Sorgen haben Patienten gegenüber pharmakogenetischen Untersuchungen?

4. Welche Informationen wären für Patienten wichtig, um eine Entscheidung für oder gegen eine pharmakogenetische Untersuchung treffen zu können? Welche Anforderungen an Beratung und Aufklärung im Fall einer pharmakogenetischen Untersuchung werden an Hausärzte gestellt?

5. Lassen sich Determinanten / Prädiktoren dafür finden, dass Menschen pharmakogenetischen Untersuchungen eher mit Hoffnungen oder Befürchtungen begegnen?

Ziel der Dissertation ist es, diese Thematik aus Sicht von Patienten zu untersuchen. Anhand der Ergebnisse sollten sich mögliche Konsequenzen für die hausärztliche Praxis erarbeiten lassen. 


\section{Material und Methode}

\subsection{Methodische Anlage der Untersuchung}

Um die Einstellung von Patienten zu pharmakogenetischen Untersuchungen in einem Fragebogen verlässlich erheben zu können, führten wir zunächst eine umfassende Literatursuche in MEDLINE durch (Stichworte: Pharmacogenetics, Delivery of Health Care, Ethics, Attitude, Patient Acceptance of Health Care). In den entsprechenden Veröffentlichungen fanden sich vor allem theoretische Betrachtungen über psychologische, soziale und ethische Konsequenzen von pharmakogenetischen Tests. Die Auswertung des Literatur-Reviews zeigte, dass vor allem:

- die Erwartung negativer psychosozialer Konsequenzen,

- die Angst vor Diskriminierung und

- die Sorge über eine mögliche Nichteinhaltung des Datenschutzes

Hauptfaktoren für die Akzeptanz oder Ablehnung von pharmakogenetischen Untersuchungen darstellen. Weil die Quellen vornehmlich aus theoretisch-konzeptionellen Arbeiten bestanden, bestätigte dies noch einmal den Bedarf an empirischen Untersuchungen zur persönlichen Meinung von Patienten über die Vor- und Nachteile pharmakogenetischer Tests.

Problematisch für eine solche Befragung war das fehlende Wissen der Bevölkerung über Pharmakogenetik und pharmakogenetische Tests. Um trotzdem eine solide Basis für eine Befragung zu diesem Thema zu schaffen, beschlossen wir, den Studienteilnehmer durch ein standardisiertes Informationsblatt zunächst Grundzüge pharmakogenetischer Tests zu vermitteln. Zu diesem Zweck wurde eine Patientenbroschüre entwickelt, in der die Begriffe „Pharmakogenetik“ und „pharmakogenetischer Test" erläutert, ein Anwendungsbeispiel und der Ablauf einer pharmakogenetischen Untersuchung dargestellt sowie mögliche Vorteile (z. B. das Finden der optimalen Dosierung von Medikamenten) und Risiken (z. B. das Aufdecken eines bisher nicht bekannten Krankheitsrisikos) genannt werden. Am Ende der Broschüre wurden die Patienten gebeten, ihre Meinung zu diesem Thema in einem kurzen strukturiertem Telefoninterview zu äußern (siehe Anhang Nr. 2 Patientenbroschüre). 


\subsection{Stichprobe und Rekrutierung}

Vermutlich werden pharmakogenetische Tests zukünftig vor allem bei chronischen Erkrankungen, die eine längere medikamentöse Behandlung erfordern und bei denen ein Therapieversagen eine erhöhte Morbidität und Mortalität bedeuten könnte (Lichter und Kurth 1997), zur Anwendung kommen. Aus diesem Grund bot sich die Befragung von Patienten mit Asthma bronchiale oder chronisch obstruktiven Lungenerkrankungen (COPD) an, die an einer Studie im Rahmen des Projektes „Medizinische Versorgung in der Praxis (MedViP)" teilnahmen. In dieser Studie ging es um eine mögliche Assoziation von Genen mit der Wirkung von Asthma-Medikamenten (Himmel et al. 2006). Um an dieser Studie teilnehmen zu können, mussten die Patienten bestimmte Einschlusskriterien erfüllen (z. B. Sprachkenntnisse, keine schweren psychiatrischen Erkrankungen).

Die Datenerhebung in der Hauptstudie umfasste einen Termin mit der Studienkrankenschwester in der Hausarztpraxis (Blutabnahme zur Analyse genetischer Polymorphismen, Lungenfunktionstest, Fragebögen). Nach der Untersuchung wurden sämtliche 328 Studienteilnehmer telefonisch kontaktiert und gefragt, ob sie an einer telefonischen Patientenbefragung zum Thema „Pharmakogenetik“ teilnehmen möchten (vgl. Abbildung 2). Stimmten sie zu, erhielten sie nachfolgend per Post ein persönliches Anschreiben sowie die Einverständniserklärung und die Informationsbroschüre über das Thema Pharmakogenetik (siehe Anhänge 1, 2, 3). Insgesamt erklärten sich 196 (60 \%) der angerufenen Patienten mit dem Telefoninterview einverstanden. Mit innen wurden nach Rücklauf der Einverständniserklärung die Telefoninterviews durchgeführt. 


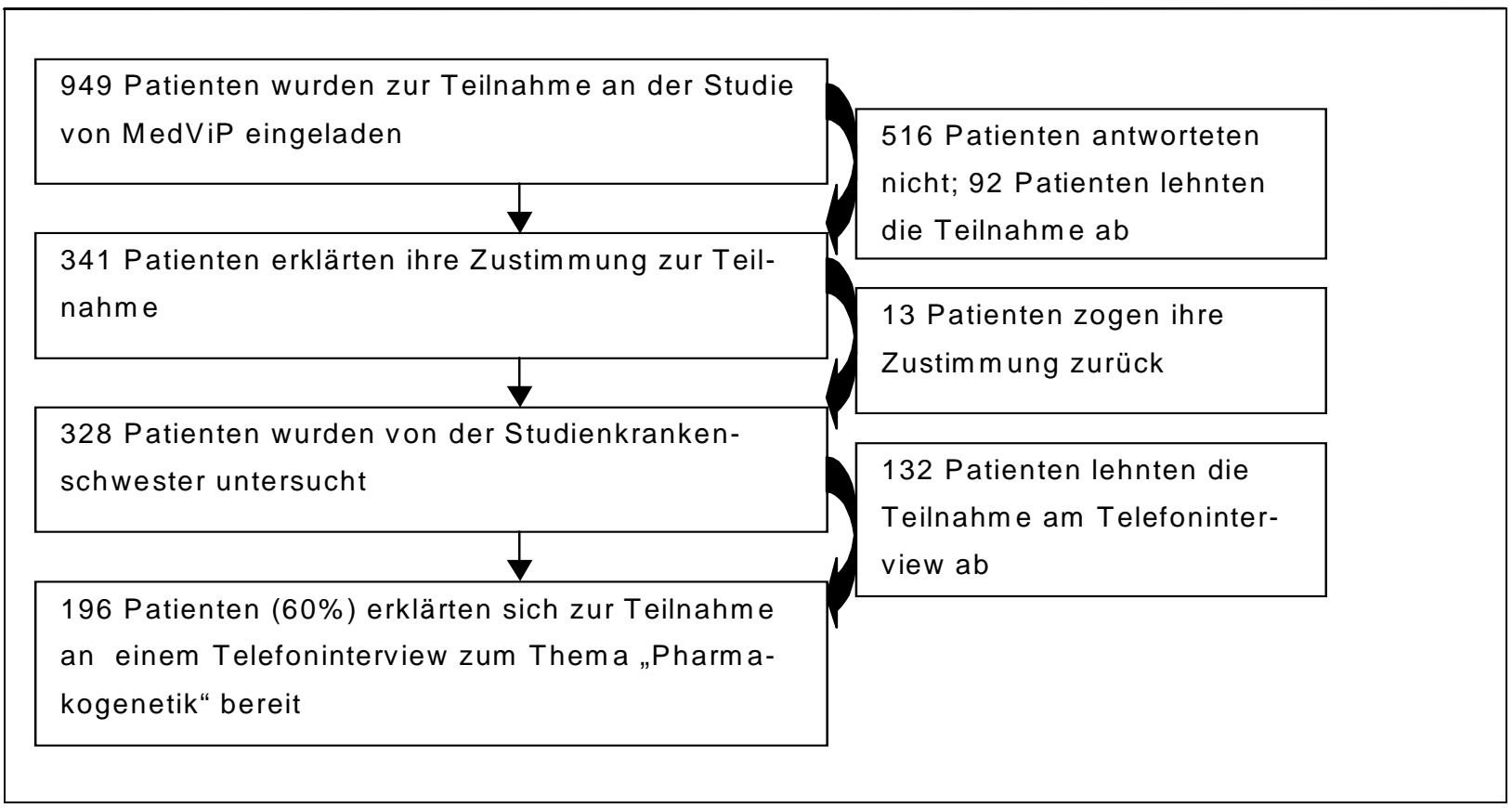

Abbildung 2: Studienteilnahme von Patienten mit Asthma bronchiale oder chronischobstruktiver Lungenerkrankung (COPD)

\subsection{Fragebogen}

Der im Telefoninterview verwendete Fragebogen enthielt 18 geschlossene und 5 offene Fragen, die nach ausführlicher Literaturrecherche generiert und zunächst in zehn Probeinterviews pilotiert wurden. Den Fragen vorangestellt waren eine nochmalige Erklärung des Begriffes „pharmakogenetischer Test“ sowie ein Anwendungsbeispiel (Anhang 4). Die Teilnehmer wurden um ihre persönliche Meinung zu den jeweiligen Fragen gebeten. Bei den Items zu den Themenbereichen „Testakzeptanz“, „Arztwunsch“, „mögliche Sorgen“, „mögliche Hoffnungen“, „persönliche Einschätzung“, „mögliche Auswirkungen und Bewertung eines pharmakogenetischen Tests“ war eine dreistufige Antwortskala bzw. manchmal die Auswahl zwischen „Ja“ oder „Nein“ vorgegeben (siehe Anhang 4).

Bei den geschlossen Fragen sollte sich der Patient für eine Antwort entscheiden, während der Interviewer bei den offenen Fragen alle Antworten wortgenau mitschrieb. Die unterschiedlichen Aussagen wurden - je nach ihren Kernaussagen - in verschiedene Kategorien eingruppiert (siehe ausführlich Kapitel 4.5). 


\subsection{Durchführung der Interviews}

Nach Erhalt der ausgefüllten Einverständniserklärung wurden die zur Teilnahme bereiten Patienten telefonisch kontaktiert. Beim ersten Anruf stellte sich der Interviewer mit Namen sowie seiner Beziehung zur Abteilung Allgemeinmedizin der Universität Göttingen vor und bedankte sich zunächst für die Teilnahmebereitschaft. Dann wurde gefragt, ob der jetzige Zeitpunkt passend wäre oder das Interview lieber zu einem anderen Termin stattfinden sollte. Je nach Antwort wurde das Interview im Anschluss durchgeführt oder ein Termin vereinbart.

Bei Interviewbeginn wurden die Patienten darüber informiert, dass die Antworten protokolliert werden. Es wurde gefragt, ob die Pharmakogenetik-Broschüre gelesen wurde. Zudem erklärte der Interviewer die Ablaufstruktur der Interviews: nach einer kurzen Erklärung zum Thema und einem Anwendungsbeispiel würden die offenen und die Auswahlfragen folgen. Abschließend wurde der Patient gebeten, bei Unklarheiten oder sonstigen Fragen den Interviewer darauf anzusprechen.

Nach dem einführendem Beispiel (siehe Anhang 4) folgte die erste Frage: „Würden Sie vor Verschreibung des Asthmamedikaments einen pharmakogenetischen Test durchführen lassen?“ Die Antwortkategorien „Ja“, „Nein“ und „Weiß nicht“ waren vorgegeben. In diesem Zusammenhang wurden die Patienten auch nochmals darauf hingewiesen, dass die Fragen nur rein hypothetisch sind und der Test nicht wirklich durchgeführt wird.

Es folgten nun im Teil II die offenen Fragen, z. B. nach den Gründen zu einer Position. Die Aussagen wurden vom Interviewer möglichst wortgenau mitgeschrieben. Im Anschluss wurden dem Patienten fünf verschiedene Personengruppen des Gesundheitswesens genannt - z. B. der Hausarzt oder ein auf Genetik spezialisierter Mitarbeiter - und er wurde gefragt, welche Gruppe inm als erster Ansprechpartner über Pharmakogenetik am liebsten wäre. 
Der Teil III des Fragebogens enthielt die geschlossenen Fragen über die möglichen Sorgen bzw. Hoffnungen bezüglich pharmakogenetischer Tests, für jede Frage stand eine dreistufige Antwortskala zur Verfügung.

\section{Beispiel Sorgen:}

Dass z. B. ein pharmakogenetischer Test zufällig ein Ihnen bisher unbekanntes Krankheitsrisiko finden könnte, würde Ihnen das

große Sorgen / etwas Sorgen / keine Sorgen bereiten?

\section{Beispiel Hoffnungen:}

Dass ein pharmakogenetischer Test entdeckt, welches Medikament (oder welche Dosis eines Medikaments) bei Ihnen am besten wirkt, machen Sie sich da große Hoffnungen / etwas Hoffnung / keine Hoffnung?

Der Teil V des Fragebogens enthielt Items zur persönlichen Einschätzung, z. B. über mögliche Nachteile eines ungünstigen pharmakogenetischen Tests bei Arbeitgeber oder Krankenkasse oder mögliche emotionale Auswirkungen.

\section{Beispiel persönliche Einschätzung:}

Glauben Sie, dass in Zukunft Druck auf Patienten ausgeübt werden könnte, einem pharmakogenetischen Test zuzustimmen?

Antwortmöglichkeiten waren „eher ja“ und „eher nein“.

Die vorletzte Frage bezog sich auf das Vertrauen in den pharmakogenetischen Test: Inwieweit würden die Patienten bei einem ungünstigen Testergebnis der Empfehlung folgen und auf Medikamente verzichten oder doch - entgegen dem Testergebnis das Medikament ausprobieren wollen. Zusätzlich zur geschlossenen Frage wurden die Patienten gebeten, ihre Gründe für die jeweilige Entscheidung zu nennen, diese wurden wieder möglichst wörtlich protokolliert.

Zum Schluss wurden die Patienten noch befragt, ob sie die Kenntnis ihrer genetischen Veranlagung als Vorteil oder Nachteil empfinden würden. Damit beendete der 
Interviewer den Fragebogen, wobei er dem Patienten anbot, noch Ergänzungen seinerseits zu äußern bzw. noch vorhandene Fragen zu klären. Am Ende dankte der Interviewer für die Teilnahme.

Weitere soziodemographische Daten der Teilnehmer sowie Angaben zu ihrer Lebensqualität gemäß des St. George's Respiratory Questionnaire (SGRQ) (Jones et al. 1991) wurden aus der Hauptstudie übernommen.

\subsection{Auswertung der offenen Fragen}

Die weitgehend wortgetreu mitprotokollierten Antworten auf die offenen Fragen des Interviews wurden in Anlehnung an den Ablauf induktiver Kategorienbildung (Mayring 1997) nach ihrem inhaltlichen Kern zusammengefasst. Inhaltlich zusammengehörige Antwortkategorien wurden übergeordneten Themenkomplexen zugeordnet. Im Laufe der Analyse wurden die Themenkomplexe erweitert und neu strukturiert (zirkuläre Strategie). Um eine orientierende Übersicht zu gewinnen, wurden die Themenkomplexe im Ergebnisteil der vorliegenden Arbeit jeweils tabellarisch dargestellt und im Text erläutert (siehe als Beispiel die Darstellung der Gründe für die Zustimmung zu einem pharmakogenetischen Test in Tabelle 3, Seite 45 ).

\subsection{Statistik}

Die standardisierten Antworten wurden zunächst deskriptiv ausgewertet. Um Assoziationen zwischen Hoffnungen und Sorgen („Kriterien“) und möglichen Einflussfaktoren („Prädiktoren“) zu analysieren, verwendeten wir die logistische Regressionsanalyse. Dafür berechneten wir jeweils die Summe der Items bezüglich der Hoffnungen und Sorgen aus den Patienteninterviews. Diese Gesamtpunktzahlen wurden nun in zwei Gruppen geteilt. Wenn ein Teilnehmer mehrfach „keine Hoffnungen“ und nie „große Hoffnungen“ angab, galt dieser als „Nicht-hoffnungsvolle-Einstellung" (Gesamtpunktzahl < 4; Gesamtpunktzahl $\geq 4$ : „Hoffnungsvolle Einstellung“); ähnlich für Teilnehmer, die wiederholt „keine Sorgen“ und nie „große Sorgen“ äußerten: Nicht- 
ängstliche-Einstellung“ (Gesamtpunktzahl < 4; Gesamtpunktzahl $\geq 4$ : „Ängstliche Einstellung") benannt. Beide Kriterien ergaben sich durch Antworten auf unterschiedliche Interview-Fragen; eine hoffnungsvolle Einstellung bezüglich pharmakogenetischer Tests schließt daher eine sorgenvolle Einstellung bezüglich der möglichen Konsequenzen, wie z. B. der Einhaltung des Datenschutzes, theoretisch nicht aus.

Um Assoziationen zwischen möglichen Prädiktoren und Kriterien bewerten zu können, wurden als Effektgrößen das Odds Ratios (ORs) und das entsprechende 95\% Konfidenzintervall berechnet. Prädiktoren waren Alter, Geschlecht, Wohnsitz, Schulabschluss und Lebensqualität (gemessen mit dem St. George's Respiratory Questionnaire; Jones et al. 1991). Zur Datenanalyse wurde das Statistical Analysis Software (SAS) Programm (Version 9.1) verwendet.

\subsection{Ethik und Datenschutz}

Alle teilnehmenden Patienten erklärten ihr freiwilliges Einverständnis (informed consent). Zu Beginn des Telefoninterviews wiederholte der Interviewer noch einmal, dass alle Angaben anonym behandelt werden und auch behandelnde Ärzte keine Einsicht erhielten.

Das Vorgehen bei der Datenerhebung und der Dateneingabe wurde in Form einer Standard Operating Procedure (SOP) ${ }^{8}$ schriftlich fixiert (Anhang 5). Es wurden keine persönlichen Daten auf den Fragebögen notiert, Praxen und Patienten wurden nur

\footnotetext{
${ }^{8}$ Standard Operating Procedure (SOP): „Standardarbeitsanweisung“; eine Arbeitsanweisung, die das Vorgehen innerhalb eines Arbeitsprozesses beschreibt. Häufig wiederkehrende Arbeitsabläufe werden textlich beschrieben und den Ausführenden erklärend an die Hand gegeben.
} 
als Kennziffern erfasst, so dass die Anonymität gewährleistet war. Die Daten wurden zur Datenanalyse in SAS eingegeben.

Die Studie wurde durch die Ethikkommission der Universität Göttingen genehmigt (Antragsnummer 29/7/02). 


\section{Ergebnisse}

\subsection{Stichprobe}

Von den 328 kontaktierten Patienten mit der Diagnose Asthma bronchiale oder chronisch obstruktiver Lungenerkrankung (COPD) erklärten sich 196 (60 \%) mit der Teilnahme an einem Telefoninterview einverstanden.

Etwas über die Hälfte der Teilnehmer (55\%) war weiblich. Das Durchschnittsalter aller Teilnehmer betrug 57,6 Jahre (Range von 24 - 81 Jahre, Median =61). Die Normalbevölkerung Deutschlands im Jahre 2004 (dem Zeitpunkt der Interviews) war im Vergleich hierzu jünger (42,7 Jahre) und hatte einen etwas geringeren Frauenanteil (51,1 \%) (Quelle: Statistisches Bundesamt 2004). Gut die Hälfte der Studienteilnehmer hatte einen Hauptschulabschluss (vgl. Abbildung 3).

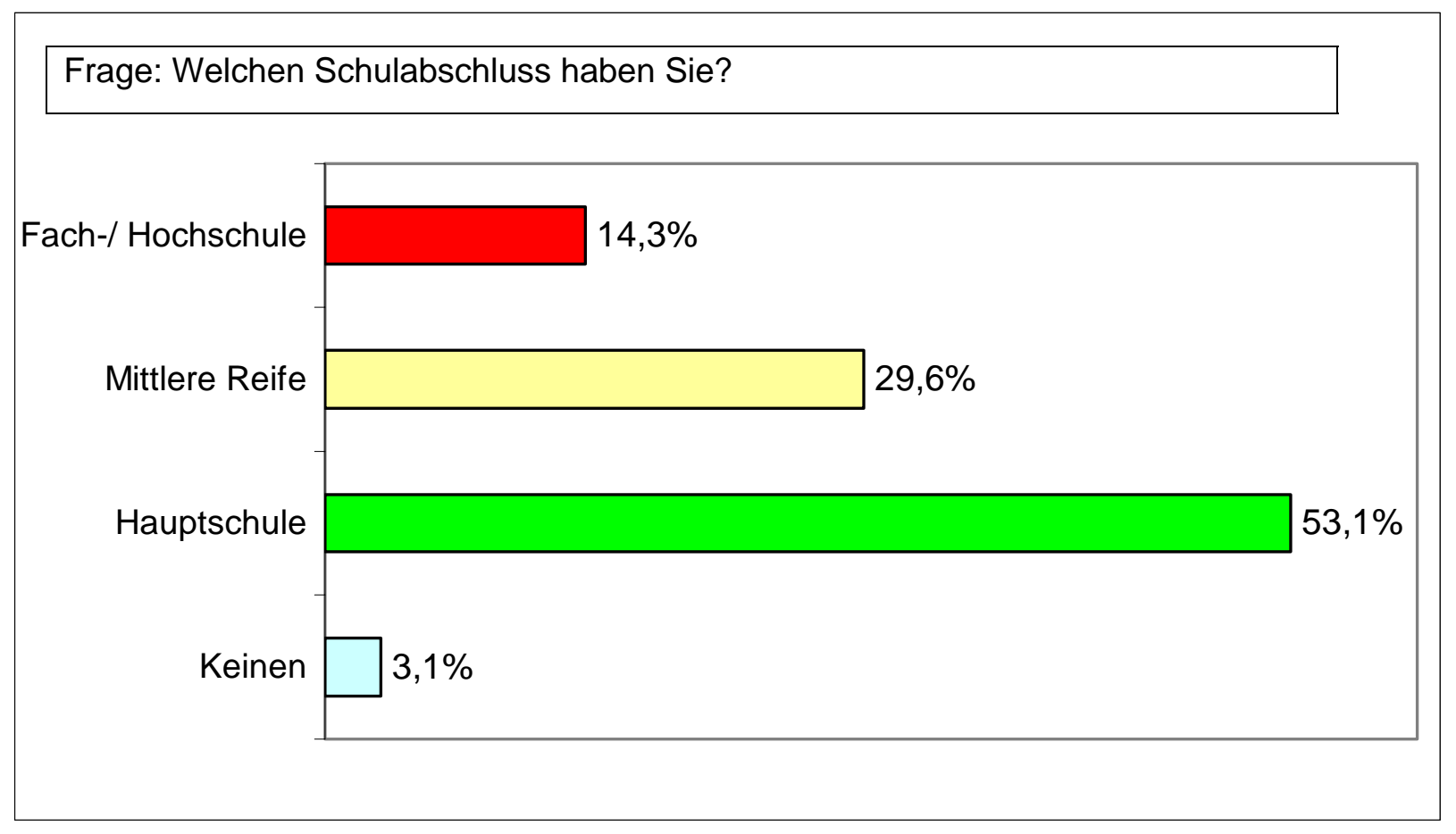

Abbildung 3: Schulischer Abschluss der Interviewteilnehmer 
Bezogen auf die Berufssituation setzte sich die Stichgruppe folgendermaßen zusammen:

- 51,0 \% Rentenempfänger (Früh-, Erwerbsunfähigkeits- bzw. Altersrente)

- 29,6 \% Voll- bzw. Teilzeitbeschäftigte

- $10,2 \%$ Arbeitslose

- $\quad$ 6,6 \% Hausfrauen bzw. Hausmänner

- $\quad$ 0,5 \% Auszubildende bzw. Studierende

- 2,0 \% der Teilnehmer machten keine Angaben zu ihrer momentanen beruflichen Situation.

Eine leichte Mehrheit von 56,6\% hatte einen Wohnort auf dem Land. Die meisten Befragten (77,6 \%) lebten innerhalb der Familie bzw. einer Gemeinschaft; $16,3 \%$ lebten alleine und 2 der Befragten (1\%) lebten in einem Alten- bzw. Pflegeheim (von weiteren 10 Interviewteilnehmern (5,1 \%) erhielten wir keine Angaben auf diese Frage).

Zwischen den am Interview teilnehmenden und nicht-teilnehmenden Patienten fanden wir keine Unterschiede bezüglich Alter (57,6 vs. 58,1 Jahre; nicht signifikant), Geschlecht (55 \% vs. 50 \% Frauen; nicht signifikant) oder Krankheitsdauer (18,5 vs. 18,1 Jahre; nicht signifikant).

\subsection{Bereitschaft und Rahmenbedingungen zur Durchführung von pharmakogenetischen Untersuchungen}

Die Mehrheit (95,9 \%) der befragten 196 Patienten würde der Durchführung eines pharmakogenetischen Tests z. B. bei Asthma bronchiale zustimmen. Drei Patienten würden die Testdurchführung ablehnen, fünf Patienten wären unentschlossen.

Dieses Ergebnis spiegelt sich auch in der Beantwortung der letzten Frage des Interviews „Wäre es für Sie ein Vor- oder eher ein Nachteil, wenn Sie über Ihre genetische Veranlagung Bescheid wissen?" wider. Die große Mehrheit (94,4\%) sah darin 
„eher einen Vorteil“; 4,6 \% empfanden es eher als Nachteil; 1,0\% sahen es weder als Vor- noch als Nachteil.

Auf die Frage, wer sie als erstes wegen einer pharmakogenetischen Untersuchung ansprechen sollte, erhielt von den möglichen Alternativen (Einfachnennung) der Hausarzt die größte Zustimmung. Insgesamt ergaben sich folgende Nennungen:

- Hausarzt bzw. Hausärztin (78,1\%)

- der behandelnde Facharzt (13,3\%)

- $\quad$ ein auf Genetik spezialisierter Mitarbeiter $(7,7 \%)$

- ein Universitätsmitarbeiter (1\%)

- $\quad$ eine speziell ausgebildete Krankenschwester (0\%).

Des Weiteren interessierte uns das Vertrauen in die Ergebnisse pharmakogenetischer Untersuchungen. In einer hypothetischen Situation zeigt ein pharmakogenetischer Test, dass es für den Patienten nur ein Medikament gäbe, welches aber vermutlich nur wenig helfen oder starke Nebenwirkungen verursachen würde. Die folgende Frage lautete, ob die Teilnehmer das Medikament dann trotzdem ausprobieren oder sich auf den Test verlassen und es nicht nehmen würden: 56,6 \% würden das Medikament dennoch einnehmen wollen; die Übrigen (43,4 \%) würden der Testempfehlung folgen und unter diesen Umständen auf das Medikament verzichten.

Bei der Gruppe, die das Medikament trotz der gegenteiligen Empfehlung des pharmakogenetischen Tests einnehmen würde, waren die Hauptgründe für diese Entscheidung die „Hoffnung, dass das Medikament trotzdem etwas hilft“ (67 Nennungen) und das „Ausprobieren, um nach eigenen Erfahrungen mit dem Medikament selbst die Entscheidung für oder gegen eine weitere Einnahme treffen zu können“ (68 Nennungen). Weitere Gründe für die Medikamenteneinnahme zeigt Tabelle 1. 
Tabelle 1: Gründe von Patienten für die Einnahme eines Medikaments entgegen der Empfehlung pharmakogenetischer Tests

Positiver Effekt des Medikamentes trotz der ungünstigen Prognose

Akzeptanz der Nebenwirkungen
Kategorie rungen zu entscheiden

\section{$\underline{\text { Zitat-Beispiele }}$}

Nennungen

(Mehrfachnen-

nungen möglich)

Ausprobieren, um auf Grundlage eigener Erfah-
„Ich möchte eigene Erfahrungen mit Effekt / den Nebenwirkungen machen, danach treffe ich eine eigene Entscheidung."

„Kann ja sein, dass es doch etwas hilft.“ „Etwas Hilfe ist besser als gar nichts.“ „ Der Versuch als letzter Strohhalm."

„Lieber etwas Nachteile in Kauf nehmen, dafür geht es vielleicht etwas besser."
68

67

Die Argumente der Patientengruppe, die das Medikament gemäß der Testempfehlung nicht einnehmen würde, waren vor allem die „Vermeidung der prognostizierten Nebenwirkungen“ (55 Nennungen) und „keine Einnahme von nutzlosen Medikamenten“ (25 Nennungen; weitere Angaben siehe Tabelle 2). 
Tabelle 2: Gründe von Patienten für die Nichteinnahme eines Medikaments entsprechend der Empfehlung pharmakogenetischer Tests

\begin{tabular}{|c|c|c|}
\hline$\underline{\text { Kategorie }}$ & Zitat-Beispiele & $\begin{array}{l}\text { Nennungen } \\
\text { (Mehrfachnen- } \\
\text { nungen möglich) }\end{array}$ \\
\hline Vermeidung der Nebenwirkungen & $\begin{array}{l}\text { „Wegen der Nebenwirkungen würde } \\
\text { ich es nicht nehmen.“ }\end{array}$ & 55 \\
\hline Keine Einnahme von nutzlosen Medikamenten & „Ich will nichts nehmen, was nicht hilft.“ & 25 \\
\hline Vertrauen in den Test & „Ich würde dem Test vertrauen.“ & 14 \\
\hline Suche nach nicht-medikamentösen Alternativen & $\begin{array}{l}\text { „Dann muss ich eben nach Alternati- } \\
\text { ven suchen." }\end{array}$ & 9 \\
\hline Akzeptieren der Krankheiten & $\begin{array}{l}\text { "Gewisses Maß an 'Wehwehchen' } \\
\text { muss in Kauf genommen werden." }\end{array}$ & 4 \\
\hline Informationsbedarf & $\begin{array}{l}\text { „Ich würde es mit dem Arzt bespre- } \\
\text { chen und dann mit ihm entscheiden.“ }\end{array}$ & 1 \\
\hline
\end{tabular}

Bei den möglichen Konsequenzen pharmakogenetischer Untersuchungen ging eine Mehrheit von 64,3 \% der Patienten nicht davon aus, dass in Zukunft Druck auf Patienten ausgeübt werden könnte, einem pharmakogenetischen Test zuzustimmen (35,7 \% befürchteten dies). Etwas über $40 \%$ der Patienten bezweifelten, dass sie die komplette Tragweite eines pharmakogenetischen Tests für sich und ihre Familie erfassen könnten (59,7 \% nahmen an, dass sie die Tragweite erfassen könnten).

\subsection{Zustimmungsgründe zur Testdurchführung und Hoffnungen in pharmakogenetische Tests}

Fast alle Befragten verbanden mit pharmakogenetischen Tests die Hoffnung, falsche Medikamenten bzw. falsche Dosierung von Medikamenten zu vermeiden (74,5\% große Hoffnungen; 25,0 \% etwas Hoffnung). Abbildung 4 zeigt die Hoffnungen bezüglich optimaler Dosierung und Nebenwirkungen. 
Frage: Machen Sie sich große / etwas / keine Hoffnungen, dass ein pharmakogenetischer Test....

entdeckt, welches Medikament (oder welche Dosis eines Medikaments) bei Ihnen am besten wirkt

entdeckt, welches Medikament (oder welche Dosis) bei Ihnen die wenigsten Nebenwirkungen verursacht

es Ihnen in Zukunft erspart, ein falsches Medikament oder die falsche Dosierung einnehmen zu müssen

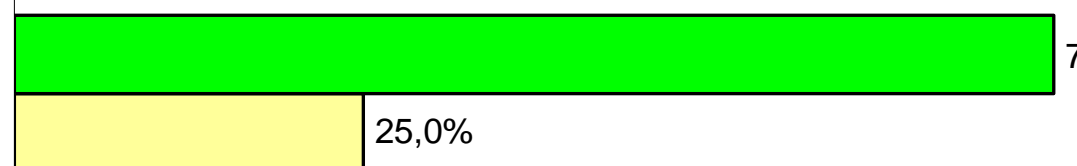
$74,5 \%$
$0,5 \%$

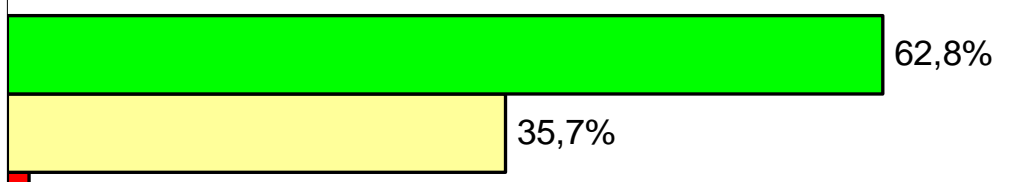

$1,5 \%$

keine Hoffungen $\square$ etwas Hoffnung $\square$ große Hoffnung

Abbildung 4: Hoffnungen von Patienten bezüglich pharmakogenetischer Tests

Auf die offene Frage nach den Gründen für eine Zustimmung zu einem pharmakogenetischen Test gab es vor allem zwei Antwortkategorien, die mit deutlicher Mehrheit genannt worden sind: zum einen „das Bedürfnis nach der Gewissheit, dass ein verschriebenes Medikament helfen wird“ (76 Nennungen), zum anderen die „Hoffnung, durch pharmakogenetische Tests ein optimales bzw. wirksameres Medikament auswählen zu können“ (ebenfalls 76 Nennungen). Weitere Antwortkategorien zeigt Tabelle 3 . 
Tabelle 3: Gründe für die Zustimmung zum pharmakogenetischen Test

\begin{tabular}{|c|c|c|}
\hline Kategorie & Zitat-Beispiele & $\begin{array}{l}\text { Nennungen } \\
\text { (Mehrfachnennun- } \\
\text { gen möglich) }\end{array}$ \\
\hline $\begin{array}{l}\text { Gewissheit über Wirksamkeit der Medi- } \\
\text { kamente }\end{array}$ & $\begin{array}{l}\text { „Ich möchte sicher gehen, dass das Medi- } \\
\text { kament etwas bringt.“ }\end{array}$ & 76 \\
\hline $\begin{array}{l}\text { Auswahl eines wirksameren Medikamen- } \\
\text { tes }\end{array}$ & $\begin{array}{l}\text { „Ich habe die Hoffnung auf ein neues Medi- } \\
\text { kament, das besser wirkt." }\end{array}$ & 76 \\
\hline $\begin{array}{l}\text { Besserung der Beschwerden und der Le- } \\
\text { bensqualität }\end{array}$ & „Ich hoffe auf eine höhere Lebensqualität.“ & 30 \\
\hline Vermeidung wirkungsloser Medikation & $\begin{array}{l}\text { „Ich möchte nichts einnehmen, was nichts } \\
\text { bringt.“ }\end{array}$ & 29 \\
\hline Weniger Nebenwirkungen & $\begin{array}{l}\text { „Ich möchte Medikamente mit weniger } \mathrm{Ne} \text { - } \\
\text { benwirkungen einnehmen.“ }\end{array}$ & 19 \\
\hline $\begin{array}{l}\text { Kein wahlloses Ausprobieren von Medi- } \\
\text { kamenten }\end{array}$ & $\begin{array}{l}\text { „Ich möchte nicht wahllos Medikamente } \\
\text { ausprobieren.“ }\end{array}$ & 18 \\
\hline Eigene Erfahrung mit Medikamenten & $\begin{array}{l}\text { „Ich habe den Eindruck, dass manche Me- } \\
\text { dikamente mir gar nicht helfen." }\end{array}$ & 15 \\
\hline Reduzierung der Medikamentenanzahl & $\begin{array}{l}\text { „Ich möchte weniger Medikamente einneh- } \\
\text { men.“ }\end{array}$ & 8 \\
\hline Optimale Dosierung von Medikamenten & $\begin{array}{l}\text { „Ich hoffe meine Medikamente besser do- } \\
\text { sieren zu können.“ }\end{array}$ & 7 \\
\hline Wissen über Krankheitsanlagen & $\begin{array}{l}\text { „Ich möchte wissen, für welche Krankheiten } \\
\text { ich genetisch veranlagt bin.“ }\end{array}$ & 3 \\
\hline Einsparung von Kosten & $\begin{array}{l}\text { „Ich denke, dass durch optimale Arzneithe- } \\
\text { rapie Kosten eingespart werden können.“ }\end{array}$ & 3 \\
\hline Arzt-Empfehlung & „Wenn Arzt dazu rät, würde ich zustimmen.“ & 1 \\
\hline $\begin{array}{l}\text { Positive Auswirkungen für nachfolgende } \\
\text { Generationen }\end{array}$ & $\begin{array}{l}\text { „Denke, dass es auch für nachfolgende Ge- } \\
\text { nerationen gut wäre." }\end{array}$ & 1 \\
\hline $\begin{array}{l}\text { Gute medikamentöse Therapie schon vor } \\
\text { Krankheitsausbruch }\end{array}$ & $\begin{array}{l}\text { „Ich hoffe, schon vor dem Ausbruch der } \\
\text { Krankheit Medikamente zu finden und die- } \\
\text { sen so zu beeinflussen.“ }\end{array}$ & 1 \\
\hline Keine Gründe & & 4 \\
\hline
\end{tabular}


Die meisten Patienten verbanden mit einem pharmakogenetischen Test die „Hoffnungen auf Besserung der Beschwerden bzw. des Gesundheitszustandes" (97 Nennungen). Weitere Antwortkategorien und Nennungen siehe Tabelle 4. 
Tabelle 4: Art der Hoffnungen in Bezug auf pharmakogenetische Tests

\begin{tabular}{|c|c|c|}
\hline$\underline{\text { Kategorie }}$ & Zitat-Beispiele & $\begin{array}{l}\text { Nennungen } \\
\text { (Mehrfachnennun- } \\
\text { gen möglich) }\end{array}$ \\
\hline $\begin{array}{l}\text { Besserung der Beschwerden bzw. des } \\
\text { Gesundheitszustands }\end{array}$ & $\begin{array}{l}\text { „Würde hoffen, dass mir bei starken Be- } \\
\text { schwerden dadurch geholfen werden könn- } \\
\text { te.“ }\end{array}$ & 97 \\
\hline $\begin{array}{l}\text { Auswahl eines individuell optimalen Me- } \\
\text { dikamentes (gezielte Therapie) }\end{array}$ & $\begin{array}{l}\text { „Ich würde hoffen, ein auf den eigenen Kör- } \\
\text { per eingestelltes Medikament zu bekom- } \\
\text { men.“ }\end{array}$ & 62 \\
\hline Auswahl wirksamerer Medikamente & $\begin{array}{l}\text { „Ich hoffe auf ein neues Medikament, das } \\
\text { helfen kann.“ }\end{array}$ & 43 \\
\hline Geringere Anzahl von Medikamenten & $\begin{array}{l}\text { „Ich hätte die Hoffnung, nicht zehn Medika- } \\
\text { mente, sondern nur eines nehmen zu müs- } \\
\text { sen.“ }\end{array}$ & 19 \\
\hline Weniger Nebenwirkungen & $\begin{array}{l}\text { „Hätte Hoffnung, Medikamente mit weniger } \\
\text { Nebenwirkungen bekommen zu können.“ }\end{array}$ & 16 \\
\hline $\begin{array}{l}\text { Schnellere Auswahl eines passenden } \\
\text { Medikamentes }\end{array}$ & $\begin{array}{l}\text { „Würde hoffen, schnell ein passendes Medi- } \\
\text { kament zu finden.“ }\end{array}$ & 11 \\
\hline $\begin{array}{l}\text { Positive Auswirkung für nachfolgende } \\
\text { Generationen }\end{array}$ & $\begin{array}{l}\text { „Ich würde hoffe, dass es auch für nachfol- } \\
\text { gende Generation positiv wäre.“ }\end{array}$ & 9 \\
\hline Wissen über eigene Erbanlagen & $\begin{array}{l}\text { „Würde begrüßen, dadurch mehr über mei- } \\
\text { ne Erbanlagen zu erfahren.“ }\end{array}$ & 6 \\
\hline Kein Ausprobieren von Medikamenten & $\begin{array}{l}\text { „Es wäre schön, Medikamente nicht aus- } \\
\text { probieren zu müssen.“ }\end{array}$ & 5 \\
\hline Optimale Dosierung von Medikamenten & $\begin{array}{l}\text { „Hoffe, dass man Medikamente besser do- } \\
\text { sieren könnte.“ }\end{array}$ & 3 \\
\hline $\begin{array}{l}\text { Bessere Kriterien zur Medikamenten- } \\
\text { auswahl für die Ärzte }\end{array}$ & $\begin{array}{l}\text { „Medikamentenauswahl für Ärzte wäre ein- } \\
\text { facher.“ }\end{array}$ & 2 \\
\hline Einsparung von Arzneimittelkosten & „Ich würde eine Kostendämpfung erhoffen.“ & 2 \\
\hline Keine Hoffnungen & Keine Hoffnungen & 4 \\
\hline
\end{tabular}




\subsection{Gründe für die Ablehnung eines Tests und Sorgen gegenüber pharmakogenetischen Untersuchungen}

Soweit die wenigen Patienten, die einen pharmakogenetischen Test ablehnen würden, Gründe nannten, bezogen sich diese darauf, dass der Test bisher auch nicht nötig war und sie ohne ihn gut auskamen. Weitere Ablehnungsgründe waren $\mathrm{z}$. B. die Kosten der Tests (vgl. Tabelle 5).

Tabelle 5: Gründe für die Ablehnung eines pharmakogenetischen Tests (wenn zutreffend)

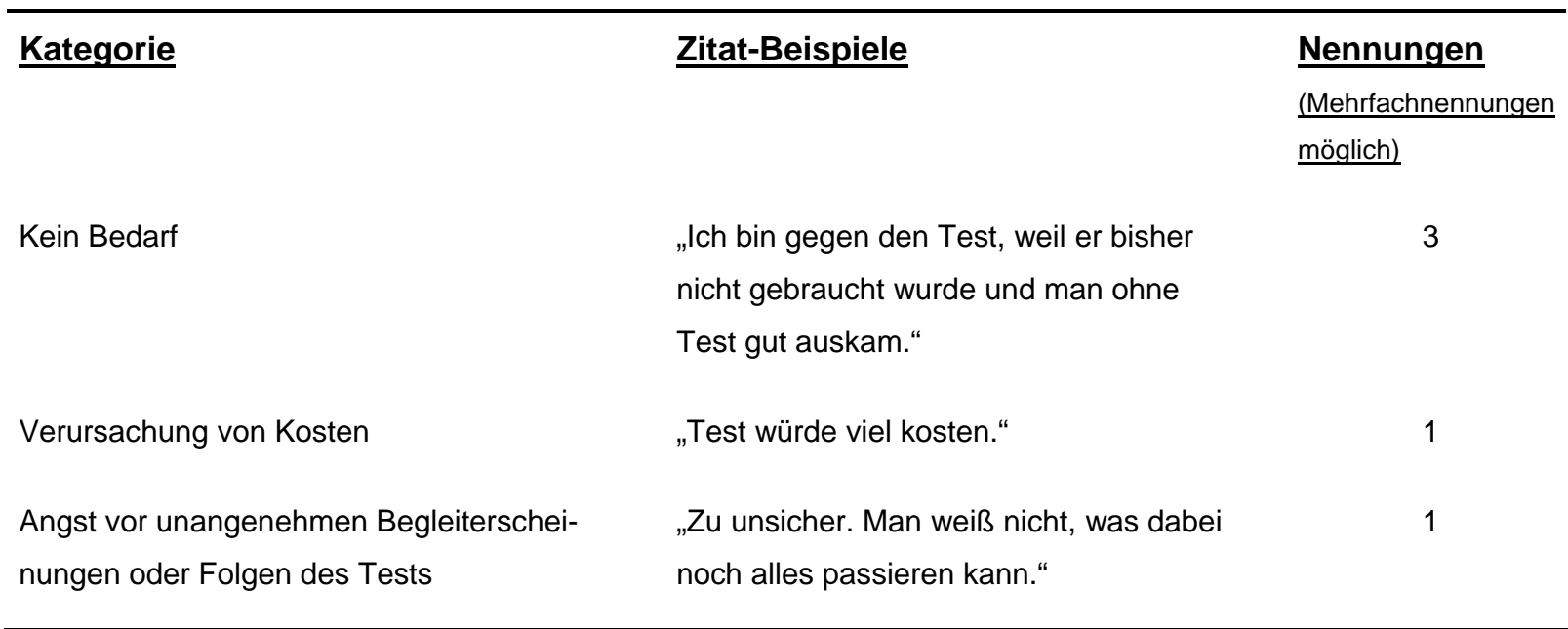

Den meisten Patienten bereitete die Möglichkeit, dass das Testergebnis an unbefugte Personen gelangen könnte - also der Datenschutz nicht gewahrt wäre - Sorgen (35,7 \% große Sorgen; 30,6 \% etwas Sorgen; 33,7 \% keine Sorgen). Im Gegensatz dazu jedoch war die Möglichkeit, dass durch die Verordnung eines genetisch speziell zugeschnittenen Medikaments die Krankenversicherung indirekt etwas über die genetische Veranlagung des Patienten erfährt, nebensächlich: nur 9,2 \% bereitete diese Eventualität große Sorgen, die Mehrheit von 73,0 \% hatte keine Sorgen.

Die möglichen Konsequenzen eines pharmakogenetischen Tests bereiteten den Patienten ebenfalls Sorgen. Ein ungünstiges Testergebnis (kein passendes Medikament vorhanden, wenig erwünschte und viele unerwünschte Wirkungen) betrachtet gut ein Drittel der Befragten mit großen Sorgen (37\% mit etwas Sorgen). Etwas we- 
niger negativ wird der Fall einer gleichzeitigen Krankheitsassoziation gesehen, hier äußerten $15 \%$ große Sorgen (vgl. Abbildung 5). Während des Interviews wiesen sogar einige Patienten darauf hin, dass sie diese zufällige Entdeckung einer möglichen Krankheit als positiv empfinden, weil es innen eine frühzeitige Diagnose und Therapie ermöglichen könnte. Bei der offenen Frage, welche Ängste oder Sorgen die Patienten mit einem pharmakogenetischen Test verbinden, gab eine deutlich Mehrheit an, dass sie keine Ängste oder Sorgen bezüglich eines pharmakogenetischen Tests hätten (171 Nennungen). Die weiteren Antworten ließen sich vor allem der Kategorie „Angst bezüglich des Datenschutzes“ zuordnen (Tabelle 6). 
Frage: Machen Ihnen die aufgeführten möglichen Folgen eines pharmakogenetischen Tests große / etwas / keine Sorgen?

...dass das Testergebnis stärker berücksichtigt werden könnte als Ihr persönlicher Wunsch nach einem Medikament

...dass das Ergebnis an unbefugte Personen weitergegeben werden könnte

$3,1 \%$
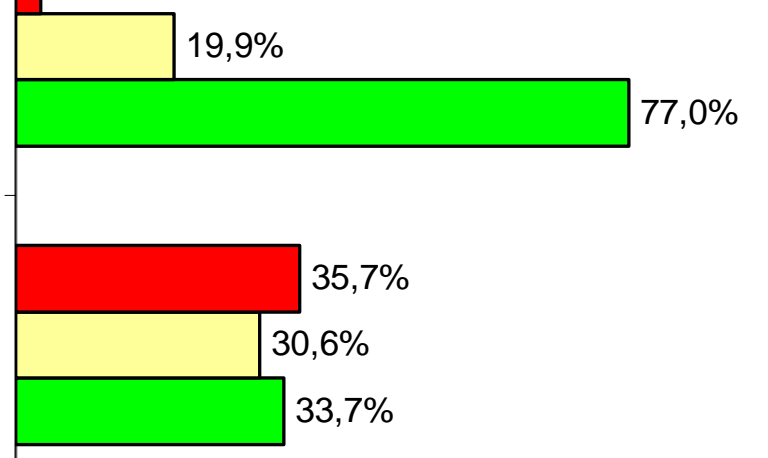

$33,7 \%$

$15,30 \%$

...dass ein Test zufällig ein unbekanntes Krankheitsrisiko finden könnte

...dass ein Test ergibt, dass für Sie kein passendes Medikament vorhanden ist

...dass die Krankenversicherung durch ein auf Sie zugeschnittenes Medikament etwas über ihre genetische Veranlagung erfährt
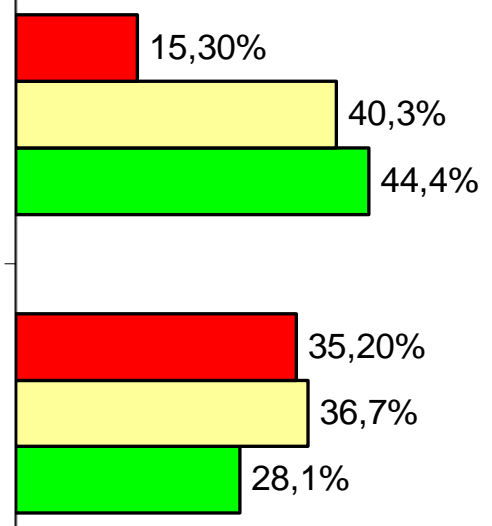

$9,20 \%$

$17,9 \%$

Abbildung 5: Sorgen der Patienten bezüglich pharmakogenetischer Tests 
Tabelle 6: Sorgen oder Ängste bezüglich pharmakogenetischer Tests

\begin{tabular}{|c|c|c|}
\hline Kategorie & Zitat-Beispiele & $\begin{array}{l}\text { Nennungen } \\
\text { (Mehrfachnennun- } \\
\text { gen möglich) }\end{array}$ \\
\hline Keine Sorgen oder Ängste & „Ich hätte keine Sorgen.“ & 171 \\
\hline $\begin{array}{l}\text { Datenschutz bzw. Missbrauch der Test- } \\
\text { ergebnisse }\end{array}$ & $\begin{array}{l}\text { „Ich habe Sorgen, dass man Weitergabe } \\
\text { und Missbrauch der Ergebnisse nicht aus- } \\
\text { schließen könnte.“ }\end{array}$ & 11 \\
\hline $\begin{array}{l}\text { Mögliche Konsequenzen eines pharma- } \\
\text { kogenetischen Test }\end{array}$ & $\begin{array}{l}\text { „Angst, weil man nicht weiß, was noch auf } \\
\text { einen zukommt.“ }\end{array}$ & 7 \\
\hline Wissen über Erbanlagen & $\begin{array}{l}\text { „Was würde ich den Kindern vererben? Das } \\
\text { will man gar nicht wissen." }\end{array}$ & 2 \\
\hline Kein geeignetes Medikament vorhanden & $\begin{array}{l}\text { „Was ist, wenn es kein Medikament für mich } \\
\text { gibt?" }\end{array}$ & 1 \\
\hline $\begin{array}{l}\text { Keine Medikamente für kleinere Sub- } \\
\text { gruppen }\end{array}$ & $\begin{array}{l}\text { „Bedenken, dass Pharmafirmen dann keine } \\
\text { Medikamente für kleinere Patientengruppen } \\
\text { produzieren.“ }\end{array}$ & 1 \\
\hline
\end{tabular}

Ausgehend von dem hypothetischen Fall, dass pharmakogenetische Tests ergeben hätten, dass bei einer vorhandenen Krankheit entweder eine besonders hohe Dosierung nötig oder kein passendes Medikament vorhanden wäre (nur wenig wirksam, starke Nebenwirkungen), befürchteten $44 \%$ der Befragten - bei Bekanntwerden des Ergebnisses - Nachteile bei der Krankenkasse (Abbildung 6). Knapp ein Drittel der Befragten würde sich in diesem Falle selbst als „andersartig“ bzw. „defekt" fühlen (Abbildung 7). 


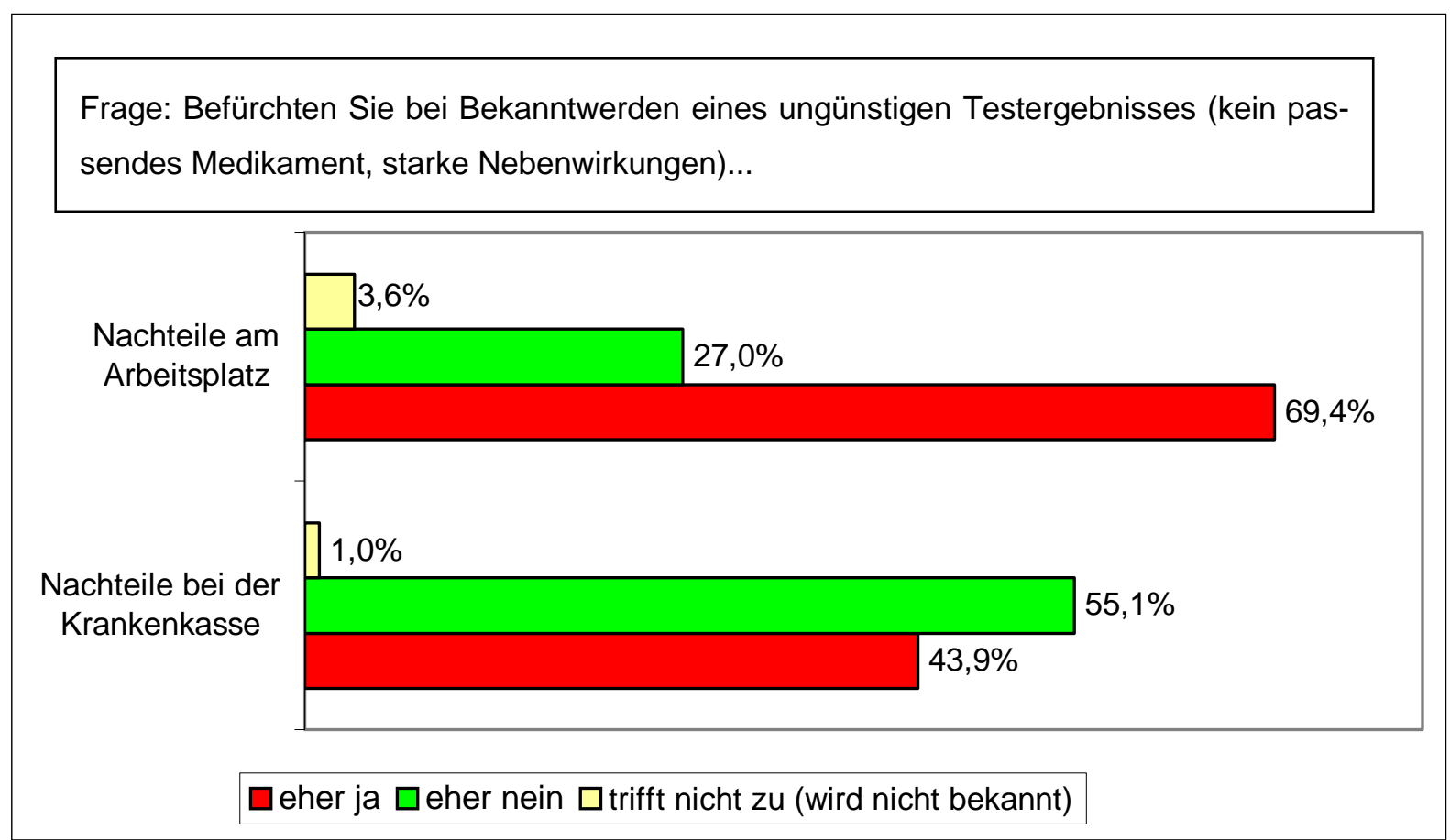

Abbildung 6: Einschätzung über mögliche Nachteile bei einem negativen Ergebnis eines pharmakogenetischen Tests

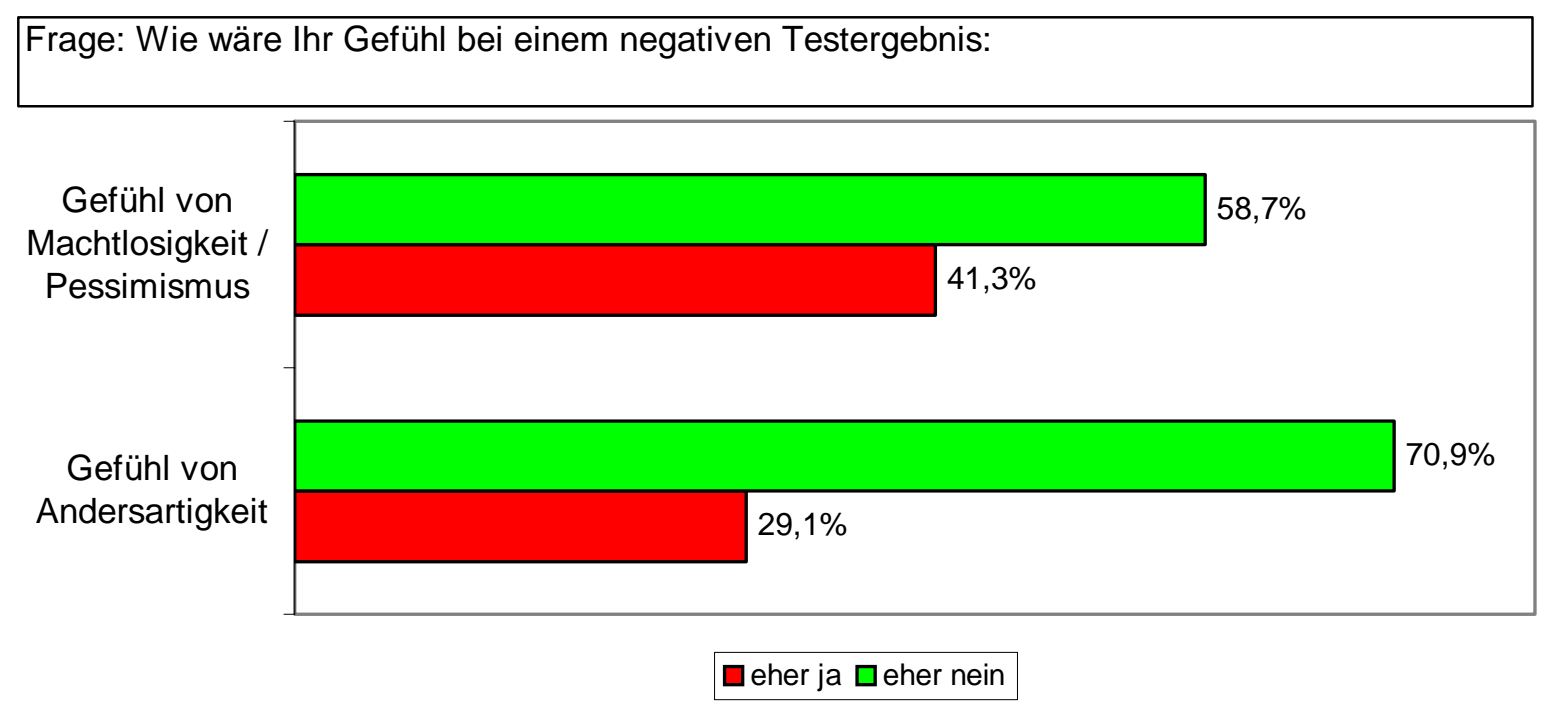

Abbildung 7: Wie würden sich Patienten mit einem negativen Ergebnis eines pharmakogenetischen Tests erleben? 


\subsection{Informationswünsche für die Entscheidungsfindung zur Durch- führung pharmakogenetischer Untersuchungen}

Auf die Frage, welche Informationen für die Befürwortung bzw. Ablehnung eines pharmakogenetischen Tests wichtig wären, hielten 59 der Befragten keine weiteren Informationen für nötig (siehe Tabelle 7). Die übrigen Befragten wünschten sich häufig Informationen über Vorteile und Nutzen des pharmakogenetischen Tests (43 Nennungen); die Arztempfehlung sei die entscheidende Information, meinten $40 \mathrm{Be}$ fragte. Weitere Aspekte, die auf diese Frage genannt wurden:

- Informationen über Risiken und Folgen eines pharmakogenetischen Tests (29 Nennungen),

- Informationen über Sicherheit vor Missbrauch der Testergebnisse und Datenschutz (16),

- Informationen über Ablauf und technisches Vorgehen bei einem pharmakogenetischen Test (14),

- Informationen über die weitere Verwendung der Testergebnisse (12),

- Informationen über die Fehlerquote des Tests (8),

- Informationen über die Kosten für pharmakogenetische Tests (5),

- Informationen, wie umfassend die Erbanlagen untersucht werden, z. B. auch krankheitsassoziierte Erbanlagen (4),

- Informationen, für welche Medikamente der Test eine Aussage treffen kann (2) und

- Informationen über die Auswirkungen des pharmakogenetischen Tests auf nachfolgende Generationen (2). 
Tabelle 7: Gewünschte Informationen zur Entscheidung für oder gegen einen pharmakogenetischen Test

\section{Kategorie}

Keine weiteren Informationen

Vorteile und Nutzen pharmakogenetischer Tests

Arzt-Empfehlung

Folgen oder Risiken pharmakogenetischer Tests

Sicherheit vor Missbrauch der Testergebnisse und Datenschutz

Ablauf und technisches Vorgehen

Weitere Verwendung der Testergebnisse

Fehlerquote des Tests

Kosten pharmakogenetischer Tests

Testergebnisse bezüglich der Erbanlagen

Medikamente, für die der Test eine Aussage treffen kann

Auswirkung pharmakogenetischer Tests für nachfolgende Generationen

\section{Zitatbeispiele}

„Keine weiteren Informationen nötig.“

59

„Welchen Nutzen hat der Patient vom phar-

makogenetischen Test?"

„Verlasse mich auf die Empfehlung des Arztes."

„Ich möchte über Risiken des Tests informiert werden."

„Wie werden der Datenschutz und die weitere Verwendung von Probenmaterial gehandhabt?"

„Wie kann man aus den Blutproben Medikamente bestimmen?"

„Würde wissen wollen, inwieweit Ergebnisse noch weiter verwertet werden können."

„Wie hoch ist das Fehlerrisiko des Tests?"

8

5

„Ist der Test für Patienten kostenlos?“

„Werden noch andere Erbanlagen festgestellt, so dass man Krankheitsveranlagungen erfahren kann?"

„Ist der Test nur bei Asthma-Medikamenten möglich?"

„Welche Auswirkung kann der Test auf nach2 
5.6 Determinanten und Prädiktoren einer hoffnungsvollen bzw. sorgenvollen Einstellung gegenüber pharmakogenetischen Tests

In den beiden einfachen logistischen Regressionsanalysen zeigte sich für das Kriterium der ängstlichen und der hoffnungsvollen Einstellung jeweils nur ein Prädiktor als bedeutsam: Weibliche Patienten standen pharmakogenetischen Tests häufiger ängstlich gegenüber (Odds Ratio $\mathrm{OR}=2,85,95 \%$-Konfidenzintervall $\mathrm{KI}=1,58-5,12$; vgl. Tabelle 8). Jüngere Patienten zeigten sich mit höherer Wahrscheinlichkeit optimistisch bezüglich der Vorteile pharmakogenetischer Tests (OR $=2,12$; 95\%Konfidenzintervall = 1,01 - 4,46; vgl. Tabelle 9). 
Tabelle 8: Prädiktoren für eine ängstliche bzw. sorgenvolle Einstellung bezüglich pharmakogenetischer Tests

\begin{tabular}{|c|c|c|c|c|}
\hline \multirow[t]{2}{*}{ Prädiktoren } & \multicolumn{4}{|l|}{ Prävalenz } \\
\hline & N (\%) & OR & $95 \% \mathrm{KI}$ & $\mathbf{P}$ \\
\hline \multicolumn{5}{|l|}{ Alter } \\
\hline$>$ median $(60,7 \mathrm{~J})$. & $42(42.86)$ & 1 & & \\
\hline$<$ median & $50(51.02)$ & 1.39 & $0.79-2.44$ & 0.25 \\
\hline \multicolumn{5}{|l|}{ Geschlecht } \\
\hline männlich & $29(32.95)$ & 1 & & \\
\hline weiblich & $63(58.33)$ & 2.85 & $1.58-5.12$ & 0.0005 \\
\hline \multicolumn{5}{|l|}{ Wohnort } \\
\hline Land & $51(45.95)$ & 1 & & \\
\hline Stadt & $41(48.24)$ & 1.10 & $0.62-1.93$ & 0.75 \\
\hline \multicolumn{5}{|l|}{ Schulausbildung } \\
\hline $\begin{array}{l}\text { Realschulabschluss oder höher (Abi- } \\
\text { tur, Fachabitur) }\end{array}$ & $40(46.51)$ & 1 & & \\
\hline $\begin{array}{l}\text { kein Schulabschluss oder Hauptschul- } \\
\text { abschluss }\end{array}$ & $52(47.27)$ & 1.03 & $0.59-1.82$ & 0.92 \\
\hline \multicolumn{5}{|l|}{ Lebensqualität } \\
\hline SGRQ* > median (eher schlecht) & $40(42.55)$ & 1 & & \\
\hline SGRQ < median (eher gut) & $52(50.98)$ & 1.40 & $0.80-2.47$ & 0.24 \\
\hline
\end{tabular}

*SGRQ: St. Georges's Respiratory Questionnaire (Jones et al. 1991) , wenn > als median von $33=$ schlechte Lebensqualität, $<$ median = gute Lebensqualität 
Tabelle 9: Prädiktoren für eine hoffnungsvolle Einstellung bezüglich pharmakogenetischer Tests

\begin{tabular}{|c|c|c|c|c|}
\hline \multirow[t]{2}{*}{ Prädiktoren } & \multicolumn{4}{|l|}{ Prävalenz } \\
\hline & N (\%) & OR & 95\% KI & $\mathbf{P}$ \\
\hline \multicolumn{5}{|l|}{ Alter } \\
\hline$>$ median $(60,7 \mathrm{~J})$ & $74(75.51)$ & 1 & & \\
\hline$<$ median & $85(86.73)$ & 2.12 & $1.01-4.46$ & 0.05 \\
\hline \multicolumn{5}{|l|}{ Geschlecht } \\
\hline männlich & $68(77.27)$ & 1 & & \\
\hline weiblich & $91(84.26)$ & 1.57 & $0.77-3.23$ & 0.22 \\
\hline \multicolumn{5}{|l|}{ Wohnort } \\
\hline Land & $88(79.28)$ & 1 & & \\
\hline Stadt & $71(83.53)$ & 1.33 & $0.64-2.76$ & 0.45 \\
\hline \multicolumn{5}{|l|}{ Schulausbildung } \\
\hline $\begin{array}{l}\text { kein Schulabschluss oder Hauptschul- } \\
\text { abschluss }\end{array}$ & $87(79.09)$ & 1 & & \\
\hline $\begin{array}{l}\text { Realschulabschluss oder höher (Abi- } \\
\text { tur, Fachabitur) }\end{array}$ & $72(83.72)$ & 1.36 & $0.65-2.83$ & 0.41 \\
\hline \multicolumn{5}{|l|}{ Lebensqualität } \\
\hline SGRQ > median (eher schlecht) & $76(80.85)$ & 1 & & \\
\hline SGRQ < median (eher gut) & $83(81.37)$ & 1.04 & $0.51-2.12$ & 0.93 \\
\hline
\end{tabular}




\section{Diskussion}

Für die Beratung und Durchführung pharmakogenetischer Untersuchungen ist es gerade für Ärzte essentiell, die Einstellung von Patienten - also den späteren Nutzern zu kennen, damit Sie optimal auf deren Hoffnungen, Sorgen und Erwartungen eingehen und reagieren können. Aufgrund fehlender Daten war unbekannt, ob Patienten pharmakogenetische Tests durchführen lassen werden und welche Hoffnungen und Sorgen sie dabei haben. Ziel dieser Studie war daher hausärztliche Patienten nach ihren Sorgen, Hoffnungen und Erwartungen bezüglich pharmakogenetischer Untersuchungen zu befragen, um diese bei der zukünftigen Anwendung pharmakogenetischer Tests berücksichtigen zu können. Insgesamt war die Bereitschaft zur Durchführung pharmakogenetischer Untersuchungen sehr groß. Mehrheitlich wünschten die Befragten den eigenen Hausarzt als ersten Ansprechpartner zu diesem Thema.

\subsection{Rahmenbedingungen für die Durchführung pharmakogeneti- scher Untersuchungen}

Unsere Studie zeigte eine sehr positive Grundeinstellung gegenüber pharmakogenetischen Untersuchungen: Fast $96 \%$ der befragten Interviewteilnehmer würden bei einer Erkrankung der Durchführung eines pharmakogenetischen Tests zustimmen. $94 \%$ empfänden es als Vorteil, über ihre genetische Veranlagung Bescheid zu wissen. Diese positive Grundeinstellung gegenüber genetischen Untersuchungen fanden auch Berth et al. in ihrer 2002 veröffentlichten Studie: ca. zwei Drittel der für Deutschland repräsentativen Stichprobe $(n=2076$ Personen) befürworteten genetische Untersuchungen.

In unserer Studie äußerten Frauen eher Sorgen gegenüber pharmakogenetischen Tests, während jüngere Patienten sich optimistischer zeigten, dass die Anwendung pharmakogenetischer Tests zu einer Verbesserung der medikamentösen Therapie führen könnte. Dies stimmt partiell mit den Ergebnissen der bereits zitierten Studie 
von Berth et al. (2002) überein, in der ebenfalls Ältere eher ängstlicher gegenüber genetischen Untersuchungen waren.

Die von Sturgis et al. 2005 aufgestellte Behauptung über eine positive Verbindung zwischen Bildungsstand und Bereitschaft zu genetischen Untersuchungen konnten wir nicht finden. Interessanterweise meinten $40 \%$ der Befragten unserer Studie, dass sie nicht die komplette Tragweite und mögliche Konsequenzen pharmakogenetischer Tests für sich und ihre Familie erfassen könnten. Diese Patienten würden also pharmakogenetische Untersuchungen durchführen lassen, ohne deren Folgen sicher überschauen zu können. Dies korrespondiert mit Literaturbefunden zum vergleichsweise geringen Kenntnisstand der Bevölkerung über Genetik und zu den Möglichkeiten genetischer Untersuchungen (Press et al. 2001).

Bezüglich der Einstellung der Bevölkerung zu Gentests fanden ebenfalls Shaw und Bassi (2001) überwiegend positive Meinungen zu genetischen Untersuchungen, gleichzeitig aber auch negative Aspekte und Bedenken, wie z. B. die Sicherung des Datenschutzes oder mögliche negative Konsequenzen am Arbeitsplatz. Eine ähnliche Tendenz spiegelt sich auch in unserer Untersuchung wider: Trotz der insgesamt sehr positiven Grundeinstellung und der hohen Bereitschaft zur Durchführung pharmakogenetischer Untersuchungen wurden auch negative Aspekte wie Sorgen um den Datenschutz genannt. Dass trotz dieser möglichen Konsequenzen und Nachteile Patienten über ihre genetischen Veranlagungen Bescheid wissen wollen, stellten auch Andrykowski et al. (1996) fest, als 93 \% der befragten Frauen darüber informiert werden wollten, ob sie eine genetische Prädisposition für Brustkrebs hatten.

Um sich für oder gegen die Durchführung pharmakogenetischer Tests entscheiden zu können, wünschten Patienten in einem Beratungsgespräch vor allem folgende Informationen: Vorteile und Nutzen pharmakogenetischer Tests; Risiken und mögliche „Nebenwirkungen“ der Tests, Datenschutz, Testablauf, Testkosten, spezifischere 
Angaben zum Fehlerrisiko, Auswirkungen für nachfolgende Generationen sowie Informationen zur Möglichkeit krankheitsassoziierte Erbanlagen festzustellen (Meyer et al. 2002). Diese Vielzahl der von den Patienten geforderten Informationen macht deutlich, wie gründlich und umfassend ein Beratungsgespräch sein müsste, zumal vielen Patienten dieses Thema noch vollkommen unbekannt ist (Press et al. 2001).

In der englischen TARGET (TPMT Azathioprine Response to Genotyping and Enzyme Testing) - Studie äußerten sich Patienten, die mit Azathioprin therapiert wurden, über pharmakogenetische Untersuchungen und ließen ihre hohen Erwartungen an Aufklärungsgespräche erkennen (Fargher et al. 2007 b). Daher wären wohl auch ausführliche, neutrale Patientenbroschüren zum Thema „pharmakogenetische Untersuchungen" von Vorteil; sie könnten Arzt und Patient helfen, den Testablauf und die wichtigsten Aspekte dieses Themas darzustellen. Das wäre auch deshalb sinnvoll, weil Patienten sich häufig über unzureichende Information und wenig sensible Kommunikation beklagen und sich daher unzureichend aufgeklärt fühlen (Dierks und Schaeffer 2005).

Hapgood warf 2003 die Frage auf, ob Patienten nach der Durchführung einer pharmakogenetischen Untersuchung das Etikett „Non-Responder“ für ein Medikament annähmen, ohne es ausprobiert zu haben. Zudem handele es sich bei den Testergebnissen um Wahrscheinlichkeiten, es könnten also auch „Non-Responder" von der medikamentösen Therapie profitieren, daher würde einem Patienten nach einem pharmakogenetischen Test möglicherweise zu Unrecht eine Therapie verweigert (Smart et al. 2004). In unserer Studie würde mehr als die Hälfte der Patienten ein Medikament entgegen der Testempfehlung ausprobieren, wenn sie nach einer pharmakogenetischen Untersuchung ein negatives Ergebnis erhielten (in dem hypothetischen Fall es wäre kein passendes Medikament vorhanden und mit zahlreichen $\mathrm{Ne}-$ benwirkungen wäre zu rechnen). So scheinen die befragten Patienten ein eher geringes Vertrauen in die Testergebnisse zu haben oder aber den Bedarf nach „Handlungsfähigkeit“ bzW. „Aktionismus“ zu verspüren, um sich nicht einer Krankheit hilflos ausgeliefert zu fühlen. Auch Campos-Outcalt (2007) fordert, dass ein sinnvoller klini- 
scher Test relevante therapeutische Informationen wie Dosierungsrichtlinien oder mögliche Alternativen enthalten sollte.

In diesem Zusammenhang muss die spezielle Situation chronisch Erkrankter beachtet werden. Besonders für Patienten mit chronischen Erkrankungen ist das Gefühl einer konstanten Unsicherheit eine der bedeutsamsten Herausforderungen innerhalb ihrer Behandlung (Mishel 1997). Ursächlich für diese Verunsicherungen sind u. a. der Umgang mit krankheitsbedingten Symptomen, der Verlust der natürlichen Selbstverständlichkeit des Körpers und die Unberechenbarkeit des Krankheitsverlaufs (Schaeffer 2006). Chronische Erkrankungen sind geprägt durch einen kaum kalkulierbaren Wechsel von stabilen, instabilen und krisenhaften Phasen (Corbin und Strauss 2004), mit der Folge von Unsicherheit, Stress und dem Gefühl des Ausgeliefertseins (Lazarus 1993). Daraus können Angst, Depressionen und weitere emotionale Verstörungen resultieren, welche die Handlungsfähigkeit unterminieren können (Mishel 1997). Die positive Einstellung gegenüber pharmakogenetischen Untersuchungen könnte als Ausdruck dieser Unsicherheit interpretiert werden, da v. a. das „Bedürfnis nach Gewissheit, dass ein Medikament hilft“ von den Patienten mit großen Hoffnungen verbunden wird, sie also durch einen pharmakogenetischen Test ein Stück Sicherheit gewinnen könnten. Andererseits könnte sich die Information über das Ergebnis eines pharmakogenetischen Tests als nachteilig erweisen, da dieses Wissen den Placeboeffekt des Medikaments möglicherweise reduziert (Hapgood 2003).

Viele der von uns befragten Patienten scheinen sich einen geschickten Weg zwischen positiven und negativen Folgen eines pharmakogenetischen Tests zu suchen: Sie würden einen solchen Test durchführen lassen, um die Auswahl der für sie geeigneten Medikamente verbessern und Nebenwirkungen vermeiden zu können, wie auch Weihrauch (2002) meint. Ein negatives Testergebnis würden sie aber nicht so stark gewichten, sondern dann wieder auf die Einnahme von „StandardMedikamenten“ gemäß ihrer Erkrankung zurückgreifen; in der Hoffnung, dass das Medikament trotz des Testergebnisses - zumindest in einem gewissen Ausmaß - hel- 
fen könnte. Auch das persönliche Ausprobieren, um das Testergebnis anhand des subjektiven Empfindens bestätigen oder verwerfen zu können und danach dementsprechend das Medikament weiter einzunehmen oder abzusetzen, war ein wesentliches Argument der Befragten.

Ein weiterer wichtiger und von mehreren Patienten genannter Aspekt spiegelt sich im Begriff des „letzten Strohhalms“: Die Skepsis gegenüber dem Testergebnis könnte den Patienten die Möglichkeit offen halten, trotz eines ungünstigen Testergebnisses weiterhin auf Besserung ihrer Gesundheit hoffen zu können, was gerade für chronisch kranke Patienten äußerst wichtig ist. Andererseits bergen diese Zweifel an der Testgüte und somit den Ergebnissen pharmakogenetischer Untersuchungen Gefahren für die Patienten, da diese aus Misstrauen die resultierenden therapeutischen Konsequenzen ablehnen und entgegen der Testempfehlung wirkungslose und nebenwirkungsreiche Medikamente einnehmen könnten (Mountcastle-Shah und Holtzman 2000).

Eine positive Einstellung gegenüber pharmakogenetischen Tests und die Bereitschaft zu ihrer Durchführung scheinen besonders von zwei Bedingungen abzuhängen: (1) die Beratung und Informationsvermittlung über Ziele, Nutzen und mögliche Folgen pharmakogenetischer Untersuchungen und (2) die Gewährleistung des Datenschutzes. Als Ansprechpartner wird vorwiegend der eigene Hausarzt gewünscht. Auch für beteiligte Ärzte ist wichtig, welche therapeutischen Konsequenzen aus dem Vorliegen bestimmter Genotypen resultieren können (Austin et al. 2000, Kirchheiner et al. 2006). Ein Modell für die konkrete Nutzung der Testergebnisse wird seit 2006 in Holland angewendet, wo genotyp-basierte Dosierungsrichtlinien in eine elektronische Medikamenten-Datenbank integriert wurden (Swen et al. 2008). 


\subsection{Einstellung und Hoffnungen von Patienten bezüglich pharma- kogenetischer Untersuchungen}

In der 2006 vom englischen Zentrum für Genetik im Gesundheitswesen (Nowgen) durchgeführten Befragung von 1006 Erwachsenen glaubten 74 \% der Befragten, dass durch genetische Forschung die Auswahl von Medikamenten verbessert werden könnte (Finegold et al. 2008). Dieses Ergebnis bestätigte sich in unserer Untersuchung. Die hohe Bereitschaft zu pharmakogenetischen Untersuchungen verknüpfen die Interviewteilnehmer vor allem mit den Hoffnungen nach einer vorhersagbaren Wirkung eines Medikaments, der optimalen medikamentösen Therapie und der Besserung ihres Gesundheitszustandes. Auch in der Untersuchung von Fargher (2007 a), in der Patienten und Gesundheitspersonal in England über Pharmakogenetik befragt wurden, standen die Teilnehmer den Vorteilen pharmakogenetischen Untersuchungen und der Möglichkeit, Informationen über ihr eigenes, individuelles Risiko für Nebenwirkungen zu erhalten, sehr positiv gegenüber. Als weitere positive Aspekte wurden genannt: individuelle Dosierung, Profil der individuellen Nebenwirkungen, erhöhtes Vertrauen in die Medikamente, schnellere optimale Dosierung, frühere Behandlung einer Erkrankung und Auswahl des am besten geeigneten Medikamentes.

Die Ergebnisse der o. g. Untersuchungen bestätigten sich auch in unserer Studie. So nannten die meisten unserer Studienteilnehmer als Hauptgründe für die Durchführung pharmakogenetischer Tests „die Gewissheit, ob ein Medikament hilft“, sowie die Möglichkeit der „besseren medikamentösen Behandlung durch ein individuell optimales Medikament“. Schon vor der Einnahme hoffen die Befragten zu erfahren, ob das verordnete Medikament mit hoher Wahrscheinlichkeit nutzen wird und individuell aus einer Palette von Arzneimitteln - für sie ausgewählt wurde. Diese Gewissheit könnte den positiven Effekt des Medikaments prinzipiell verstärken, da die Unsicherheit der Patienten bezüglich der Einnahme und der im Beipackzettel aufgeführten Nebenwirkungen reduziert wird. Würde ein pharmakogenetische Test eine hohe Ansprechwahrscheinlichkeit ergeben, könnte auf Seiten der Patienten das Vertrauen in das Medikament und die Bereitschaft zur regelmäßigen Einnahme gesteigert werden (Hapgood 2003). 
Patienten stehen zur Zeit einer zunehmenden „Arzneimittelflut“ gegenüber (Steinman et al. 2006). Weiterhin ändert sich durch medikamentöse Umstellungen z. B. bei Wechsel von stationärer auf ambulante Therapie oft auch das vertraute Behandlungsschema des Patienten (Grimmsmann et al. 2007). Davon fühlen sich besonders Ältere überfordert, da durch Abnahme der kognitiven Leistungsfähigkeit das Verständnis und die Umsetzung für komplexe Therapieregime vermindert sind (Borchelt 2005). Verlockend scheint da die Aussicht, aus der Vielzahl von Medikamenten das oder die nach pharmakogenetischen Gesichtspunkten jeweils Besten herauszufinden und dadurch eventuell auch die erforderliche Zahl von Medikamenten zu senken. Umso wichtiger ist die Aufklärung des Patienten darüber, dass pharmakogenetische Untersuchungen nur eine Wahrscheinlichkeit des Ansprechens auf eine Wirkstoffgruppe bzw. Hinweise zur Dosierung ergeben. Eine solche Information könnte Patienten zu einer realistischen Einschätzung des Testergebnisses verhelfen (Schmedders et al. 2003).

Als weitere Motive zur Durchführung pharmakogenetischer Untersuchungen nannten die Patienten: Hoffnung auf Besserung des Gesundheitszustandes, Medikamente mit weniger Nebenwirkung zu erhalten, Medikamente nicht wahllos „auszuprobieren“, die Anzahl der Medikamente zu reduzieren, Medikamente optimal zu dosieren und Kosten für Medikamente einzusparen. Patienten, die unter chronischen Erkrankungen leiden, sind oft sehr bestrebt, etwas „für ihre Gesundheit" zu unternehmen, um durch diesen Versuch der aktiven Einflussnahme auf ihre Situation und ihre Therapie aus der Rolle des mehr oder weniger passiven Akteurs zu entkommen (Schaeffer 2006). Übertriebene Versprechungen, wie die angeblich sichere Vermeidung unnötiger $\mathrm{Ne}$ benwirkungen, dürften diese Patienten noch stärker als die „Normalbevölkerung“ ansprechen.

Einige Patienten stehen selbst den möglichen Nachteilen genetischer Untersuchungen positiv gegenüber. Drei der Befragten hofften durch die Durchführung eines pharmakogenetischen Tests mehr über ihre Krankheitsanlagen zu erfahren. Während einige Patienten das "Nicht-Wissen“ über mögliche zukünftige Krankheiten als 
positiv empfanden, sahen andere Patienten dieses frühzeitige Wissen als wünschenswert an, vermutlich verknüpft mit der Hoffnung, durch eine frühzeitige Therapie den Krankheitsausbruch bzw. Krankheitsverlauf positiv beeinflussen zu können (Marteau und Lerman 2001). So würde es nur 15 \% der Patienten große Sorgen bereiten, wenn ihnen durch einen pharmakogenetischen Test unbeabsichtigt eine Krankheitsdisposition bekannt würde, während $45 \%$ der Patienten diesbezüglich keine Sorgen hätten. Einer der Patienten versprach sich davon sogar „positive Auswirkungen auf nachfolgende Generationen“. Auch in der repräsentativen Untersuchung von Singer et al. (1999) in den USA überwogen für $50 \%$ der Befragten die Vorteile von genetischen Untersuchungen.

Vor allem jüngere Studienteilnehmer sahen mehr positive Aspekte und hatten optimistischere Erwartungen an pharmakogenetische Untersuchungen. In der Studie von Berth et al. (2002) hatten Alter und Geschlecht keinen bzw. wenig Einfluss (Ältere sahen geringfügig häufiger negative Aspekte als Jüngere). Möglicherweise haben ältere Patienten im Lauf ihres Lebens erfahren, dass sie mit dem bisherigen Behandlungsschema zu einer zufriedenstellenden medikamentösen Therapie gelangen konnten, während jüngere Patienten die Hoffnung haben, diesen Prozess durch pharmakogenetische Tests zu beschleunigen und zu optimieren.

Wir fanden keinen Einfluss des Bildungsstandes auf die Einstellung zu pharmakogenetischen Tests. Dies unterschied sich zur o. g. Studie von Berth et al. (2002), in der Personen mit höherer Bildung mehr positive und weniger negative Aspekte hinsichtlich genetischer Untersuchungen angaben.

\subsection{Sorgen bezüglich pharmakogenetischer Untersuchungen}

Eine deutliche Mehrheit von knapp 90 \% der Befragten antwortete auf die offene Frage, welche Sorgen oder Ängste innen pharmakogenetische Untersuchungen be- 
reiten, dass sie wegen der Tests keine Sorgen oder Ängste hätten. Insgesamt würden sogar nur drei der Interviewteilnehmer (1,5 \%) die Durchführung pharmakogenetischer Untersuchungen ablehnen.

Eine deutlichere Ablehnung fand sich in der 2006 durchgeführten und bereits erwähnten Nowgen-Studie. Zwar hielten 84 \% genetische Forschung zur Verbesserung der Gesundheit für geeignet, dennoch würden 40 \% der Befragten genetische Untersuchungen nicht durchführen lassen, egal ob zur Identifizierung von Gesundheitsrisiken oder um bessere Behandlungsmöglichkeiten zu finden (Finegold et al 2008). Bei diesem Ergebnis ist jedoch zu bedenken, dass den Interviewteilnehmer eine große Menge von Fragen über verschiedene Themen gestellt worden ist, sie sich also eventuell nicht so intensiv mit der Möglichkeit pharmakogenetischer Untersuchungen gedanklich beschäftigt hatten, wie es in einem Arztgespräch vielleicht der Fall gewesen wäre, oder ihnen die Unterscheidung zwischen genetischen und pharmakogenetischen Untersuchungen nicht immer eindeutig war (Finegold et al. 2008). Im Gegensatz dazu waren unsere Interviewpartner zum einen durch die Informationsbroschüre über pharmakogenetische Untersuchungen informiert und wurden auch nur darüber befragt, zum anderen waren sie durch ihre Lungenerkrankung in der Patientenrolle und daher eventuell aufgeschlossener.

In der Studie von Fargher (2007 a) wurden als mögliche Nachteile von pharmakogenetischen Tests v. a. genannt: vermehrte Sorgen, verstärkte Beschwerden, Aufdecken weiterer Krankheitsveranlagungen oder störende Einflüsse auf die Auswertung. Ähnliche negative Aspekten gaben auch unsere Studienteilnehmer an, so waren die Hauptargumente für die Ablehnung pharmakogenetischer Tests unserer Befragten, dass der Test bisher auch nicht nötig gewesen sei, er Kosten verursachen und eventuelle unangenehme Begleiterscheinungen oder Folgen mit sich bringen könne. Auch für Woodcock (2005) könnten pharmakogenetische Untersuchungen - wie viele neue Technologien - nicht unerhebliche Kosten mit sich bringen. Kosten und Aufwand sollten daher in einem positiven Verhältnis zum Nutzen stehen (Kirchheiner et al. 2006). 
Im Zusammenhang mit genetischen Untersuchungen wird immer wieder auf die Bedeutung des Schutzes und der Sicherung der Daten vor Missbrauch hingewiesen (March et al. 2001, Buchanan et al. 2002). Auch in der Studie von Berth et al. (2002) war der Datenschutz ein wesentlichen Aspekt bei genetischen Untersuchungen: Nur eine Minderheit (7,2\% der deutschen Bevölkerung) äußerte keine Befürchtungen über den möglichen Missbrauch der Ergebnisse, allerdings hatte nur knapp ein Drittel diesbezüglich starke Befürchtungen. Dass Patienten insbesondere die Folgen eines unzureichenden Datenschutzes fürchten, zeigte auch die Studie von Mogilner et al. über Gentests bei Brustkrebs (1998). Darin begründeten Patienten eine ablehnende Haltung v. a. mit der Befürchtung einer negativen psychischen Befindlichkeit, beruflicher Diskriminierung und Nachteilen im Versicherungsschutz. Desgleichen zeigte sich in der Studie von Fargher (2007 a), wo die Patienten ebenfalls Vertrauen und Schutz der persönlichen Daten als Schwerpunkt äußerten. Auch unsere Interviewteilnehmer sahen die Relevanz dieses Aspektes, interessanterweise gaben aber nur ca. $6 \%$ der Patienten spontan die Sorge um den Datenschutz und den Missbrauch der Testergebnisse an, während auf die konkrete Frage 66 \% Sorgen über die Wahrung des Datenschutzes äußerten.

Wenn negative Ergebnisse pharmakogenetischer Untersuchungen bekannt würden, befürchtete in unserer Studie fast die Hälfte der Befragten Nachteile bei der Krankenkasse und über zwei Drittel Nachteile beim Arbeitgeber. Ca. einem Drittel bereitete die Weitergabe der Testergebnisse an die Krankenkasse Sorgen, während die Weitergabe an Unbefugte im Gegensatz dazu bei zwei Dritteln der Befragten mit etwas bis großen Sorgen verbunden war. Diese Problematik wird nicht nur von der Patientenseite so gesehen. Ein Beispiel ist die Untersuchung von Levy et al. (2007) in der amerikanische Hausärzte über einen genetischen Test, der die Raucherentwöhnungsbehandlung verbessern soll, befragt wurden. Da dieser Test auch mögliche Krankheitsassoziationen aufdecken könnte, äußerten sich die Hausärzte sehr besorgt, v. a. über mögliche Diskrimination im Bereich Arbeit oder Versicherung als Folge dieser Untersuchung. Die möglichen sozialen Folgen pharmakogenetischer Tests wie z. B. Zugang zur Versicherung und zum Arbeitsmarkt sind bisher nicht absehbar (Issa 2002). Um negative Auswirkungen zu verhindern, ist daher in den USA 
ein Gesetzentwurf in Arbeit, der die Diskrimination durch missbräuchliche Verwendung genetischer Informationen v. a. bei Personal- und Versicherungsentscheidungen verhindern soll (Finegold et al. 2008).

Bei den von uns befragten Patienten scheinen gegenüber der eigenen Krankenkasse ein größeres Vertrauen und weniger Angst vor Nachteilen zu herrschen, was sich eventuell aus den bisherigen Erfahrungen mit den gesetzlichen Krankenkassen erklären lässt. Dort sind Beitragskosten und Erstattung der Krankenversicherungen immer noch weitgehend unabhängig von Erkrankung und Vorgeschichte des Patienten. Im Gegensatz dazu ist die Sorge um den Arbeitsplatz bei Weitergabe von Testergebnissen wesentlich größer. Dies könnte mit der aktuellen Arbeitsmarksituation hohe Arbeitslosenzahlen, viele Langzeitarbeitslose - und einer Angst, aus Krankheitsgründen mit eventuell höheren Fehlzeiten schneller gekündigt zu werden, zusammenhängen. Chronisch erkrankte Patienten sind im Vergleich zu Gesunden in höherem Ausmaß von Kündigung und Arbeitslosigkeit bedroht, ebenso können längere Arbeitsunfähigkeitszeiten zu „Mobbing“ führen (Breuer und Kapp 2006). Auch die Studie von Yelin et al. (2006) zeigte, dass Patienten mit COPD und in geringerem Ausmaß auch Patienten mit Asthma bronchiale das Arbeitsleben um Jahre früher als Arbeitnehmer ohne chronische Atemwegserkrankungen verlassen. In unserer Studie stand ca. die Hälfte der Studienteilnehmer bei Durchführung der Untersuchung als Rentenempfänger nicht mehr im Arbeitsprozess, so dass diese Einstellung auch in der früheren eigenen Erfahrung als chronisch Kranker am Arbeitsmarkt begründet liegen könnte.

Abgesehen von den äußerlichen Veränderungen - wie der Situation am Arbeitsplatz und bei der Krankenkasse - interessierten uns ebenfalls die möglichen persönlichen Konsequenzen eines negativen Testergebnisses. Ein ungünstiges Testergebnis könnte z. B. das Gefühl der vollkommenen Abhängigkeit bzw. des Ausgeliefertseins verbunden mit einer Macht- bzw. Hilflosigkeit hervorrufen (Robertson 2001). Zudem sind chronische Erkrankungen eine psychische Belastung und schränken die Lebensqualität ein (Breuer und Kapp 2006). Als weitere Folgen eines pharmakogeneti- 
schen Tests nennt die Literatur z. B. ein verzerrtes Selbstbild, hervorgerufen durch das Gefühl, aufgrund einer genetischen Variabilität „anders“ oder „defekt” zu sein (Renegar et al. 2001). In unserer Studie würde sich ca. ein Drittel der Befragten nach einem ungünstigen Testergebnis „andersartig“ bzw. „defekt“, 40 \% würden sich „machtlos“ bzw. „pessimistisch“ fühlen. Natürlich sind dies hypothetische Angaben, aber sie zeigen doch deutlich, dass die Durchführung pharmakogenetischer Untersuchungen und die damit eventuell verbundenen negativen Ergebnisse eindeutige Auswirkungen im psychischen und emotionalen Bereich des betroffenen Patienten nach sich ziehen könnten (Moldrup 2001).

Mögliche psychische Auswirkungen von prädiktiven Gentests überprüften ebenso Broadstock et al. (2000): Interessanterweise zeigten weder die Träger des untersuchten Genes noch die Nicht-Träger während der zwölf Monate nach der Testdurchführung eine erhöhte psychische Belastung. Im Gegenteil, beide Seiten hatten weniger Sorgen nach dem Test, dieser Effekt fand bei den Nicht-Trägern schneller und in größerem Ausmaß statt. Dennoch sollte sich jeder Arzt vor der Empfehlung zu pharmakogenetischen Untersuchungen bewusst sein, dass bei einzelnen chronisch kranken Patienten, die insgesamt eine statistisch höhere Wahrscheinlichkeit zu Depressionen haben (Fittig et al. 2005), sich ein ungünstiges Testergebnis negativ auf das Krankheitsempfinden und das Erleben der eigenen Person auswirken könnte.

Eine mögliche stärkere Gewichtung des Testergebnisses gegenüber dem persönlichen Wunsch nach einem Medikament bereitete den meisten Befragten keine Sorgen, hierbei könnte das Vertrauen in den Arzt und dessen Bewertung des Testergebnisses eine Rolle spielen (siehe auch Kapitel 6.4). 


\subsection{Konsequenzen für die hausärztliche Praxis: Beratungsanlie- gen und Informationsbedarf}

Patienten stehen der Möglichkeit pharmakogenetischer Untersuchungen aufgeschlossen gegenüber; dabei ist es ihr mehrheitlicher Wunsch, dass pharmakogenetische Untersuchungen in der hausärztlichen Praxis durchgeführt werden und dort auch die Beratung stattfindet. Für die Aufklärung über bzw. Durchführung von pharmakogenetischen Tests würden 78 \% der Befragten den eigenen Hausarzt bevorzugen. Dieses Ergebnis fand auch Fargher (2007 a), in dessen Befragung Patienten ebenfalls eine klare Präferenz für den eigenen Hausarzt äußerten. Die dauerhafte Beziehung und das persönliche Vertrauensverhältnis - vermutlich geringer ausgeprägt beim Spezialisten - dürften den Ausschlag hierfür geben (Donahue et al. 2005).

Ein wesentlicher Faktor der Arzt-Patienten-Beziehung ist das Vertrauen des Patienten in den behandelnden Arzt. Ommen et al. (2007) stellten vier hochsignifikante Einflussfaktoren für das Vertrauen in den behandelnden Arzt fest: das Informationsverhalten des Arztes, die wahrgenommene Einbeziehung des Patienten in die Therapie, der durch den Patienten beurteilte Behandlungserfolg und das Alter des Patienten. In Beratungsgesprächen zu pharmakogenetischen Untersuchungen sollte der beratende Arzt daher den Patienten aktiv miteinbeziehen und informieren, damit zum einen die Arzt-Patienten-Beziehung gefördert wird und zum anderen der Patient selbst hinter der getroffenen Entscheidung steht.

Die Bedeutung des Arztes zeigt sich auch in dem Ergebnis, dass für ein Fünftel der Befragten unserer Studie eine Empfehlung ihres Arztes das entscheidende Kriterium zur Testdurchführung wäre. Die Meinung des Arztes könnte also die eigene Einstellung gegenüber dem Test beeinflussen. Die Patienten bringen dem Arzt ein sehr großes Vertrauen entgegen und geben die Entscheidung zur Testdurchführung teilweise an ihn ab. Der Arzt müsste daher schon vor dem Beratungsgespräch individuell für den jeweiligen Patienten die möglichen Vorteile und den Nutzen, aber auch die Nachteile und möglichen negativen Konsequenzen überdenken. Diese Überlegungen 
muss er in einem strukturierten Beratungsgespräch dem Patienten darlegen (Emery und Hayflick 2001), denn letztendlich soll der Patient die Entscheidung selbst treffen. Eine ärztliche Beratung zu pharmakogenetischen Untersuchungen sollte sich auch an den o. g. Hoffnungen und Sorgen der Patienten orientieren. So sollten unrealistische Hoffnungen geklärt, auf den Wahrscheinlichkeitscharakter der Testergebnisse hingewiesen und mögliche mit der Untersuchung verbundene Sorgen oder negative Konsequenzen angesprochen werden (Schmedders et al. 2003).

Die eigentliche Durchführung pharmakogenetischer Untersuchungen besteht aus der Blutabnahme, die in der Hausarztpraxis erfolgen kann, und dem Versenden der Blutprobe in ein spezifisches Labor (Kirchheiner et al. 2003). Der Arzt ist dann wieder bei der Interpretation, der Mitteilung und der weiteren Verwendung der Testergebnisse gefordert. Auch für den sorgsamen Umgang mit diesen sensiblen Daten trägt der behandelnde Mediziner die Verantwortung und muss sicherstellen, dass diese unter keinen Umständen in falsche Hände gelangen (Robertson et al. 2002). Unsere Studie hat gezeigt, wie wichtig der Datenschutz in diesem Zusammenhang von den Patienten bewertet wird.

In Zukunft könnten die Beratung und Aufklärung über pharmakogenetische Tests neue wichtige ärztliche Aufgaben werden (Emery und Hayflick 2001). In unserer Studie fürchtete mehr als ein Drittel der Befragten, dass in Zukunft Druck auf Patienten ausgeübt werden könnte, pharmakogenetische Tests durchführen zu lassen. Dies veranschaulicht die Schwierigkeiten der Beratungsgespräche: Patienten sollen sich danach informiert, aber nicht zu einer Entscheidung gedrängt fühlen. 


\subsection{Diskussion der Methode}

Die Patienten, die an unseren Telefoninterviews teilnahmen, stammten aus einer Gruppe von Studienteilnehmern eines pharmakogenetischen Forschungsprojekts. Die Vermutung, diese Patienten seien möglicherweise offener für das Thema pharmakogenetische Untersuchungen als der „Durchschnittspatient“, ist nahe liegend. Dennoch hatten auch diese Patienten Sorgen bezüglich der möglichen Folgen und Konsequenzen dieser Tests, vor allem in der Einhaltung des Datenschutzes.

Im Gegensatz zu den Studienteilnehmern bei Berth et al. (2002) handelt es sich bei unseren Befragten nicht um eine deutschlandrepräsentative Stichprobe, sondern um Patienten mit chronischen Lungenerkrankungen. Dies erschien sinnvoll, da es sich bei den möglichen Nutzern pharmakogenetischer Untersuchungen ebenfalls häufig um chronisch Kranke - und nicht die gesunde Normalbevölkerung - handeln wird. Daher ist für die Anwendung pharmakogenetischer Tests also vor allem die Einstellung chronisch kranker Patienten und nicht der Gesunden entscheidend.

Ein weiteres Problem für diese Form der Befragung ist die fehlende Information der Bevölkerung zu genetischen Fragestellungen (Henneman et. al. 2004). Um dennoch vergleichbare Voraussetzungen für die Interviewfragen zu schaffen, hielten wir es für nötig, die wichtigsten Informationen über pharmakogenetische Untersuchungen als kurze Informationsbroschüre den Patienten vor der Durchführung des Interviews zukommen zu lassen (siehe Anhang 2). Wir bemühten uns dabei, die Informationen möglichst sachlich und neutral darzustellen und positive sowie negative Aspekte im gleichen Verhältnis zu nennen. Trotz größter Sorgfalt und Umsicht ist eine rein sachliche Darstellung schon deshalb nahezu ausgeschlossen, weil pharmakogenetische Untersuchungen selbst in der Fachöffentlichkeit unterschiedlich bewertet werden. 


\subsection{Schlussfolgerung}

Unsere Studie zeigt eine äußerst positive und aufgeschlossene Einstellung der von uns befragten chronisch kranken Patienten gegenüber pharmakogenetischen Untersuchungen. Ängste verbinden die Patienten vorwiegend mit einer unzureichenden Sicherstellung des Datenschutzes, einem ungünstigen Testergebnis und möglichen negativen Konsequenzen v. a. am Arbeitsplatz. Als emotionale Folgen werden ein Gefühl von Machtlosigkeit und Pessimismus befürchtet. Fast die Hälfte der Befragten bezweifelt, die Tragweite und Konsequenzen solcher Testergebnisse für sich selbst und ihre Angehörigen überschauen zu können.

Für die praktische Durchführung ist v. a. der Hausarzt als erster Ansprechpartner wichtig, da sein Wissen und seine Einstellung die Entscheidung für pharmakogenetische Tests entscheidend mitbeeinflusst. Auf Hausärzte wird die Aufgabe zukommen, ihren Patienten die Möglichkeiten pharmakogenetischer Untersuchungen umfassend und sachlich mit allen Vor- und Nachteilen sowie möglichen Konsequenzen darzulegen und dabei keine unrealistischen Erwartungen an die Ergebnisse zu wecken. Besonders der Umgang mit ungünstigen Testergebnissen könnte Ärzte dabei vor neue Herausforderungen stellen, da nur rund die Hälfte der hier Befragten eine negative Empfehlung akzeptieren würde, ohne die betreffenden Medikamente selbst ausprobiert zu haben. So wären Algorithmen und Empfehlungen hilfreich, aus welchem Testergebnis welche Wahl und Dosierung eines Medikaments abgeleitet und wie ungünstige Ergebnisse vermittelt werden könnten.

Da die Untersuchung auf einer Befragung von Patienten beruht, die an einem Forschungsprojekt teilnahmen, das eine genetische Fragestellung mit einschloss, dürfte es sinnvoll sein, die Befragung bei einer unselektierten Stichprobe chronisch erkrankter Patienten zu wiederholen. 


\section{Zusammenfassung}

Hintergrund und Ziel: Pharmakogenetische Untersuchungen könnten zukünftig bereits vor der Einnahme eines Medikaments Hinweise zu dessen Wirksamkeit, Nebenwirkungen und benötigter Dosierung geben. Ziel der Studie war die Untersuchung der Hoffnungen, Sorgen und Erwartungen, die hausärztlich betreute Patienten pharmakogenetischen Tests entgegenbringen.

Methode: 328 Patienten mit Asthma bronchiale oder COPD, die an einer übergreifenden Studie mit genetischer Fragestellung teilnahmen, wurden zur Teilnahme an einem halbstrukturierten Interview eingeladen. Der Interviewleitfaden basierte auf den Ergebnissen einer Literaturrecherche und umfasste offene und geschlossene Fragen zu Hoffnungen, Sorgen und Erwartungen bezüglich pharmakogenetischer Tests. Teilnahmebereite Patienten erhielten zuvor ein standardisiertes Informationsblatt mit einer Beschreibung pharmakogenetischer Tests.

Ergebnisse: 196 Patienten (60 \%) erklärten sich zur Teilnahme bereit und wurden telefonisch befragt. Die Mehrheit (95,9 \%) der Befragten würde der Durchführung eines pharmakogenetischen Tests (zur Anpassung der Medikation bei Asthma bronchiale) zustimmen. Über ihre genetische Veranlagung Bescheid zu wissen, sahen $94,4 \%$ als Vorteil an. Als erster Ansprechpartner wünschten sich 78,1 \% der Befragten den Hausarzt. Von der Verwendung pharmakogenetischer Tests erhofften sich die Patienten v. a. die Vermeidung falscher Medikamente bzw. falscher Dosierung (74,5\% hatten große Hoffnungen und 25,0 \% etwas Hoffnung), das optimale Medikament bzw. die optimale Dosis zu finden (62,8 \% und 36,7 \%) und Medikamente mit den wenigsten Nebenwirkungen zu erhalten (62,8 \% und 35,7\%). Sorgen bereitete den Patienten vor allem die Möglichkeit, das Testergebnis könnte an unbefugte Personen gelangen (35,7 \% hatten große Sorgen und 30,6 \% etwas Sorgen), sowie ein eventuelles ungünstiges Testergebnis, d. h., dass kein passendes Medikament gefunden würde oder Nebenwirkungen zu erwarten wären (35,2\% und 36,7 \%). In diesem Fall würden 56,6 \% der Studienteilnehmer das Medikament dennoch - also entgegen dem Testergebnis - einnehmen wollen. Weibliche Patienten standen pharmakogenetischen Tests häufiger ängstlich gegenüber (Odds Ratio [OR]: 2,85; 95\%- 
Konfidenzintervall [KI]: 1,58 - 5,12). Jüngere Patienten waren häufiger optimistisch bezüglich pharmakogenetischer Tests (OR: 2,12; 95\%-KI: 1,01 - 4,46).

Schlussfolgerung: Unsere Studie zeigt eine äußerst positive und aufgeschlossene Einstellung der befragten Patienten gegenüber pharmakogenetischen Untersuchungen. Dieser grundsätzlich positiven Grundeinstellung steht gleichzeitig Skepsis bei einem ungünstigen Testergebnis gegenüber: Viele Patienten würden ein Medikament entgegen der Testempfehlung ausprobieren. Dies zeigt, dass Aufklärungsgespräche und die Nutzung pharmakogenetischer Daten Hausärzte vor neue Herausforderungen stellen werden, wenn zukünftig pharmakogenetische Untersuchungen eine neue Option im Therapiekonzept darstellen. Ist die Einstellung von Patienten bezüglich pharmakogenetischer Tests bekannt, kann vor ihrer Anwendung optimal auf Hoffnungen, Sorgen und Erwartungen eingegangen werden. 


\section{Literaturverzeichnis}

Ach JS, Bayertz K, Wiesing U (2004): Individualisierung von Diagnostik und Therapie. Dtsch Med Wochenschr $\underline{129}, 2672$ - 2675

Alcalde MG, Rothstein MA (2002): Pharmacogenomics: ethical concerns for research and pharmacy practice. Am J Health Syst Pharm $\underline{59}, 2239$ - 2240

Anderson DC, Gomez-Mancilla B, Spear BB, Barnes DM, Cheesemann K, Shaw PM, Friedman J, McCarthy A, Brazell C, Ray SC et al. (2002): Elements of informed consent for pharmacogenetic research; perspective of the pharmacogenetics working group. Pharmacogenomics J 2, 284 - 292

Andrykowski MA, Munn RK, Studts JL (1996): Interest in learning of personal genetic risk for cancer: A general population survey. Prev Med $\underline{25}, 527$ - 536

Austin MA (2002): Ethical issues in human genome epidemiology: a case study based on Japanese American Family Study in Seattle, Washington. Am J Epidemiol 155, 585 - 592

Austin MA, Peyser PA, Khoury MJ (2000): The interface of genetics and public health: research and educational challenges. Annu Rev Public Health 21, 81 - 99

Badcott D (2006): Some causal limitations of pharmacogenetic concepts. Med Health Care Philos $\underline{9}$, $307-316$

Becquemont L (2003): Clinical relevance of pharmacogenetics. Drug Metab Rev $\underline{35}, 277$ - 285

Berth H, Dinkel A, Balck F (2002): Gesundheit durch Gentests? Akzeptanz und Befürchtungen in einer deutschlandrepräsentativen Stichprobe. Z Gesundheitspsychol 10, 97 - 107

Berth H, Dinkel A, Balck F (2003): Chancen und Risiken genetischer Diagnostik. Ergebnisse einer Umfrage in der Allgemeinbevölkerung und bei Medizinstudierenden. Z Med Psychol 12, 177 - 185

Borchelt M (2005): Wichtige Aspekte der Pharmakotherapie beim geriatrischen Patienten. Bundesgesundheitsblatt Gesundheitsforschung Gesundheitsschutz 48, 593 - 598

Brazell C, Freeman A, Mosteller M (2002): Maximizing the value of medicines by including pharmacogenetic research in drug development and surveillance. Br J Clin Pharmacol $\underline{53}, 224$-231

Breuer K, Kapp A (2006): Stationäre medizinische Rehabilitation bei erwachsenen Patienten mit atopischer Dermatitis. Hautarzt $\underline{57}, 592$ - 602

Broadstock M, Michie S, Marteau T (2000): Psychological consequences of predictive genetic testing: a systematic review. Eur J Hum Genet $\underline{8}, 731-738$

Brockmöller J, Kirchheiner J, Meisel C, Roots I (2000): Pharmacogenetic diagnostics of cytochrome P450 polymorphisms in clinical drug development and in drug treatment. Pharmacogenomics $\underline{1}, 125$ 151

Brody H, Hunt L (2006): BiDil: assessing a race-based pharmaceutical. Ann Fam Med 4 (6), 556 - 560

Buchanan A, Califano A, Kahn J, McPherson E, Robertson J, Brody B (2002): Pharmacogenetics: ethical issues and policy options. Kennedy Inst Ethics J $\underline{12}, 1$ - 15

Budnitz DS, Pollock DA, Weidenbach KN, Mendelsohn AB, Schroeder TJ, Annest JL (2006): National surveillance of emergency department visits for outpatient adverse drug events. JAMA $\underline{296}, 1858$ 1866 
Cacabelos R (2007): Pharmacogenetic basis for therapeutic optimization in Alzheimer's disease. Mol Diagn Ther $\underline{11}, 385$ - 405

Campos-Outcalt D (2007): Personalized medicine: The promise, the reality. J Fam Pract $\underline{56}, 621$ - 626

Cascorbi I (2002): Stand der Pharmakogenomik und deren zukünftige Rolle für die Arzneitherapie. Internist $\underline{43}, 506-510$

Collette D, Thürmann PA (2002): Unerwünschte Arzneimittelwirkungen Erbliche Unterschiede im Arzneistoffmetabolismus. Dtsch Med Wochenschr $\underline{127}, 1025$ - 1028

Corbin JM, Strauss AL: Weiterleben lernen - Verlauf und Bewältigung chronischer Krankheit. 2. Auflage, Huber-Verlag, Bern 2004

Corvol H, Burchard EG (2008): Pharmacogenetic response to Albuterol among asthmatics. Pharmacogenomics $\underline{9}, 505-510$

De La Vega FM, Isaac HI, Scafe CR (2006): A tool for selecting SNPs for association studies based on observed linkage disequilibrium patterns. Pac Symp Biocomput 11, 487 - 498

Delden van J, Bolt I, Kalis A, Derijks J, Leufkens H (2004): Tailor-made pharmacotherapy: future developments and ethical challenges in the field of pharmacogenomics. Bioethics $\underline{18}, 303-321$

Di Blasi Z, Harkness E, Ernst E, Georgiou A, Kleijnen J (2001): Influence of context on health outcomes: a systematic review. Lancet $\underline{357}, 757$ - 762

Dierks ML, Schaeffer D: Informationen über die Qualität der gesundheitlichen Versorgung - Erwartungen und Forderungen der Patienten. In: Krankenhausreport 2004. Schwerpunkt: Qualitätstransparenz - Instrumente und Konsequenzen. Hrsg. v. Klauber J, Robra BP, Schellschmidt H; Schattauer-Verlag, Stuttgart 2005, 135 - 150

Dojo M, Azuma T, Saito T, Ohtani M, Muramatsu A, Kuriyama M (2001): Effects of CYP 2C19 gene polymorphism on cure rates for Helicobacter pylori infection by triple therapy with proton pump inhibitor (omeprazole and rabeprazole), amoxycillin and clarithromycin. Digest Liver Dis $\underline{33}, 671$ - 675

Donahue KE, Ashkin E, Pathman DE (2005): Length of patient-physician relationship and patients' satisfaction and preventive service use in the rural south: a cross-sectional telephone study. BMC Fam Pract $\underline{6}, 40$

Eichelbaum M, Schwab M (2005): Pharmakogenetik. Kinderheilkd 153, 741 - 750

Emery J (2001): Is informed choice in genetic testing a different breed of informed decision-making? A discussion paper. Health Expert 4 , $81-86$

Emery J, Hayflick S (2001): The challenge of integrating genetic medicine into primary care. BMJ $\underline{322}$, $1027-1030$

Emery J, Kumar S, Smith H (1998): Patient understanding of genetic principles and their expectations of genetic services within the NHS: a qualitative study. Community Genet $\underline{1}, 78$ - 83

Emilien G, Ponchon M, Caldas C, Isacson O, Maloteaux JM (2000): Impact of genomics on drug discovery and clinical medicine. QJM $\underline{93}, 391$ - 423

Evans WE (2004): Pharmacogenetics of thiopurine-S-methyltransferase and thiopurine therapy. Ther Drug Monit 26, 186 - 191

Evans WE, Johnson JA (2001): Pharmacogenomics: the inherited basis for interindividual differences in drug response. Annu Rev Genomics Hum Genet 2, 9 - 39 
Evans WE, Reiling MV (1999): Pharmacogenomics: translating functional genomics into rational therapeutics. Science $\underline{286}, 487$ - 491

Evans WE, McLeod HL (2003): Pharmacogenomics - drug disposition, drug targets, and side effects. N Engl J Med 348, 538 - 549

Fargher EA, Eddy C, Newman W, Qasim F, Tricker K, Elliott RA, Payne K (2007 a): Patients' and healthcare professionals' views on pharmacogenetic testing and its future delivery in the NHS. Pharmacogenomics $\underline{8}, 1511$ - 1519

Fargher EA, Tricker K, Newman W, Elliott R, Roberts SA, Shaffer JL, Bruce I, Payne K (2007 b): Current use of pharmacogenetic testing: a national survey of thiopurine methyltransferase testing prior to azathioprine prescription. J Clin Pharm Ther 32, 187 - 195

Ferdinands JM, Mannino DM, Gwinn ML, Bray MS (2007): ADRB2 Arg16Gly polymorphism, lung function, and mortality: results from the Atherosclerosis Risk in Communities study. PLoS ONE 2, e289

Feuerstein G, Kollek R, Uhlemann T: Gentechnik und Krankenversicherung. Neue Leistungsangebote im Gesundheitssystem. Nomos Verlagsgesellschaft, Baden-Baden 2002, 149 - 177

Feuerstein G, Kollek R, Schmedders M, Aken van J (2003): Irreführende Leitbilder. Zum Mythos der Individualisierung durch pharmakogenetische Behandlungskonzepte. Eine kritische Anmerkung. Ethik Med $\underline{15}, 77$ - 86

Finegold P, Mathieson K, Holmes L, Boon M, Cottle M, Donnai D, Middleton-Price H (2008): Is the UK public ready for genetic medicine? Personalized Med $\underline{5}, 65$ - 76

Fittig E, Schweizer J, Rudolph U: Lebenszufriedenheit bei chronischen Erkrankungen: Zum wechselseitigen Einfluss von Strategien der Krankheitsbewältigung, Depression und Sozialer Unterstützung. In: Prävention - Ausgewählte Beiträge des Nationalen Präventionskongresses Dresden 1. und 2. Dezember 2005; hrsg. v. Kirch W, Badura B; Springer Verlag, Berlin 2005, 495 - 519

Gerloff T, Roots I (2005): Bedeutung der Pharmakogenetik für die tägliche Praxis. Internist $\underline{46}, 1270$ 1277

Ginsburg GS, McCarthy JJ (2001): Personalized medicine: revolutionizing drug discovery and patient care. Trends Biotechnol 19, 491 - 496

Grimmsmann T, Schwabe U, Himmel W (2007): The influence of hospitalisation on drug prescription in primary care-a large-scale follow-up study. Eur J Clin Pharmacol $\underline{63}, 783$ - 790

Gurwitz D, Weizman A, Rehavi M (2003): Education: Teaching pharmacogenomics to prepare future physicians and researchers for personalized medicine. Trends Pharmacol Sci 24, 122 - 125

Hall IP (2006): Pharmacogenetics of asthma. Chest $\underline{130}, 1873$ - 1878

Hapgood R (2003): The potential and limitations of personalized medicine in the doctor-patient relationship. Pharmacogenomics $\underline{4}, 685$ - 687

Henneman L, Timmermans DRM, van der Wal G (2004): Public experiences, knowledge and expectations about medical genetics and the use of genetic information. Community Genet $\underline{7}, 33$ - 43

Himmel W, Hummers-Pradier E, Kochen MM; MedViP-Gruppe (2006): Medizinische Versorgung in der hausärztlichen Praxis. Bundesgesundheitsblatt Gesundheitsforschung Gesundheitsschutz $\underline{49}, 151$ 159

Hodgson J, Marshall A (1998): Pharmacogenomics: Will the regulators approve?. Nat Biotechnol $\underline{16}$, $13-15$ 
Hoffrage U, Lindsey S, Hertwig R, Gigerenzer G (2000): Communicating statistical information. Science $\underline{290}, 2261$ - 2262

Horrobin DF (2001): Realism in drug discovery - could Cassandra be right? Nat Biotechnol 19, 1099 1100

Hummers-Pradier E, Hess S, Adham IM, Papke T, Pieske B, Kochen MM (2003): Determination of bleeding risk using genetic markers in patients taking phenprocoumon. Eur J Clin Pharmacol 59, 213 219

Ingelman-Sundberg M (2001): Pharmacogenetics: an opportunity for a safer and more efficient pharmacotherapy. J Intern Med 250, 186 - 200

Israel E, Chinchilli VM, Ford JG, Boushey HA, Cherniack R, Craig TJ, Deykin A, Fagan JK, Fahy JV, Fish J (2004): Use of regulary scheduled albuterol treatment in asthma: genotype-stratified, randomised, placebo-controlled cross-over trial. Lancet $\underline{364}, 1505$ - 1512

Issa AM (2002): Ethical perspectives on pharmacogenomic profiling in the drug development process. Nat Rev Drug Discov 1, 300 - 308

Johnson JA, Lima JJ (2003): Drug receptor / effector polymorphisms and pharmacogenetics: current status and challenges. Pharmacogenetics $\underline{13}, 525$ - 534

Jones PW, Quirk FH, Baveystock CM (1991): The St. George's Respiratory Questionnaire. Respir Med $\underline{85}, 25$ - 31

Kaskas BA, Louis E, Hindorf U, Schaeffeler E, Deflandre J, Graepler F, Schmiegelow K, Gregor M, Zanger UM, Eichelbaum M (2003): Safe treatment of thiopurine-S-methyltransferase deficient Crohn's disease patients with azathioprine. Gut $\underline{52}, 140$ - 142

Kelly HW (2005): What is new with the beta2-agonists: issues in the management of asthma. Ann Pharmacother $\underline{39}, 931$ - 938

Kirchheiner J, Brockmöller J (2005): Clinical consequences of cytochromes P 450 2C9 polymorphisms. Clin Pharmacol Ther $\underline{77}, 1$ - 16

Kirchheiner J, Meisel C, Goldammer M, Gerloff T, Kaiser R, Roots I (2003): Pharmakogenetik als Basis neuer Therapiekonzepte. Bundesgesundheitsblatt Gesundheitsforschung Gesundheitsschutz $\underline{46}$, $835-844$

Kirchheiner J, Nickchen K, Bauer M, Licinio J, Wong ML, Roots I, Brockmöller J (2004): Pharmacogenetics of antidepressants and antipsychotics: the contribution of allelic variations to the phenotype of drug response. Mol Psychiatry $\underline{9}, 442$ - 473

Kirchheiner J, Seeringer A, Brockmöller J (2006): Stand der Pharmakogenetik in der klinischen Arzneimitteltherapie. Bundesgesundheitsblatt Gesundheitsforschung Gesundheitsschutz 49, 995 - 1003

Kumar S, Gantley M (1999): Tensions between policy makers and general practitioners in implementing new genetics: grounded theory interview study. BMJ $\underline{319}, 1410$ - 1414

Lash LH, Hines RN, Gonzalez FJ, Zacharewski TR, Rothstein (2003): Genetics and susceptibility to toxic chemicals: Do you (or should you) know your genetic profile? Pharmacol Exp Ther 305, 403 409

Lazarus RS (1993): From psychological stress to emotions: A history changing outlook. Annu Rev Psychol 44, 1 - 21 
Lee CR, Goldstein JA, Pieper JA (2002): Cytochrome P450 2C9 polymorphisms: a comprehensive review of the in-vitro and human data. Pharmacogenetics $\underline{12}$ (3), 251 - 263

Lee SS (2003): Race, distributive justice and the promise of pharmacogenomics: ethical considerations. Am J Pharmacogenomics $\underline{3}, 385$ - 392

Levy DE, Youatt EJ, Shields AE (2007): Primary care physicians' concerns about offering a genetic test to tailor smoking cessation treatment. Genet Med $\underline{9}$ (12), $842-849$

Lichter JB, Kurth JH (1997): The impact of pharmacogenetics on the future of healthcare. Curr Opin Biotechnol 8, 692 - 695

Lima JJ, Thomason DB, Mohamed MH, Eberle LV, Self TH, Johnson JA (1999): Impact of genetic polymorphisms of the beta2-adrenergic receptor on albuterol bronchodilator pharmacodynamics. Clin Phamacol Ther $\underline{65}, 519-525$

Lin M, Aquilante C, Johnson JA, Wu R (2005): Sequencing drug response with HapMap. Pharmacogenomics J $\underline{5}, 149-156$

Lindpaintner K (2002): Pharmacogenetics and the future of medical practice. Br J Clin Pharamacol $\underline{54}$, $221-230$

Lindpaintner K (2003): Pharmakogenetik: Wegbereiter für eine individualisierte Medizin. Ther Umsch 60; 487 - 492

Lipton P (2003): Pharmacogenetics : the ethical issues. Pharmacogenomics J $\underline{3}, 14-16$

March R, Cheesman K, Doherty M (2001): Pharmacogenetics - legal, ethical and regulatory considerations. Pharmacogenomics $\underline{2}, 317$ - 327

Marshall E (2003): Preventing toxicity with a gene test. Science $\underline{302}, 588$ - 590

Marteau TM, Lerman C (2001): Genetic risk and behavioural change. BMJ 2ㅡ, 1056 - 1059

Mayring P: Techniken qualitativer Inhaltsanalyse in: Qualitative Inhaltsanalyse, 6. Auflage, Beltz Deutscher Studien Verlag, Weinheim 1997, 42 - 99

McGleenan T, Wiesing U (2001): Versicherung und Genetik - Optionen zur Verhinderung unerwünschter Auswirkungen. Gesundheitswesen $\underline{63}, 583$ - 590

McLeod HL, Miller DR, Evans WE (1993): Azathioprine-induced myelosuppression in thiopurine methyltransferase deficient heart transplant recipient. Lancet $\underline{341}, 1151$

Meisel C, Roots I, Cascorbi I, Brinkmann U, Brockmöller J (2000): How to manage individualized drug therapy: application of pharmacogenetic knowledge of drug metabolism and transport. Clin Chem Lab Med $\underline{38}, 869$ - 876

Melzer D, Zimmern R (2002): Genetics and medicalisation. BMJ 324, 863 - 864

Melzer D, Detmer D, Zimmern R (2003): Pharmacogenetics and public policy: expert views in Europe and North America. Pharmacogenomics 4, 689 - 691

Meyer T, Vinkemeier U, Meyer U (2002): Ethische Folgeneinschätzung von Genotyp-basierten Arzneimitteltherapien. Dtsch Med Wochenschr 127, 2524 - 2526

Mishel MH: Mit chronischer Krankheit leben: Mit Unsicherheit leben. In: Die Pflege chronischer Kranker; hrsg. v. Funk SG, Tornquist EM, Champagne MT, Wiese RA; Huber-Verlag, Bern 1997, 61 - 74 
Mogilner A, Otten M, Cunnigham JD, Brower ST (1998): Awareness and attitudes concerning BRCA gene testing. Ann Surg Oncol $\underline{5}, 607-612$

Moldrup C (2001): Ethical, social and legal implications of pharmacogenomics: a critical review. Community Genet $\underline{4}, 204$ - 214

Mountcastle-Shah E, Holtzman NA (2000): Primary care physicans's perceptions of barriers to genetic testing and their willingness to participate in research. Am J Med Genet $\underline{94}, 409$ - 416

Nebert DW, Bingham E (2001): Pharmacogenomics: out of lab and into the community. Trends Biotechnol $\underline{19}, 519-523$

Nebert DW, Jorge-Nebert L, Vesell ES (2003): Pharmacogenomics and "individualized drug therapy": high expectations and disappointing achievements. Am J Pharmacogenomics $\underline{3}$, 361 - 370

Nuffield Council on Bioethics (2003): Pharmacogenetics: ethical issues. Verfügbar unter: www.nuffieldbioethics.org/go/ourwork/pharmacogenetics/publication_314.html (letzter Zugriff am: 02.08.2008)

Oh KT, Anis AH, Bae SC (2004): Pharmacoeconomic analysis of thiopurine methyltransferase polymorphism screening by polymerase chain reaction for treatment with azathioprine in Korea. Rheumatology (Oxford) $\underline{43}, 156-163$

Ommen O, Janßen C, Neugebauer E, Pfaff H (2007): Einflussfaktoren auf das Vertrauen schwerverletzter Patienten in den Krankenhausarzt. Chirurg $\underline{78}, 52-61$

Pandhi P (2006): Pharmacogenomic studies: hype \& reality. Indian J Med Res $\underline{123}, 597$ - 600

Paul NW, Roses AD (2003): Pharmacogenetics and pharmacogenomics: recent development, their clinical relevance and some ethical, social and legal implications. J Mol Med 81, 135 - 140

Payne K (2008): Towards an economic evidence base for pharmacogenetics: consideration of outcomes is key. Pharmacogenomics $\underline{9}, 1$ - 4

Peters L (2003): Pharmakogenetik. Verfügbar unter: www.boamuenchen.org/linde.peters/phargen1.htm (letzter Zugriff am: 02.08.2008)

Poirier J, Delisle MC, Quirion R, Aubert I, Farlow M, Lahiri D, Hui S, Bertrand P, Nalbantoglu J, Gilfix BM (1995): Apolipoprotein E4 allele as a predictor of cholinergic deficits and treatment outcome in Alzheimer disease. Proc Natl Acad Sci USA 92, 12260 - 12264

Post SG, Whitehouse PJ, Binstock RH, Bird TD, Eckert SK, Farrer LA, Fleck LM, Gaines AD, Juengst ET, Karlinsky (1997): The clinical introduction of genetic testing for Alzheimer disease. An ethical perspective. JAMA $\underline{277}, 832-836$

Prasad C, Galbraith PA (2005): Sir Archibald Garrod and alkaptonuria - 'story of metabolic genetics'. Clin Genet $\underline{68}, 199$ - 203

Press NA, Yasui Y, Reynolds S, Durfy SJ, Burke W (2001): Women's interest in genetic testing for breast cancer susceptibility may be based on unrealistic expectations. Am J Med Genet $\underline{99}, 99-110$

Redfern WS, Wakefield ID, Prior H, Pollard CE, Hammond TG, Valentin JP (2002): Safety pharmacology - a progessive approach. Fundam Clin Pharmacol $\underline{16}, 161$ - 173

Renegar G, Rieser P, Manasco P (2001): Pharmacogenetics: the Rx perspective. Expert Rev Mol Diagn $\underline{1}, 255-263$

Robertson JA (2001): Consent and privacy in pharmacogenetic testing. Nat Genet 28, 207 - 209 
Robertson JA, Brody B, Buchanan A, Kahn J, McPherson E (2002): Pharmacogenetic challenges for the health care system. Health Affairs $\underline{21}, 155-167$

Robins R, Metcalfe S (2004): Integrating genetics as practices of primary care. Soc Sci Med $\underline{59}, 223$ 233

Rogausch A, Brockmöller J, Himmel W (2005): Pharmakogenetische Tests in der zukünftigen medizinischen Versorgung: Implikationen für Patienten und Ärzte. Gesundheitswesen $\underline{67}, 257$ - 263

Roses AD (2000): Pharmacogenetics and the practice of medicine. Nature $\underline{405}, 857$ - 865

Rothstein MA, Epps PG (2001): Pharmacogenomics and the (ir)relevance of race. Pharmacogenomics J $1,104-108$

Schaeffeler E, Fischer C, Brockmeier D, Wernet D, Moerike K, Eichelbaum M, Zanger UM, Schwab M (2004): Comprehensive analysis of thiopurine-S-methyl-transferase phenotype-genotype correlation in a large population of German-Caucasians and identification of novel TPMT variants. Pharmacogenetics $14,407-417$

Schaeffer D (2006): Bewältigung chronischer Erkrankung. Konsequenzen für die Versorgungsgestaltung und die Pflege. Z Gerontol Geriatr 39, 192 - 201

Schmedders M, Aken van J, Feuerstein G, Kollek R (2003): Individualized pharmacogenetic therapy: A critical analysis. Community Genet $\underline{6}, 114-119$

Schmitz G, Drobnik W (2003): Genpolymorphismen und interindividuelles Risiko der Pharmakotherapie. Klinikarzt $\underline{32}, 23$ - 27

Shastry BS (2006): Pharmacogenetics and the concept of individualized medicine. Pharmacogenomics J $\underline{6}, 16-21$

Shaw JS, Bassi KL (2001): Lay attitudes towards genetic testing for susceptibility to inherited diseases. J Health Psychol $\underline{6}, 405-423$

Simm M (2008): Schizophrenie: Auf genetischer Spurensuche. Dtsch Ärztebl 105, 849

Singer E, Corning AD, Antonucci T (1999): Attitudes toward genetic testing and fetal diagnosis, 1990 1996. J Health Soc Behav $\underline{40}, 429-445$

Sjögren M, Hesse C, Basun H, Köl G, Thostrup H, Kilander L, Marcusson J, Edman A, Wallin A, Karlsson I et al (2001): Tacrine and rate of progression in Alzheimer's disease - relation to ApoE allele genotype. J Neural Transm $\underline{108}, 451$ - 458

Smart A, Martin P, Parker M (2004): Tailored medicine: whom will it fit? The ethics of patient and disease stratification. Bioethics $\underline{18}, 322$ - 342

Statistisches Bundesamt, Wiesbaden (2004): Bevölkerung - Geschlecht und Staatsangehörigkeit. Verfügbar unter: http://www.destatis.de (letzter Zugriff: 02.08.2008)

Steinman MA, Landefeld CS, Rosenthal GE, Berthenthal D, Sen S, Kaboli PJ (2006): Polypharmacy and prescribing quality in older people. J Am Geriatr Soc $\underline{54}, 1516$ - 1523

Stoughton RB, Friend SH (2005): How molecular profiling could revolutionize drug discovery. Nat Rev Drug Discov 4 , 345 - 350

Sturgis P, Cooper H, Fife-Schaw C (2005): Attitudes to biotechnology: estimating the opinions of a better-informed public. New Genet Soc 24, 31 - 56 
Swen JJ, Huizinga TW, Gelderblom H, de Vries EG, Assendelft WJ, Kirchheiner J, Guchelaar HJ (2007): Translating pharmacogenomics: challenges on the road to the clinic. PLoS Med $\underline{4}, 209$

Swen JJ, Wilting I, de Goede AL, Grandia L, Mulder H, Touw DJ, de Boer A, Conemans JMH, Egberts TCG, Klungel OH et al (2008): Pharmacogenetics: From Bench to Byte. Clin Pharmacol Ther $\underline{83}, 781-$ 787

van Aken J, Schmedders M, Feuerstein G, Kollek R (2003) Prospects and limits of pharmacogenetics: the thiopurine methyltransferase (TPMT) experience. Am J Pharmacogenomics $\underline{3}, 149$ - 155

van den Akker-van Maarle ME, Gurwitz D, Detmar SB, Enzing CM, Hopkins MM, Gutierrez de Mesa E, Ibarreta D (2006): Cost-effectiveness of pharmacogenomics in clinical practice: a case study of thiopurine methyltransferase genotyping in acute lymphoblastic leukemia in Europe. Pharmacogenomics $\underline{7}, 783-792$

Vogel F (1959): Moderne Probleme der Humangenetik. Ergeb Inn Med Kinderheilkd 12, 52 - 125

Wehling M, Peiter A (2003): Arzneimitteltherapie im Alter aus Sicht des klinischen Pharmakologen. Internist $\underline{44}, 1003$ - 1009

Weihrauch TR (2002): Pharmakogenetik - Auswirkungen auf die Gesundheitsversorgung und die Gesundheitsökonomie. Med Klin 97, 420 - 428

Weijer C, Miller PB (2004): Protecting communities in pharmacogenetic and pharmacogenomic research. Pharmacogenomics J $\underline{4}, 9$ - 16

Weinshilboum R (2003): Inheritance and drug response. N Engl J Med 쏘, 529 - 537

Wertz DC (2003): Ethical, social and legal issues in pharmacogenomics. Pharmacogenomics J $\underline{3}, 194$ $-196$

Wolf CR, Smith G, Smith RL (2000): Science, medicine, and the future: Pharmacogenetics. BMJ $\underline{320}$, $987-990$

Woodcock J (2005): Pharmacogenetics: on the road to "personalized medicine". FDA Consum $\underline{39}, 44$

Yelin E, Katz P, Balmes J, Trupin L, Earnest G, Eisner M, Blanc P (2006): Work life of persons with asthma, rhinitis, and COPD: A study using a national, population-based sample. J Occup Med Toxicol $\underline{1}, 2$

Zika E, Gurwitz D, Ibarreta D (2006): Pharmacogenetics and pharmacogenomics: state-of-the-art and potential socio-economic impact in the EU. Verfügbar unter: http://www.biotechnologyireland.com/SITE/UPLOAD/DOCUMENT/pharmacoEU.pdf (letzter Zugriff am: 02.08.2008)

Zineh I, Gerhard T, Aquilante CL, Beitelshees AL, Beasley BN, Hartzema AG (2004): Availability of pharmacogenomics-based prescribing information in currently approved drugs. Pharmacogenomics $\mathrm{J}$ 4, $354-358$ 
9. Anhang

9.1 Patienten-Anschreiben nach Anruf 
Abteilung Allgemeinmedizin

Direktor: Univ.-Prof. Dr. med. Michael M. Kochen, MPH, FRCGP

Abteilung Allgemeinmedizin

Abt. Allgemeinmedizin

«Anrede»

Dipl.-Psych.

Anja Rogausch

«Vorname» «Nachname»

Humboldtallee 38

«Straße» «Hausnr»

37073 Göttingen

Telefon: (0551) 39-9537

«PLZ» «Ort»

Telefax: (0551) 39-9530

e-mail:

arogaus@gwdg.de

Projekt „Medizinische Versorgung in der Praxis“

«anrede_2»«Nachname»,

herzlichen Dank, dass Sie am Asthma-Projekt bei Ihrem Hausarzt aus der Region Göttingen und Umgebung teilnehmen. Wir freuen uns besonders, dass Sie uns zusätzlich bei einer kurzen telefonischen Umfrage (ca. 20 min.) unterstützen.

Bei dieser Umfrage geht es um Ihre Meinung: Was denken Sie darüber, wenn zukünftig bei der Auswahl eines Medikaments verstärkt Informationen aus den Erbanlagen (Genen) eines Patienten einbezogen werden?

Da dieses Thema für die meisten Menschen bisher weitgehend unbekannt ist, finden Sie eine kurze Information anbei. Bei der Befragung geht es aber nicht um Ihr Wissen, sondern allein um Ihre persönliche Sichtweise (Datenschutz und Schweigepflicht sind garantiert). Als kleines Dankeschön verlosen wir 3 x 15,- Euro unter den Teilnehmern am Telefoninterview.

Es wäre schön, wenn Sie uns die beiliegende Einverständniserklärung mit einem Terminvorschlag möglichst bald zurückschicken. Frau cand. med. Daniela Prause wird Sie dann anrufen.

Mit bestem Dank und

freundlichen Grüßen

Priv.-Doz. Dr. W. Himmel

Dipl.-Psych. Anja Rogausch

cand. med. Daniela Prause 


\subsection{Patientenbroschüre}

\section{Patienteninformation zur Pharmakogenetik}

\section{Liebe Patientin, lieber Patient,}

wir möchten Sie gerne über ein medizinisches Thema informieren, das in den letzten Jahrzehnten an Bedeutung gewonnen hat: die Pharmakogenetik. Diese Informationen dienen dazu, dass Sie sich eine eigene Meinung über mögliche Vor- und Nachteile der Pharmakogenetik bilden können.

\section{Was ist Pharmakogenetik?}

Einige Gene (Erbanlagen) bestimmen die Größe oder Haarfarbe eines Menschen. Andere Gene haben einen Einfluss darauf, ob und wie ein bestimmtes Medikament bei einem Menschen wirkt. Ein Test kann Auskunft darüber geben, wie ein Patient auf ein Medikament reagieren wird. Diese Forschungsrichtung heißt Pharmakogenetik. Die folgenden Beispiele zeigen Ihnen, wie dies abläuft:

- Herr B. leidet unter Asthma. Der Hausarzt nimmt etwas Blut ab und lässt daraus Teile des Erbguts analysieren. Diese pharmakogenetische Untersuchung zeigt, dass ein bestimmtes Medikament bei Herrn B. vermutlich gut wirken wird und wenig Nebenwirkungen zu erwarten sind.

- Herr M. leidet ebenfalls unter Asthma. Die pharmakogenetische Untersuchung hat bei ihm ergeben, dass er wahrscheinlich nur einen geringen Nutzen durch das Medikament hat, dafür aber Nebenwirkungen wahrscheinlich sind.
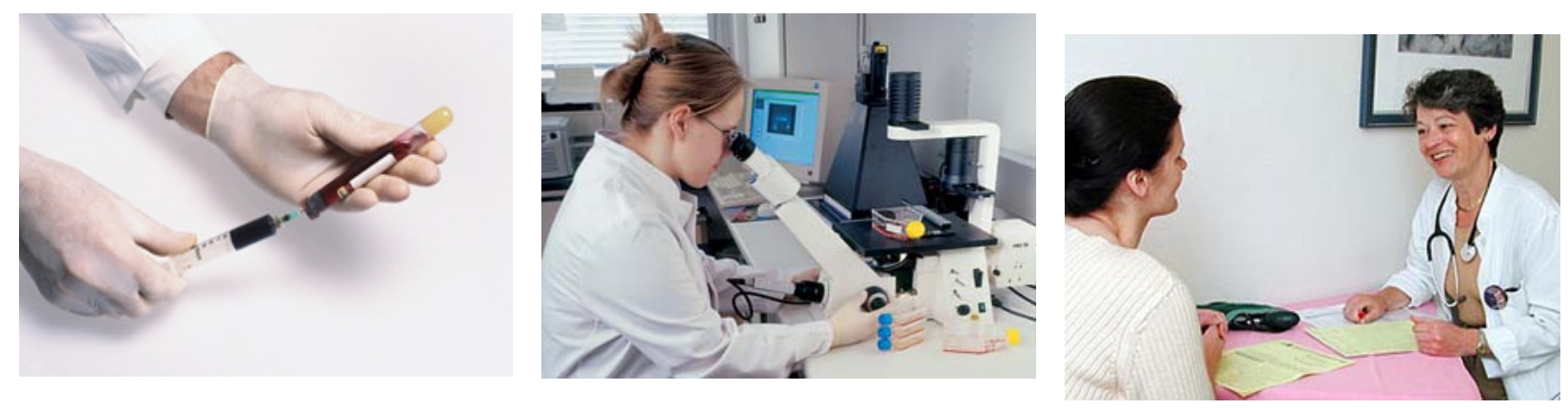


\section{Vorteile und Chancen}

Aus diesen Beispielen erkennt man also die große Chance der Pharmakogenetik: Sie ermöglicht die Abschätzung von erwünschten und unerwünschten Arzneimittelwirkungen und damit den zielgerichteteren Einsatz von Medikamenten.

Pharmakogenetik hat nichts mit Gen-Manipulation, gen-veränderten Nahrungsmitteln oder dem Klonen von Lebewesen zu tun.

\section{Gibt es Risiken?}

Pharmakogenetische Untersuchungen geben anders als bisher übliche Laboranalysen Auskunft über lebenslang unveränderliche, genetisch festgelegte Besonderheiten eines Menschen (und möglicherweise auch seiner Familienangehörigen). Patienten könnten daher zu der Überzeugung kommen: „Ich kann ja nichts tun - letztendlich entscheiden doch meine Gene über meine Gesundheit“, z.B. dann, wenn kein passendes Medikament aufgrund der Erbanlagen gefunden würde. Ein anderer Gesichtspunkt: Ein pharmakogenetischer Test könnte Hinweise auf ein Krankheitsrisiko ergeben, das bisher nicht bekannt war. Denkbar wäre auch, dass das Ergebnis eines pharmakogenetischen Tests mehr zählt als die persönliche Medikamentenbewertung des Patienten. Und schließlich könnten Patienten zur Durchführung pharmakogenetischer Tests gedrängt werden, auch wenn sie selbst nicht viel davon halten. Wenn für die Erbanlagen eines bestimmten Menschen nur wenig oder keine passenden Medikamente gefunden werden, könnte dieser Mensch durch seine schlecht behandelbare Krankheit sozial benachteiligt werden, wenn Arbeitgeber oder Versicherungen die Ergebnisse des pharmakogenetischen Tests erfahren.

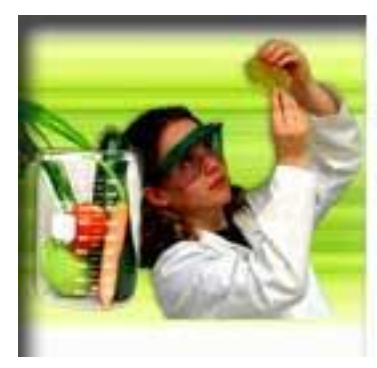

\section{Ausblick}

Dies sind verschiedene Gesichtspunkte bei der Anwendung pharmakogenetischer Tests. Es ist aber bisher nicht bekannt, ob Patienten diese als Vor- oder Nachteile empfinden und welches Gewicht sie innen beimessen. Daher möchten wir gerne lhre Meinung über die angesprochenen Gesichtspunkte in Erfahrung bringen 


\subsection{Einverständniserklärung}

\section{Einverständnis zur Patientenbefragung}

Ablauf:

- Bitte senden Sie ein Exemplar dieser Einverständniserklärung im beiliegenden Freiumschlag an die Abteilung Allgemeinmedizin der Universität Göttingen zurück.

- Eine Mitarbeiterin der Abteilung Allgemeinmedizin (Frau cand. med. Daniela Prause) ruft Sie an und beantwortet auch mögliche weitere Fragen. Die Telefonbefragung wird ca. 20 min. dauern.

- Die Teilnahme ist freiwillig, eine Nichtteilnahme bringt keinerlei Nachteile mit sich. Sie können Ihr einmal gegebenes Einverständnis jederzeit ohne Angabe von Gründen zurückziehen und auch die Beantwortung von Fragen ablehnen, ohne dass Ihnen daraus irgendwelche Nachteile entstehen.

- Alle Mitarbeiter unterliegen vollständig der Schweigepflicht, sämtliche Bestimmungen des Datenschutzrechts werden selbstverständlich eingehalten. Bei Fragen können Sie sich gerne an die Abteilung Allgemeinmedizin der Universität Göttingen (Tel.-Nr. 055139-9537; Frau Dipl.-Psych. Anja Rogausch) wenden.

\section{Einverständnis:}

- Ich, (Name des Patienten) erkläre mich damit einverstanden, dass mich eine Projektmitarbeiterin zur Terminabsprache anruft und erkläre hiermit meine freiwillige Teilnahme an der Interviewstudie. Ich weiß, dass die Teilnahme an dieser Studie freiwillig ist. Ich weiß, dass ich jederzeit und ohne Angaben von Gründen diese Zustimmung widerrufen kann, ohne dass sich dieser Entschluss nachteilig auswirken wird. Ich bin damit einverstanden, dass die im Rahmen der Studie erhobenen Daten in anonymisierter Form gespeichert und zu Forschungszwecken verwendet werden. Ich habe eine Kopie dieser Erklärung erhalten.

Terminvorschlag für Telefonbefragung:

Wochentage (bitte ankreuzen):

$\begin{array}{ll}\text { O } & \text { Alle Tage sind recht } \\ \mathbf{0} & \text { Montag } \\ \mathbf{0} & \text { Dienstag } \\ \mathbf{0} & \text { Mittwoch } \\ \mathbf{0} & \text { Donnerstag } \\ \mathbf{0} & \text { Freitag } \\ \mathbf{0} & \text { Samstag / Sonntag }\end{array}$

Gewünschte Uhrzeit (von - bis): Uhr

Telefonnummer: 


\subsection{Fragebogen Telefoninterview}

Initialen d. Patienten:

Pat.-Code

Datum:

\section{Telefoninterviews mit Patienten (Pharmakogenetik)}

\section{Ablauf:}

Telefoninterview:

a. Information: Antworten werden anonym mitgeschrieben

b. Erneutes Einverständnis erfragen;

c. Erhalt und Verständnis der Broschüre über Pharmakogenetik sicherstellen

d. Ablauf: kurze Erklärung, Bsp. Zur Veranschaulichung des Themas, offene Fragen, danach Auswahlfragen

\section{Interview Teil I:}

Wie gut ein Medikament wirkt - oder welche Dosierung am besten wirkt - hängt unter anderem von den Erbanlagen eines Patienten ab. Wenn man die Erbanlagen eines Patienten untersucht und daraus ableitet, welches Medikament oder welche Dosierung am besten wirkt, dann nennt man das einen pharmakogenetischen Test. Das lässt sich an folgenden Beispielen veranschaulichen:

- Herr B. leidet unter Asthma. Der Hausarzt nimmt etwas Blut ab und lässt daraus Teile des Erbguts analysieren. Diese pharmakogenetische Untersuchung zeigt, dass das Asthmaspray bei Herrn $B$. vermutlich gut wirken wird.

- Herr M. leidet ebenfalls unter Asthma. Die pharmakogenetische Untersuchung hat bei ihm ergeben, dass er wahrscheinlich sehr hohe Dosen des Medikaments anwenden müsste und nur einen geringen Nutzen durch das Medikament hat.

\begin{tabular}{|l|c|c|c|}
\cline { 2 - 4 } \multicolumn{1}{c|}{} & Ja & Nein & weiß nicht \\
\hline $\begin{array}{l}\text { Würden Sie vor Verschreibung des Asthmamedikaments einen } \\
\text { pharmakogenetischen Test durchführen lassen? }\end{array}$ & & & \\
\hline
\end{tabular}




\section{Interview Teil II: Offene Fragen}

1. Was wären Ihre Gründe für eine solche Zustimmung / Ablehnung?

2. Welche Informationen wären für Sie wichtig, um eine Entscheidung für oder gegen eine pharmakogenetische Untersuchung treffen zu können?

3. Haben Sie Ängste oder Sorgen in Bezug auf diese Untersuchungen? Wenn ja, welche? Was ist Ihre größte Angst / Sorge?

4. Haben Sie Hoffnungen in Bezug auf diese Untersuchungen? Wenn ja, welche? Was ist Ihre größte Hoffnung?

5. In wen hätten Sie das größte Vertrauen, wer sollte Sie wegen einer pharmakogenetischen Untersuchung zuerst ansprechen (bitte nur ein Kreuzchen machen):

\begin{tabular}{|l|l|}
\hline $\begin{array}{l}\text { Der/die behandelnde Arzt/Ärztin (z.B. } \\
\text { Facharzt oder Stationsarzt)? }\end{array}$ & \\
\hline Der/die Hausarzt/Hausärztin? & \\
\hline $\begin{array}{l}\text { Eine speziell ausgebildete Kranken- } \\
\text { schwester? }\end{array}$ & \\
\hline Ein auf Genetik spezialisierter Mitarbeiter? & \\
\hline Ein Mitarbeiter einer Universität? & \\
\hline Sonstige: & \\
\hline
\end{tabular}




\section{Interview Teil III: Sorgen, Hoffnungen etc.}

Pharmakogenetische Tests lösen bei manchen Menschen Sorgen aus, bei anderen große Hoffnungen. Ich möchte das gerne etwas genauer wissen. Zunächst geht es um mögliche Sorgen und Befürchtungen ...

Dass z.B. ein pharmakogenetischer Test zufällig ein Ihnen bisher unbekanntes Krankheitsrisiko finden könnte, würde Ihnen das

\begin{tabular}{|l|l|}
\hline große Sorgen & \\
\hline etwas Sorgen & \\
\hline keine Sorgen & \\
\hline
\end{tabular}

bereiten?

Oder dass ein pharmakogenetischer Test kein für Sie passendes Medikament finden könnte (z.B. dass vorhandene Medikamente bei Ihnen nicht wirken oder starke Nebenwirkungen zu erwarten sind), macht Ihnen das

\begin{tabular}{|l|l|}
\hline große Sorgen & \\
\hline etwas Sorgen & \\
\hline keine Sorgen & \\
\hline
\end{tabular}

Oder dass die Krankenversicherung etwas über Ihre genetische Veranlagung erfahren könnte, wenn Ihnen Ihr Arzt ein auf Sie zugeschnittenes Medikament in der zugeschnittenen Dosierung verschreibt, macht Ihnen das

\begin{tabular}{|l|l|}
\hline große Sorgen & \\
\hline etwas Sorgen & \\
\hline keine Sorgen & \\
\hline
\end{tabular}

Oder dass das Ergebnis des pharmakogenetischen Tests an unbefugte Personen weitergegeben werden könnte, macht Ihnen das

\begin{tabular}{|l|l|}
\hline große Sorgen & \\
\hline etwas Sorgen & \\
\hline keine Sorgen & \\
\hline
\end{tabular}


Oder dass das Ergebnis des pharmakogenetischen Tests stärker berücksichtigt werden könnte als Ihr persönlicher Wunsch nach einem Medikament oder für eine bestimmte Dosierung, macht Ihnen das

\begin{tabular}{|l|l|}
\hline große Sorgen & \\
\hline etwas Sorgen & \\
\hline keine Sorgen & \\
\hline
\end{tabular}

\section{Bemerkungen:}

Auch zu den möglichen Hoffnungen möchte ich gerne Ihre persönliche Meinung kennen lernen:

Dass ein pharmakogenetischer Test entdeckt, welches Medikament (oder welche Dosis eines Medikaments) bei Innen am besten wirkt, machen Sie sich da

\begin{tabular}{|l|l|}
\hline große Hoffnungen & \\
\hline etwas Hoffnung & \\
\hline keine Hoffnung & \\
\hline
\end{tabular}

Oder dass ein pharmakogenetischer Test zeigt, welche Medikamente (oder welche Dosis eines Medikaments) bei Ihnen die wenigsten Nebenwirkungen verursacht, machen Sie sich da ...

\begin{tabular}{|l|l|}
\hline große Hoffnungen & \\
\hline etwas Hoffnung & \\
\hline keine Hoffnung & \\
\hline
\end{tabular}

Oder dass es Ihnen durch pharmakogenetische Tests in Zukunft erspart bleiben könnte, die falschen Medikamente (oder Medikamente in zu hoher oder zu niedriger Dosierung) einnehmen zu müssen, machen Sie sich da

\begin{tabular}{|l|l|}
\hline große Hoffnungen & \\
\hline etwas Hoffnung & \\
\hline keine Hoffnung & \\
\hline
\end{tabular}




\section{Interview Teil IV: Persönliche Einschätzung}

Zum Schluss habe ich noch einige Fragen zu Ihrer persönlichen Einschätzung:

Glauben Sie, dass Sie persönlich die Tragweite eines pharmakogenetischen Tests für sich und Ihre Familie erfassen können?

\begin{tabular}{|l|l|}
\hline eher ja & \\
\hline eher nein & \\
\hline
\end{tabular}

Glauben Sie, dass in Zukunft Druck auf Patienten ausgeübt werden könnte, einem pharmakogenetischen Test zuzustimmen?

\begin{tabular}{|l|l|}
\hline eher ja & \\
\hline eher nein & \\
\hline
\end{tabular}

Interview Teil V: Hypothetischer Fall

Stellen Sie sich bei den folgenden Fragen bitte vor, ein pharmakogenetischer Test hätte bei Ihnen gezeigt, dass Sie bei einer vorhandenen Krankheit eine besonders hohe Dosierung des Medikamentes brauchen oder kein passendes Medikament (nur wenig wirksam, starke Nebenwirkungen) für Sie vorhanden ist.

Glauben Sie, dass Sie dann - sollte dies bekannt werden - Nachteile bei der Krankenkasse zu erwarten hätten?

\begin{tabular}{|l|l|}
\hline eher ja & \\
\hline eher nein & \\
\hline trifft nicht zu & \\
(glaubt nicht, dass es & \\
bekannt würde) & \\
\hline
\end{tabular}


Glauben Sie, dass Sie dann - sollte dies bekannt werden - Nachteile am Arbeitsplatz oder bei der Arbeitssuche zu erwarten hätten?

\begin{tabular}{|l|l|}
\hline eher ja & \\
\hline eher nein & \\
\hline trifft nicht zu & \\
(glaubt nicht, dass es & \\
bekannt würde) & \\
\hline
\end{tabular}

Glauben Sie, dass Sie sich dann selbst als „andersartig“ oder „defekt“ erleben würden?

\begin{tabular}{|l|l|}
\hline eher ja & \\
\hline eher nein & \\
\hline
\end{tabular}

Glauben Sie, dass Sie sich dann machtlos oder pessimistisch fühlen würden?

\begin{tabular}{|l|l|}
\hline eher ja & \\
\hline eher nein & \\
\hline
\end{tabular}

Wenn der Test zeigen würde, dass es für Sie nur ein Medikament gäbe, das Ihnen vermutlich wenig hilft oder starke Nebenwirkungen verursacht, würden Sie das Medikament trotzdem ausprobieren wollen oder würden Sie sich auf den Test verlassen?

\begin{tabular}{|l|l|}
\hline Nehmen & \\
\hline Nicht nehmen & \\
\hline
\end{tabular}

Gründe dafür / dagegen?

Wäre es für Sie ein Vor- oder eher ein Nachteil, wenn Sie über Ihre genetische Veranlagung Bescheid wissen?

\begin{tabular}{|l|l|}
\hline eher ein Vorteil & \\
\hline eher ein Nachteil & \\
\hline
\end{tabular}

\section{Abschluss:}

- Haben Sie selbst noch Fragen? Möchten Sie etwas ergänzen?

- Herzlichen Dank für dieses Interview! (Verabschiedung). 


\subsection{SOP „Dateneingabe in die Patiententabelle“}

Die Haupttabelle, die immer aktuell und korrekt sein sollte, ist „Patientenadressen.xIs“ > sollten Ergänzungen bzw. Korrekturen nötig sein, diese dann bitte in dieser Tabelle durchführen und in die weiteren Dateien kopieren

- Die Dateneingabe beginnt mit der jeweiligen Praxis, eingegeben werden Arztname, Ort und vollständiger Praxiscode: beginnend mit „2“ für Göttingen, dann dem dreistelligen Praxiscode (mit führenden Nullen), zum Schluss folgt die Arztzahl; > bei Unklarheiten siehe auch Kodierungsschema bzw. Arzttabelle

- Eingabe der Patientendaten wie sie auf der Einverständniserklärung stehen und im jeweiligen Praxisordner abgeheftet sind; bei Unklarheiten / Unleserlichkeiten in der Anschrift kann www.telefonbuch.de als Hilfe genutzt werden

- $\quad$ eingegebene Ordner werden mit einem Bleistift auf dem Ordnerrücken oben bei der Telefonnummer abgeharkt 


\subsection{SOP „Durchführung des Telefoninterviews“}

\section{Vorher:}

> Patientendaten in der Tabelle „Patientenadressen Telefon-Interview.xls“ heraussuchen: Telefonnummer, Code

> Patientencode auf Einverständniserklärung übertragen; Codierungsregeln beachten!!! > 5-stelliger Praxiscode + 6-stelliger Patientencode mit führenden Nullen

\section{Beginn Telefoninterview:}

$>$ Begrüßung und Vorstellung (Name, Abteilung Allgemeinmedizin, Universität Göttingen)

> Bedanken: „Herzlichen Dank, dass Sie an unserem Telefoninterview zum Thema Pharmakogenetik teilnehmen wollen"

> "Ist es Ihnen zeitlich jetzt recht oder wäre Ihnen ein anderer Zeitpunkt lieber?"

$>$ noch einige Dinge vorab:

e. Information: Antworten werden anonym mitgeschrieben

f. Erneutes Einverständnis erfragen;

g. Erhalt und Verständnis der Broschüre über Pharmakogenetik sicherstellen

h. Ablauf: kurze Erklärung, Bsp. Zur Veranschaulichung des Themas, offene Fragen, danach Auswahlfragen

i. Falls irgendetwas nicht klar sein sollte, sagen Sie bitte einfach kurz nach

\section{Durchführung des Telefoninterviews gemäß Fragebogen}

Nach dem Interview:

o Telefoninterview-Datum in Tabelle „Patientenadressen TelefonInterview.xIs" eintragen und auf Einverständniserklärung notieren

o Kopfzeile im Fragebogen ausfüllen: Initialen, Code, Datum

o Einverständniserklärung und Fragebogen zusammenheften

o Gegebenenfalls Fragebogen-Antworten in TelefoninterviewDatenmaske der Asthmadatenbank eingeben. 


\section{Danksagung}

Ich danke Prof. Dr. Wolfgang Himmel und Dr. Anja Rogausch für die freundliche Überlassung des Themas der Dissertation sowie für die hervorragende Unterstützung und für die stets unermüdliche und engagierte Betreuung bei Erstellung dieser Arbeit.

Für die kollegiale Unterstützung und konstruktive Kritik danke ich Prof. Dr. Michael M. Kochen, MPH, FRCGP sowie den Mitarbeitern der Abteilung Allgemeinmedizin der Universität Göttingen.

Mein besonderer Dank gilt den Ärzten und den Patienten, die sich bereit erklärt haben, an dieser Studie teilzunehmen. 


\section{Lebenslauf}

Am 10. Dezember 1976 wurde ich als Tochter von Reinhard und Elisabeth Prause in Bad Arolsen geboren.

Von 1983 bis 1987 besuchte ich die Grundschule Mengeringhausen, anschließend wechselte ich auf die Christian-Rauch-Schule Bad Arolsen, wo ich 1996 die allgemeine Hochschulreife (Abitur) erwarb.

Von 1997 bis 2000 absolvierte ich im Stadtkrankenhaus Bad Arolsen die Ausbildung zur examinierten Krankenschwester, nach dem erfolgreichem Abschluss nahm ich im WS 2000/2001 das Studium der Humanmedizin an der Georg-August-Universität Göttingen auf.

Meine vorklinische Ausbildung konnte ich im September 2002 abschließen, es folgten der erste Abschnitt der ärztlichen Prüfung im September 2003 und der zweite Abschnitt im März 2006. Mein praktisches Jahr, das ich in den Fächern Neurologie an der Universitätsklinik Göttingen, sowie Innere Medizin und Chirurgie an der Klinik Herzberg absolvierte, beendete ich mit dem dritten Staatsexamen im April 2007 mit der Gesamtnote gut und Erhalt der Approbation als Ärztin.

Nach Abschluss meines Studiums begann ich als Assistenzärztin in der Inneren Medizin des St. Josef-Stifts Delmenhorst, seit Juni 2008 arbeite ich als Assistenzärztin in der Medizinisch-Psychosomatischen Klinik Bad Arolsen. 